Aus der Abteilung Kinder- und Jugendpsychiatrie und Psychotherapie

(Prof. Dr. med. A. Rothenberger)

im Zentrum Psychosoziale Medizin

der Medizinischen Fakultät der Universität Göttingen

\title{
Quantitative Genexpressionsanalyse im respiratorischen Netzwerk an Mausmodellen für das Rett-Syndrom
}

\author{
INAUGURAL-DISSERTATION \\ zur Erlangung des Doktorgrades \\ der Medizinischen Fakultät der \\ Georg-August-Universität zu Göttingen \\ vorgelegt von \\ Janine Hein \\ aus Weimar
}

Göttingen 2010 
Dekan: $\quad$ Prof. Dr. med. Frömmel

\section{Prüfer:}

I. Prof. Dr. med. Rothenberger

II. Prof. Dr. sc. agr. Adham

III. Prof. Dr. med. Huppke

IV. Prof. Dr. med. Oppermann

Tag der mündlichen Prüfung: 05. April 2011 


\section{Inhaltsverzeichnis}

Abkürzungsverzeichnis

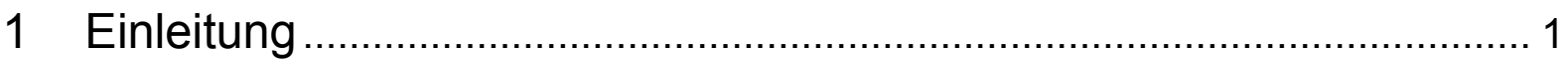

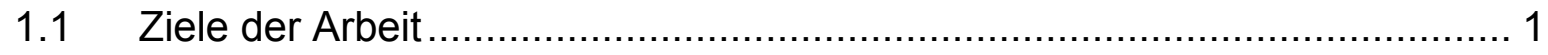

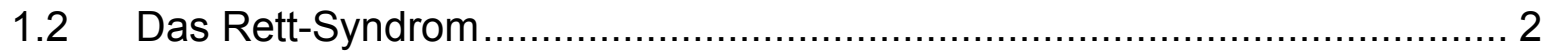

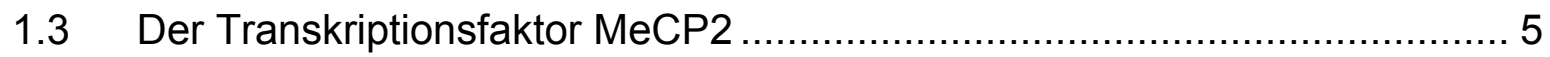

1.4 Die verwendeten Mecp2-Mausmodelle ………................................... 7

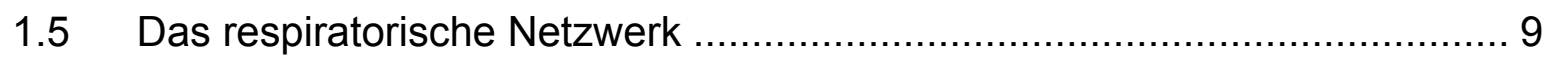

1.6 Der Prä-Bötzinger-Komplex ............................................................. 11

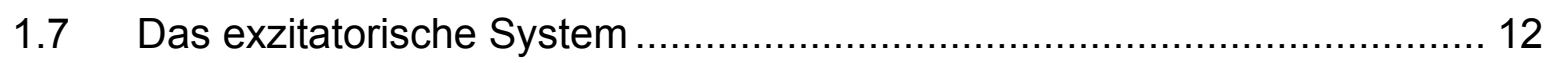

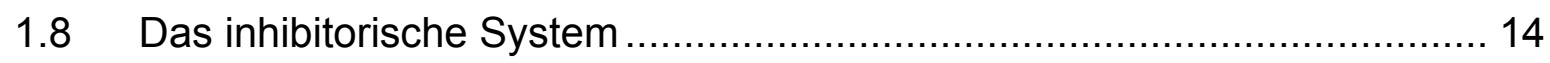

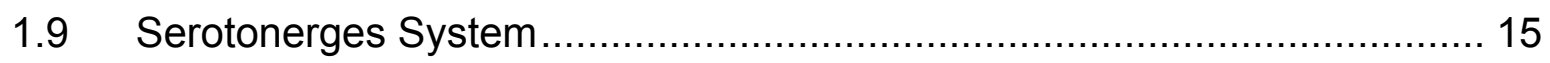

1.10 Das dopaminerge und opioiderge Transmittersystem ............................. 19

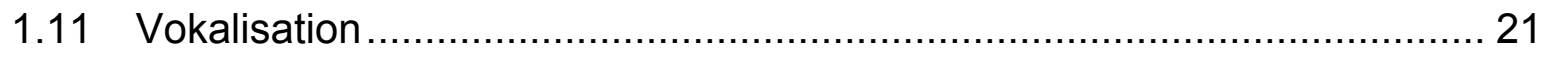

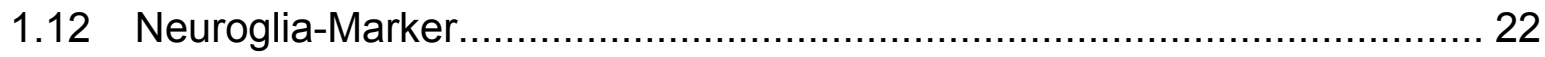

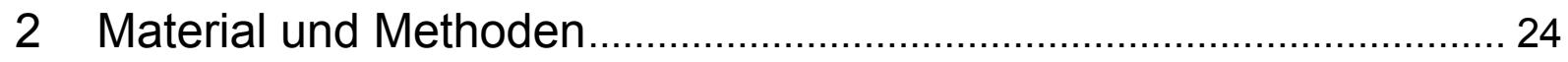

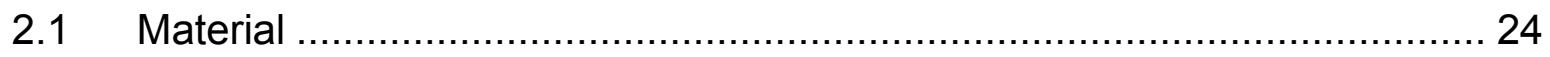

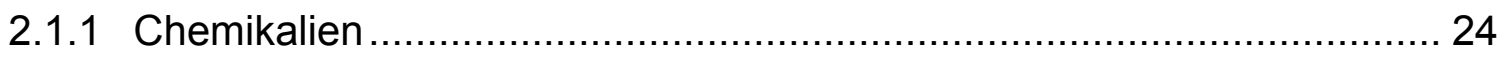

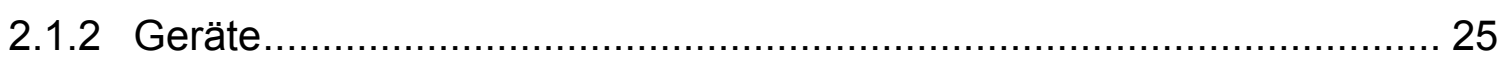

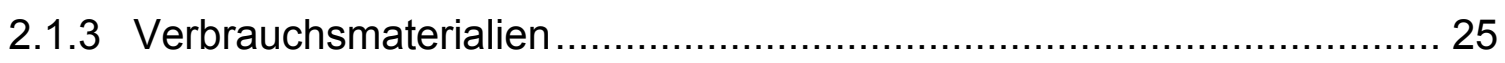

2.1.4 Knockout- und transgene Mecp2-Mäuse ........................................... 25

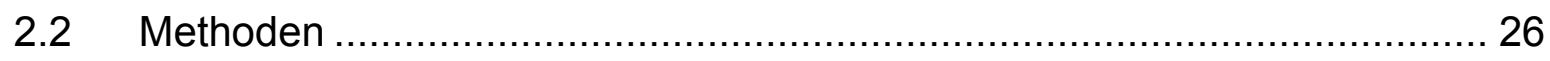

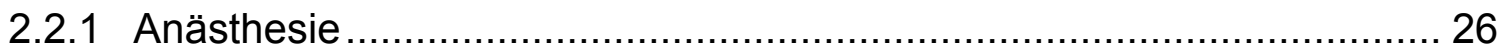

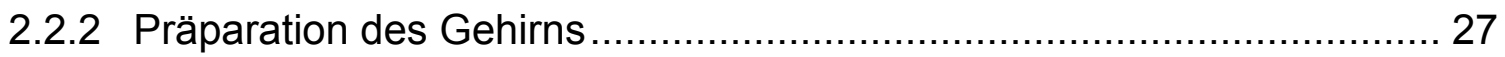

2.2.3 Präparation des Prä-Bötzinger-Komplexes aus dem Hirnstamm ............ 27

2.2.4 Isolierung von Gesamt-RNA aus Prä-Bötzinger-Komplex-Präparaten.... 27

2.2.5 Dnase-1-Behandlung und Aufreinigung ……....................................... 29

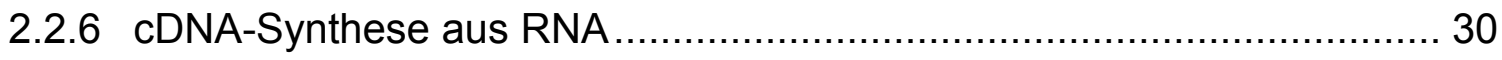

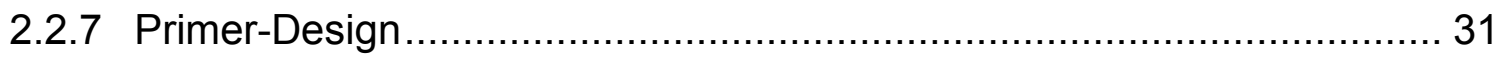




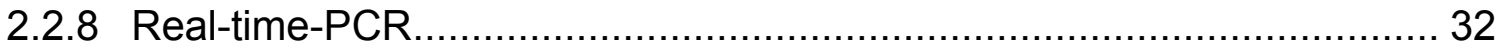

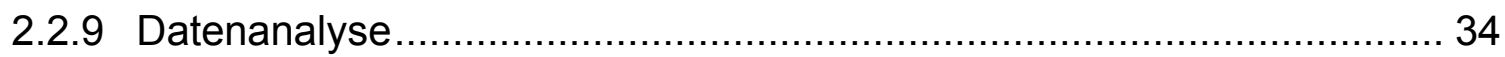

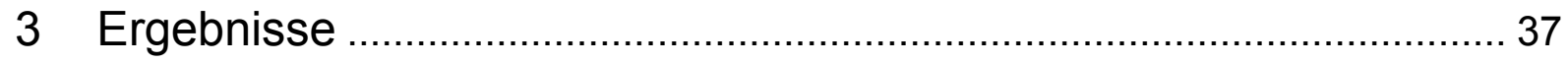

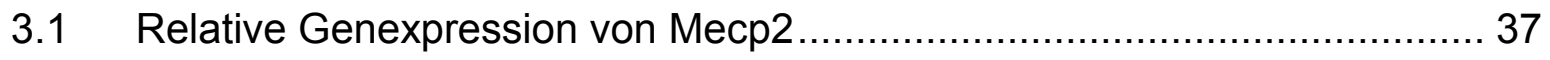

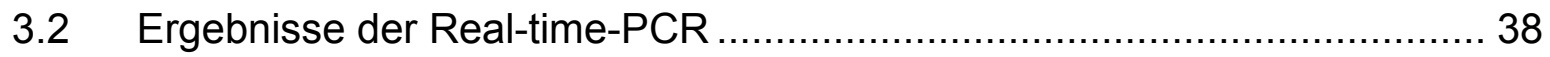

3.2.1 Relative Genexpression der Prä-Bötzinger-Komplex-Marker ................. 39

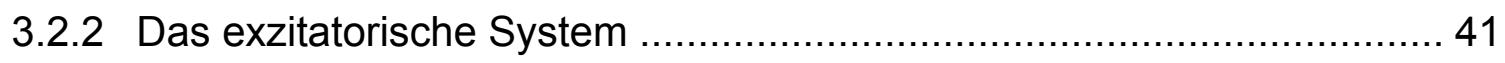

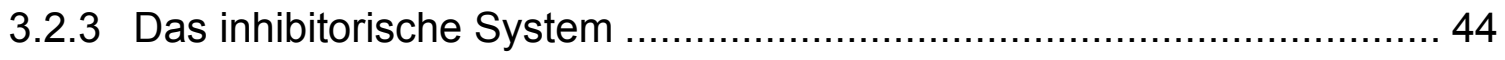

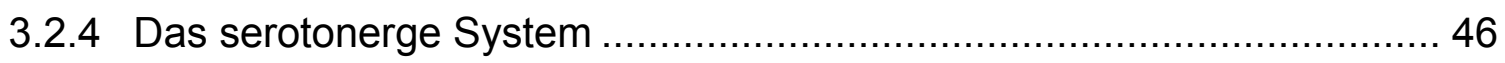

3.2.5 Das dopaminerge und opioiderge Transmittersystem ...................... 51

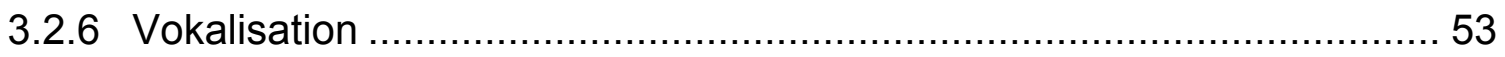

3.2.7 Relative Genexpressionen von Gliazellmarkern .............................. 54

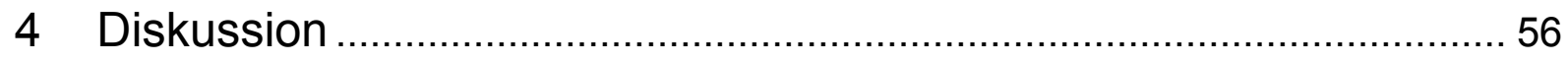

4.1 Wirkungen von MeCP2 in transgenen und Knockout-Mausmodellen........ 56

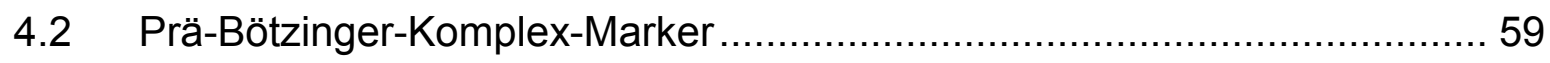

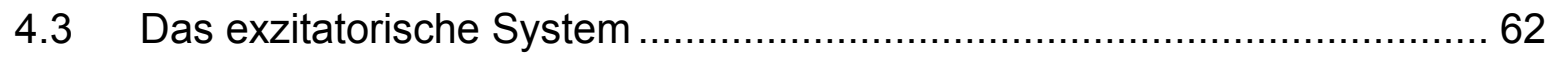

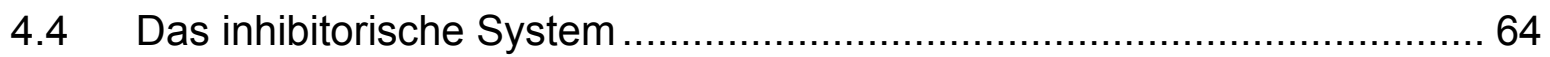

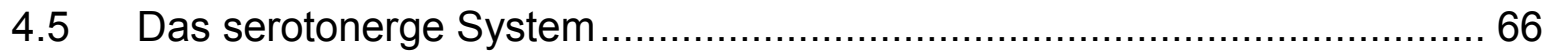

4.6 Das dopaminerge und opioiderge Transmittersystem ........................... 69

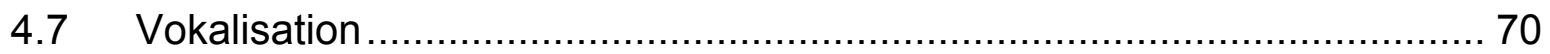

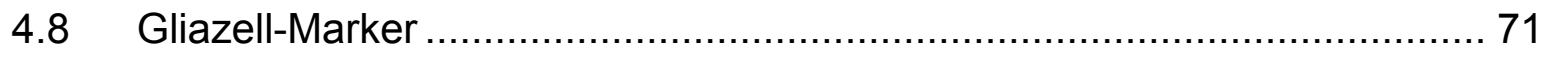

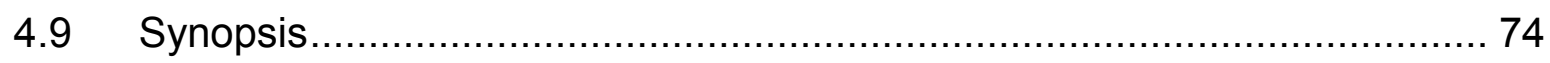

4.10 Klinische Relevanz der Ergebnisse und Forschungsperspektive ............. 75

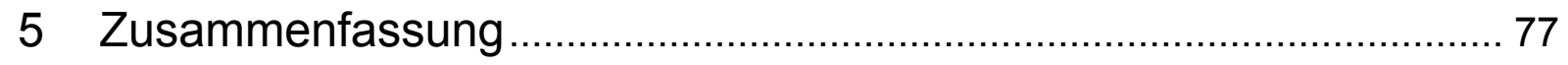

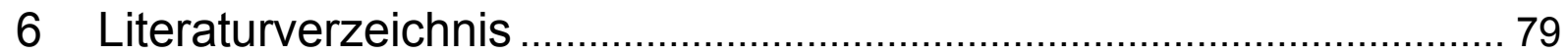




\section{Abkürzungsverzeichnis}

$\alpha$

Abb.

AMPA

$\beta$

BAC

$B D N F$

BDNF

Bdnf

BLAST

bZIP

${ }^{\circ} \mathrm{C}$

C57BL/6J

ca.

cAMP

cDNA

$\mathrm{CO}_{2}$

CP

CpG

Ct

$\Delta$

DDC

$D d c$

D/x5

DNA

DNase

DOPA

Drd4

DRG

Dr. med.
Alpha

Abbildung

a-Amino-3-hydroxy-5-methyl-4-isoxazol-Propionsäure

Beta

bacterial artificial chromosomes

humanes Gen, kodierend für BDNF

Proteinname für „brain-derived neurotrophic factor“

Mausgen, kodierend für BDNF

Basic Local Alignment Search Tool

Basic Leucine Zipper Domain, Proteindomäne

Grad Celsius

„Black 6“, Wildtypmausstamm

circa

zyklisches Adenosinmonophosphat

komplementäre Einzelstrang-DNA

Kohlenstoffdioxid

Crossing Point

Cytosin-phosphatidyl-Guanin

Crossing Point

Delta (Differenz)

Proteinname für DOPA-Decarboxylase

Mausgen, kodierend für DOPA-Decarboxylase

Mausgen, kodierend für distal-less homeobox 5 Protein

desoxyribonucleic acid, Desoxyribonukleinsäure

Desoxyribonuklease

Dihydroxyphenylalanin

Mausgen, kodierend für Dopaminrezeptor D4

dorsale respiratorische Gruppe

Doktor der Medizin 
Dr. rer. nat. Doktor der Naturwissenschaften

E

Extinktion

E 620

Geschmacksverstärker Glutamat

early-I-Neurone

früh-inspiratorische Neurone

EGFP

Enhanced Green Fluorescent Protein

$E_{2}$-Neurone

exspiratorische Neurone

EPSP

exzitatorisches postsynaptisches Potential

et al.

et alii (lat.): und andere

FOXP2

humanes Gen, kodierend für FoxP2

FoxP2

Proteinname für „forkhead box protein 2“

Foxp2

Mausgen, kodierend für FoxP2

FVB

Friend Virus B, Wildtypmausstamm

Y

Gamma

g

Gramm

GABA

Y-Aminobuttersäure

Gabra6

Mausgen, kodierend für $\mathrm{GABA}_{\mathrm{A}}$-Rezeptor Untereinheit Alpha 6

Gabrb1

Mausgen, kodierend für $\mathrm{GABA}_{\mathrm{A}}$-Rezeptor Untereinheit Beta 1

GABRB3

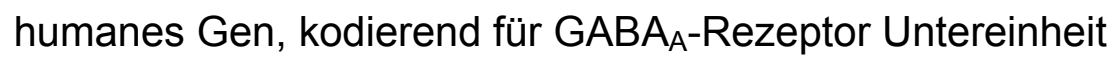

Beta 3

GAPDH

Glycerinaldehyd-3-phosphat-Dehydrogenase

Gapdh

Mausgen, kodierend für GAPDH

GFAP

Proteinname für „glial fibrillary acidic protein“

GFAP

humanes Gen, kodierend für GFAP

Gfap

Mausgen, kodierend für GFAP

GOT

Glutamat-Oxalacetat-Transaminase

GPT

Glutamat-Pyruvat-Transaminase

G-Protein

GTP-bindendes Protein

$\mathrm{G}_{\mathrm{i}}$-Proteine

hemmend wirkendes GTP-bindendes Protein

Grin1

Mausgen, kodierend für Glutamatrezeptor, ionotroph, NMDA1

Grin2a

Mausgen, kodierend für Glutamatrezeptor, ionotroph, NMDA2A

Grin2d

Mausgen, kodierend für Glutamatrezeptor, ionotroph, NMDA2D 


\begin{tabular}{|c|c|}
\hline GTP & Guanosintriphosphat \\
\hline HDAC1/2 & Histondeacetylasen 1 und 2 \\
\hline $5-\mathrm{HT}$ & 5-Hydroxytryptamin (Serotonin) \\
\hline $5-\mathrm{HT}_{1-7}-\mathrm{R}$ & Serotonin $_{1-7}$-Rezeptor, Serotonin ${ }_{1-7}-$ Rezeptoren \\
\hline \multirow[t]{2}{*}{ Htr4 } & Mausgen, kodierend für 5-Hydroxytryptamin (Serotonin) \\
\hline & Rezeptor 4 \\
\hline \multirow[t]{2}{*}{$H \operatorname{tr} 5 b$} & Mausgen, kodierend für 5-Hydroxytryptamin (Serotonin) \\
\hline & Rezeptor 5B \\
\hline IPSP & inhibitorisches postsynaptisches Potential \\
\hline $\mathrm{K}$ & Kappa \\
\hline $\mathrm{KO}$ & Knockout, Mecp2-/y -Modell \\
\hline I & Liter \\
\hline late-I-Neurone & spät-inspiratorische Neurone \\
\hline M & Molmasse \\
\hline $\mathrm{m}$ & Meter, Milli- \\
\hline$\mu$ & My, Mikro- \\
\hline MAO & Monoaminooxidase \\
\hline MBD & Methyl-CpG-Bindungsdomäne \\
\hline MECP2 & humanes Gen, kodierend für MeCP2 \\
\hline MeCP2 & Proteinname für Methyl-CpG-Bindungsprotein 2 \\
\hline Mecp2 & Mausgen, kodierend für MeCP2 \\
\hline $\min$ & Minute, Minuten \\
\hline$\mu-\mathrm{OR} 1$ & $\mu$-Opioidrezeptor 1 \\
\hline mRNA & messenger RNA \\
\hline$m \sin 3 A$ & Co-Repressor \\
\hline $\mathrm{n}$ & nano \\
\hline NA & Nucleus ambiguus \\
\hline $\mathrm{NH}_{2-}$ & Amino-Gruppe \\
\hline NK-1 & Neurokinin-1 \\
\hline
\end{tabular}




$\begin{array}{ll}\text { NK-1-R } & \text { Neurokinin-1-Rezeptor, Neurokinin-1-Rezeptoren } \\ \text { NMDA } & \text { N-Methyl-D-Aspartat } \\ \text { N-Terminus } & \text { Amino-Gruppenende } \\ \text { NTS } & \text { Nucleus tractus solitarius }\end{array}$

$\begin{array}{ll}\text { Oprk1 } & \text { Mausgen, kodierend für den k-Opioidrezeptor } 1 \\ \text { Oprm1 } & \text { Mausgen, kodierend für den } \mu \text {-Opioidrezeptor } 1\end{array}$

P7 Entwicklungsstadium P7, postnatal 7 Tage alt

P40 Entwicklungsstadium P40, postnatal 40 Tage alt

PCR Polymerasekettenreaktion

poly-A Adenin-reich

poly-T Thymin-reich

post-I-Neurone post-inspiratorische Neurone

preBotC Prä-Bötzinger-Komplex

pre-I-Neurone prä-inspiratorische Neurone

ramp-I-Neurone Rampen-inspiratorische Neurone

RAS retikuläres Aktivierungssystem

RNA ribonucleic acid, Ribonukleinsäure

rpm revolutions per minute, Umdrehungen pro Minute

rRNA ribosomale RNA

RT-PCR reverse Transkriptase Polymerasekettenreaktion

S100 Proteinfamilie, "soluble in $100 \%$ saturated ammonium sulfate"

S100A1 Proteinname für „calcium binding protein Alpha 1“

S100A6 Proteinname für „calcium binding protein Alpha 6“

S100b Mausgen, kodierend für S100B

S100B Proteinname für "calcium binding protein Beta“

sec Sekunde, Sekunden

Slc6a4 Mausgen, kodierend für „solute carrier family 6 member 4“

SSRI selektive Serotonin-Reuptake-Inhibitoren

Sst Mausgen, kodierend für Somatostatin 


$\begin{array}{ll}\text { T } & \text { transgen } \\ \text { Tacr1 } & \text { Mausgen, kodierend für Tachykininrezeptor 1 } \\ \text { TierSchG } & \text { Tierschutzgesetz } \\ \text { Tph1 } & \text { Proteinname für Tryptophan-Hydroxylase 1 } \\ \text { Tph2 } & \text { Proteinname für Tryptophan-Hydroxylase 2 } \\ \text { Tph2 } & \text { Mausgen, kodierend für Tryptophan-Hydroxylase 2 } \\ \text { TRD } & \text { transkriptionelle Repressordomäne } \\ \text { tRNA } & \text { Transfer-RNA } \\ \text { T/-, +/y } & \text { transgenes Mausmodell } \\ \text { U } & \text { Unit, Units } \\ \text { UBE3A } & \text { humanes Gen, kodierend für die Ubiquitin-Protein-Ligase E3A } \\ \text { V } & \text { Volt } \\ \text { vgl. } & \text { vergleiche } \\ \text { VRG } & \text { ventrale respiratorische Gruppe } \\ \text { WT } & \\ \text { WT } & \text { korrespondierender Wildtyp des Knockout-Mausmodells } \\ \text { K } & \text { korrespondierender Wildtyp des transgenen Mausmodells } \\ \text { Xq28 } & \text { Kanockout-Mausmodell } \\ \text { ZNS } & \text { gleiner } \\ & \end{array}$




\section{$1 \quad$ Einleitung}

\section{$1.1 \quad$ Ziele der Arbeit}

Die vorliegende Dissertation soll dazu beitragen, Veränderungen in der Genregulation von potentiellen Zielgenen des Transkriptionsfaktors MeCP2 (Methyl-CpG-Bindungsprotein 2) bei fehlendem beziehungsweise überexprimiertem MeCP2 aufzudecken. MeCP2 dient nicht nur wie zunächst angenommen als Suppressor der Gentranskription, sondern aktiviert in $85 \%$ der Fälle die RNAExpression (Chahrour et al. 2008). Seit 1998 ist bekannt, dass Mutationen im humanen Gen MECP2 und der damit verbundene Proteinausfall beziehungsweise die eingeschränkte Proteinfunktion zum Krankheitsbild des Rett-Syndroms führen (Amir et al. 1999 und Wan et al. 1999). Erstaunlicherweise zeigen männliche Kinder mit einer Duplikation des MECP2-Gens unter anderem eine schwere mentale Retardierung, eine progressive Spastik und die Neigung zu epileptischen Anfällen (Van Esch et al. 2005). Das entspricht zwar nicht komplett einer Rett-Symptomatik, dennoch gibt es bezüglich der mentalen Retardierung und der Anfallsneigung Überschneidungen. Somit führt sowohl der Verlust als auch eine Duplikation des MECP2-Gens zu einem neurologischen Krankheitsbild. 2007 zeigte ein MicroarrayExperiment, das von einer Arbeitsgruppe unter der Leitung von Dr. rer. nat. Dr. med. Manzke (Zentrum für Molekulare Physiologie des Gehirns, CMPB, Göttingen; Abteilung für Neuro- und Sinnesphysiologie, Universität Göttingen) durchgeführt wurde, Unterschiede in der Genexpression von Mecp2-defizienten Mäusen gegenüber ihren korrespondierenden Wildtypen. Die vorliegende Dissertation soll nicht der Auswertung und Veröffentlichung der Daten des Microarrays dienen, dies obliegt der oben genannten Arbeitsgruppe. Bekannte Gene, die unter nachgewiesener direkter Kontrolle von MeCP2 stehen, sind bisher Bdnf (Gen des brain derived neurotrophic factor) und DIx5 (Gen des distal-less homeobox 5 Proteins) (Horike et al. 2005). Welche weiteren Gene für eine direkte Kontrolle durch MeCP2 in Frage kommen könnten, ist Gegenstand der aktuellen Forschung. Um dieser Fragestellung nachzugehen, wurde in der vorliegenden Arbeit sowohl ein Mecp2-Knockout-Mausmodell (Mecp2-/y -Modell) als auch ein transgenes Mecp2Mausmodell (Mecp2 $2^{T /,+/ y}-$ Modell) verwendet. Evidenzen für eine potentielle direkte Regulierung des jeweiligen Gens durch MeCP2 ergeben sich, wenn die relativen Genexpressionen gegenüber Wildtypmäusen ein gegensinniges Expressionsmuster 
in den Mecp2-Mausmodellen zeigen. Dagegen würde eine gleichsinnige Verteilung der Expressionsergebnisse wahrscheinlich auf eine indirekte Genregulierung hindeuten. Die Auswahl der untersuchten Gene weicht von den Genen des Microarrays ab und beruht daher zum einem auf dem Prinzip der Verschaltung des respiratorischen Netzwerkes und zum anderem auf bereits gefundene beziehungsweise vermutete Zusammenhänge zu Genen von Neurotransmittersystemen, welche die Aktivität des respiratorischen Netzwerkes modulieren. Als anatomisch untersuchte Struktur diente der für die Rhythmogenese essentielle Prä-Bötzinger-Komplex im respiratorischen Netzwerk, welches funktional auf einer reziproken inhibitorischen Verschaltung basiert. Daher leitet sich unter anderem die Analyse von Genen der etablierten Prä-Bötzinger-Komplex-Maker (Tacr1 und Sst), Glutamat-Rezeptoren (Grin1, Grin2a und Grin2d) als Vertreter der Exzitation und $\mathrm{GABA}_{\mathrm{A}}$-Rezeptoren (Gabra6 und Gabrb1) als Vertreter der Inhibition ab. Zusammenhänge zwischen dem serotonergen, dopaminergen und opioidergen System werden vermutet, so dass die Auswahl auf Tph2 und Ddc (als Enzyme der Serotoninsynthese), Slc6a4 (Serotonintransporter), Htr4 und Htr5b (Serotoninrezeptoren), S100B (Wachstumsfaktor für serotonin-bildende Zellen), Drd4 (Dopaminrezeptor) und Oprm1 (Opioidrezeptor) fiel. Da erlernte Fähigkeiten wie die Sprache beim Rett-Syndrom verloren gehen, wurde das Gen für den Transkriptionsfaktor FOXP2 (Foxp2) in die Analysen mit einbezogen. Des Weiteren wurde das Gen für das Intermediärfilament GFAP (Gfap) untersucht, da ein direkter Zusammenhang zwischen MeCP2 und Gfap vermutet wird (Setoguchi et al. 2006). Die Kenntnis über direkte Zielgene von MeCP2 ist nicht nur für die weitere Aufklärung der Symptomatik des Rett-Syndroms, sondern auch für dessen eventuell zukünftige kausale Therapie von besonderem Interesse.

\subsection{Das Rett-Syndrom}

Das Rett-Syndrom ist eine tiefgreifende Entwicklungsstörung, welche erstmals 1966 von dem Wiener Arzt und Jugendpsychiater Professor Andreas Rett beschrieben wurde (Hagberg et al. 1983). Das Syndrom betrifft überwiegend Mädchen und tritt mit einer geschätzten Prävalenz von 1 zu 10.000 bis 1 zu 15.000 in Deutschland auf. Hagberg führte 1985 epidemiologische Studien in Schweden durch, aufgrund derer 
die Prävalenz in Deutschland abgeschätzt wird (Hagberg et al. 1985). Damit ist das Rett-Syndrom selten, aber dennoch nach dem Down-Syndrom die häufigste Ursache schwerer Behinderungen bei Mädchen.

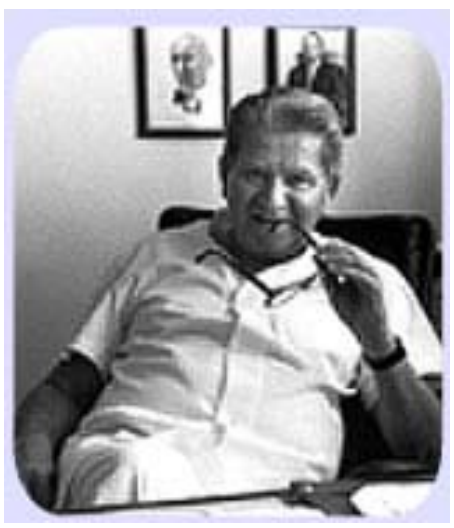

Abb. 1.1 Professor Andreas Rett (Quelle: www.rettsyndrome.org.uk)

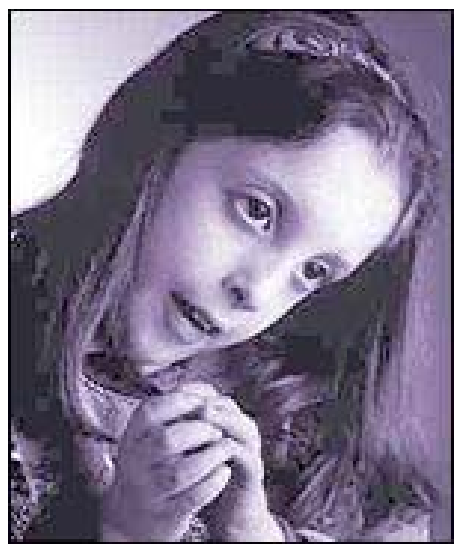

Abb. 1.2 Rett-Patientin mit typischer Haltung der Hände

(Quelle:news.bbc.co.uk/2/low/health/ 1831801.stm)

Anfänglich entwickeln sich die Kinder scheinbar regelgerecht. Zwischen dem siebten und vierundzwanzigsten Lebensmonat verlieren die Kinder aber dann, nach einer Phase des Entwicklungsstillstandes, erlernte Fähigkeiten wie das Sprechen und den Gebrauch der Hände. Ferner sind folgende Symptome für das Rett-Syndrom unter Umständen unterschiedlich stark ausgeprägt, aber dennoch typisch: autistische Verhaltensweisen, epileptische Anfälle, Bewegungsstereotypien in Form typischer waschender und knetender Handbewegungen, Hyper- und Hypoventilation, durch Gleichgewichtsstörungen charakterisierte Ataxie, variable mentale Retardierung. Auf einer internationalen Konferenz 1984 in Wien wurden die von Rett formulierten Kriterien zur Diagnosestellung komplettiert und festgelegt (Lindberg und Rett 2000). Wie hoch der Anteil an Rett-Patienten ist, die unter Atemdysregulationen leiden, ist durch Studien noch nicht ausreichend geklärt. Die Ventilationsstörungen sind jedoch Bestandteil der momentanen Forschung, da sie zu lebendsbedrohlichen Zuständen führen können.

Im Jahre 1998 wurde das verantwortliche Gen, MECP2, auf Bande 28 im langen Arm des X-Chromosoms (Xq28) gefunden und von Amir et al. (1999) und Wan et al. (1999) publiziert. Als Ursache der Krankheit zeigt sich in 80 bis $90 \%$ der Fälle eine dominante De-novo-Mutation aller Mutationstypen des X-Chromosoms, die hauptsächlich in den väterlichen Keimbahnen entsteht (Trappe et al. 2001). Hierdurch erklärt sich die Gynäkotropie des Rett-Syndroms. Aufgrund eines MECP2Mutations-Mosaiks können jedoch auch Jungen betroffen sein (Renieri et al. 2003). Die Variabilität des Phänotyps ist unter anderem durch das Muster der X-Chromosomeninaktivierung begründet (Watson C et al. 2005, Weaving et al. 2003). Seit Oktober 1999 steht ein Gentest zur Verfügung, der auch bei Patienten angewendet werden kann, die wesentlich vielgestaltiger das Rett-Syndrom 
präsentieren (Laccone 2006). Dieser Gentest filtert auch die weniger typischen Fälle heraus und ordnet sie eindeutig dem Rett-Syndrom zu. Die Diagnose kann nun wesentlich früher gestellt werden.

Neben der Kausalität zum Rett-Syndrom sind auch andere Krankheiten wie das Angelman-Syndrom und der frühkindliche Autismus mit MECP2-Mutationen assoziiert. Samaco et al. (2005) vermuteten einen regulierenden Einfluss von MeCP2 auf die Expression von UBE3A (Gen für die Ubiquitin-Protein-Ligase E3A) und GABRB3 (Gen für den $\mathrm{GABA}_{\mathrm{A}}$-Rezeptor Beta 3). UBE3A-Mutationen können neben Imprinting-Defekte für das Angelman-Syndrom verantwortlich sein und GABRB3 wird als ein Kandidatengen für Autismus gehandelt (Samaco et al. 2005). Ähnlichkeiten im Phänotyp des Angelman-Syndroms können bei unerfahrenen Untersuchern zu Verwechslungen führen. Carney et al. entdeckten (2003) bei autistischen Frauen Denovo-Mutationen im MECP2-Gen. Sowohl Watson P et al. (2001) als auch Imessaoudene et al. (2001) fanden bei männlichen und weiblichen Patienten mit Angelman-Syndrom MECP2-Mutationen. Dagegen konnten Beyer et al. (2002) keinen Zusammenhang zwischen Autismus und MECP2 nachweisen. Zusammenfassend kann eine Assoziation zwischen MECP2 und Autismus sowie Angelman-Syndrom jedoch nicht völlig ausgeschlossen werden.

Für die an Rett-Syndrom Erkrankten haben Hagberg und Witt-Engerström eine weltweit anerkannte allgemeine Einteilung der Entwicklung erstellt, die sich in vier Stadien unterteilt (Hagberg et al. 1985). Das Stadium der Stagnation (1. Stadium, 6.18. Lebensmonat), ist durch eine Verlangsamung und eventuell einen Stillstand der motorischen Entwicklung, Desinteresse, Aktivitätsabnahme, einen relativ zu kleinen Kopfumfang und verminderten Blickkontakt gekennzeichnet. In der Phase der Regression (2. Stadium, Beginn zwischen 1. und 3. Lebensjahr) können sich der Verlust schon erworbener Fähigkeiten (Sprache und Gebrauch der Hände), die typischen stereotypen Handbewegungen, ein sozialer und emotionaler Rückzug, Schreiphasen, Störungen der sensorischen Perzeption und Integration (leicht zu verwechseln mit Autismus) sowie epileptische Anfälle zeigen. In der Plateauphase (3. Stadium, 2. bis 10. Lebensjahr) verringern sich die Häufigkeit des autistischen Verhaltens und die Reizbarkeit der Patienten. Apraxie, Ataxie und die Handstereotypien verstärken sich. Die Phase der motorischen Verschlechterung (4. Stadium, ca. ab dem 10. Lebensjahr) wird durch kognitive Fortschritte auf der einen Seite und Schwäche, Abmagerung, Skoliose und Spastizität auf der anderen 
Seite dominiert. Die meisten Patienten sind spätestens jetzt auf einen Rollstuhl angewiesen (Lindberg und Rett 2000).

Aktuell gibt es noch keine kausale Therapie. Zur Verbesserung der Lebensqualität werden zur Zeit Musik-, Physio-, Hydro-, Ergo-, Hippotherapie sowie Logopädie angewendet. Darüber hinaus befindet sich die Anwendung mit Buspiron - ein partieller 5- $\mathrm{HT}_{1 \mathrm{~A}}-$ Rezeptoragonist - als Anxiolytikum in der Erprobung.

\subsection{Der Transkriptionsfaktor MeCP2}

MeCP2, das Methyl-CpG (Cytosin-phosphatidyl-Guanin) -Bindungsprotein 2, ist Teil einer Proteinfamilie, deren Mitglieder alle eine Methyl-CpG-Bindungsdomäne (MBD) aufweisen und mit MBD1, 2, 3 und 4 bezeichnet werden. Das humane MECP2-Gen besteht aus vier Exons und drei Introns, wobei $98 \%$ des kodierenden Materials Bestandteil von Exon 3 und 4 ist (Lewis et al. 1992). Das Protein MeCP2 setzt sich aus 486 Aminosäuren zusammen und beinhaltet zwei funktionelle Domänen. Im NTerminus des Proteins befindet sich die MBD, welche an symmetrisch methylierte CpG-Inseln des 5'-Endes eines Gens bindet (Adler et al. 1995, Free et al. 2001, Klose et al. 2005). Die zweite funktionelle Domäne ist im Zentrum des Proteins lokalisiert und fungiert als transkriptionelle Repressordomäne (TRD). Die TRD wiederum interagiert mit dem Co-Repressor mSin3A, wodurch die Histondeacetylasen 1 und 2 (HDAC1/2) gebunden werden, was zu einer kompakten Chromatinstruktur führt, die dann für die Transkription nicht mehr zugänglich ist (Dragich et al. 2000). MeCP2 verhindert demnach nur die Transkription solcher Gene, deren Promotorregionen aus symmetrisch methylierten CpG-Inseln bestehen (Nan et al. 1997). Bei den methylierten Genen wird meist von „Downstream-Genen“ gesprochen (Cassel et al. 2006), das heißt, ihre Transkription beziehungsweise Translation führt zur Herunterregelung von spezifischen Stoffwechselwegen. Bisher bekannte Zielgene von MeCP2 sind Bdnf und DIx5 (Horike et al. 2005). Darüber hinaus ist jedoch bei einer Vielzahl von verschiedenen potenziellen Zielgenen eine so genannte Konsensussequenz gefunden worden. MeCP2 benötigt zum Binden methylierte CpG-Inseln mit angrenzender Adenin/Thymin-reicher Sequenz, zum Beispiel CGNNTTAA, CGNNNTTAA, CCGGNNTTAA und CGNNNTATTA (Klose et al. 2005). Zwei generelle Mechanismen der Genregulation werden von MeCP2 


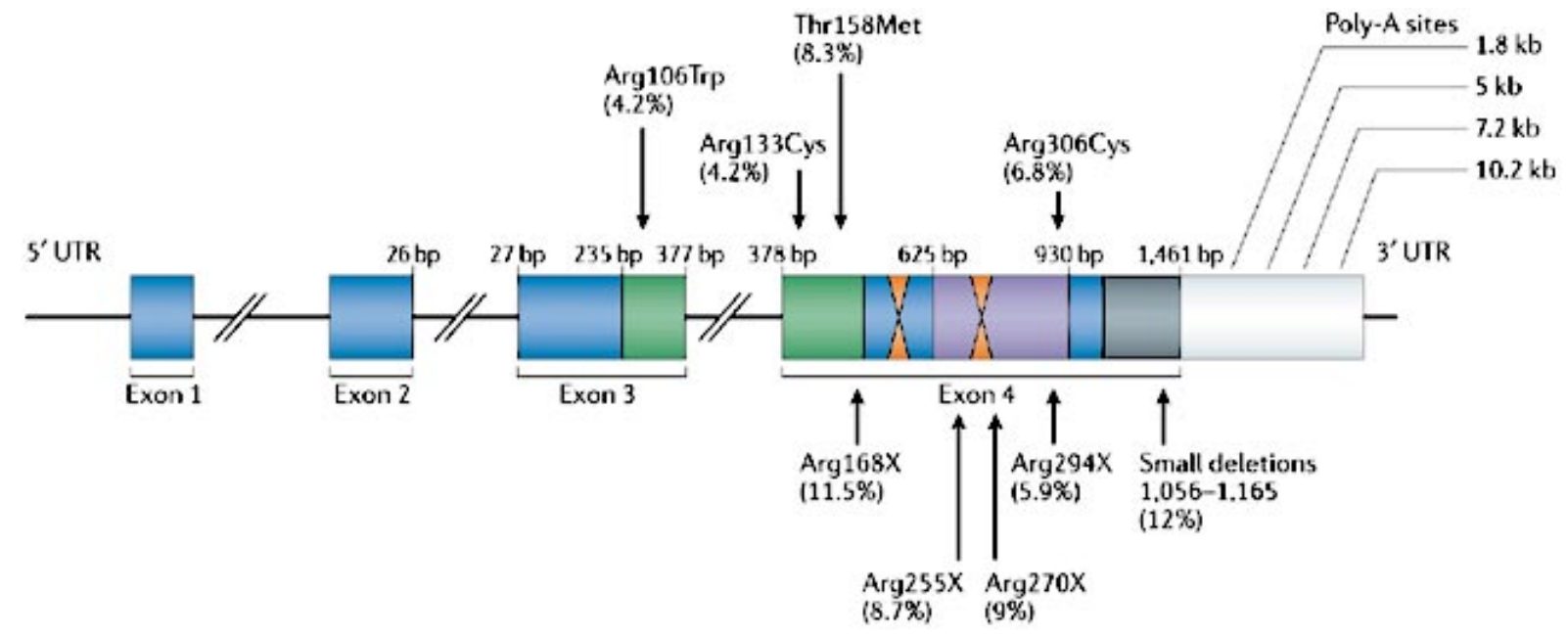

MBD $\square$ TRD $/$ NLS $\square$ ww

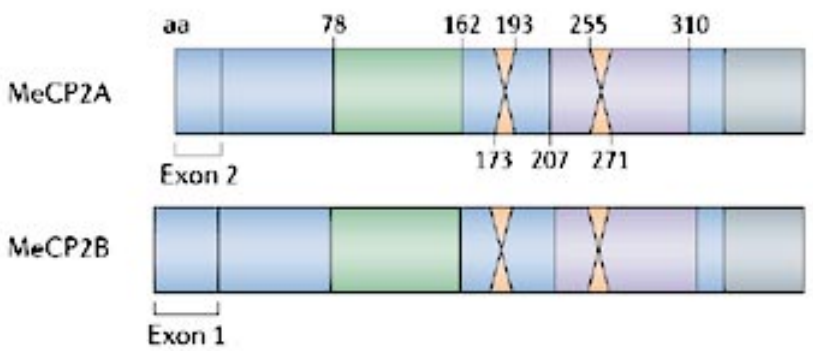

Copyright $\odot 2006$ Nature Publishing Group

Nature Reviews | Genetics

Abb. 1.3 Oben MECP2-Genstruktur mit den Positionen und Häufigkeiten der gängigen Mutationen, die beim Rett-Syndrom assoziiert sind. Unten Die zwei Isoformen des MeCP2-Proteins, MeCP2A und MeCP2B, die durch alternatives Splicen entstehen. Abkürzungen: $M B D$ : Methyl-CpG-Bindungsdomäne, NLS: nucleäres Lokalisationsignal, poly(A): Polyadenylation, TRD: transkriptionelle Repressordomäne, $X$ : Stopcodon. Entnommen aus Bienvenu und Chelly (2006), Seite 419

vereint, die DNA-Methylierung und die Histondeacetylierung. Die DNA-Methylierung spielt nicht nur eine wichtige Rolle bei der transkriptionellen Repression, sondern auch bei der Inaktivierung des X-Chromosoms (D'Esposito et al. 1996), beim genomischen Imprinting, bei der Inaktivierung parasitärer Elemente im Genom, für die Unterscheidung des ursprünglichen DNA-Strangs vom neu synthetisierten Strang und bei der Tumorgenese. Es sind bisher zwei alternative Isoformen des Proteins bekannt, MeCP2e1 und MeCP2e2 oder auch als MeCP2A und MeCP2B bezeichnet, dessen funktionelle Unterschiede allerdings noch unklar sind (Mnatzakanian et al. 2004). 


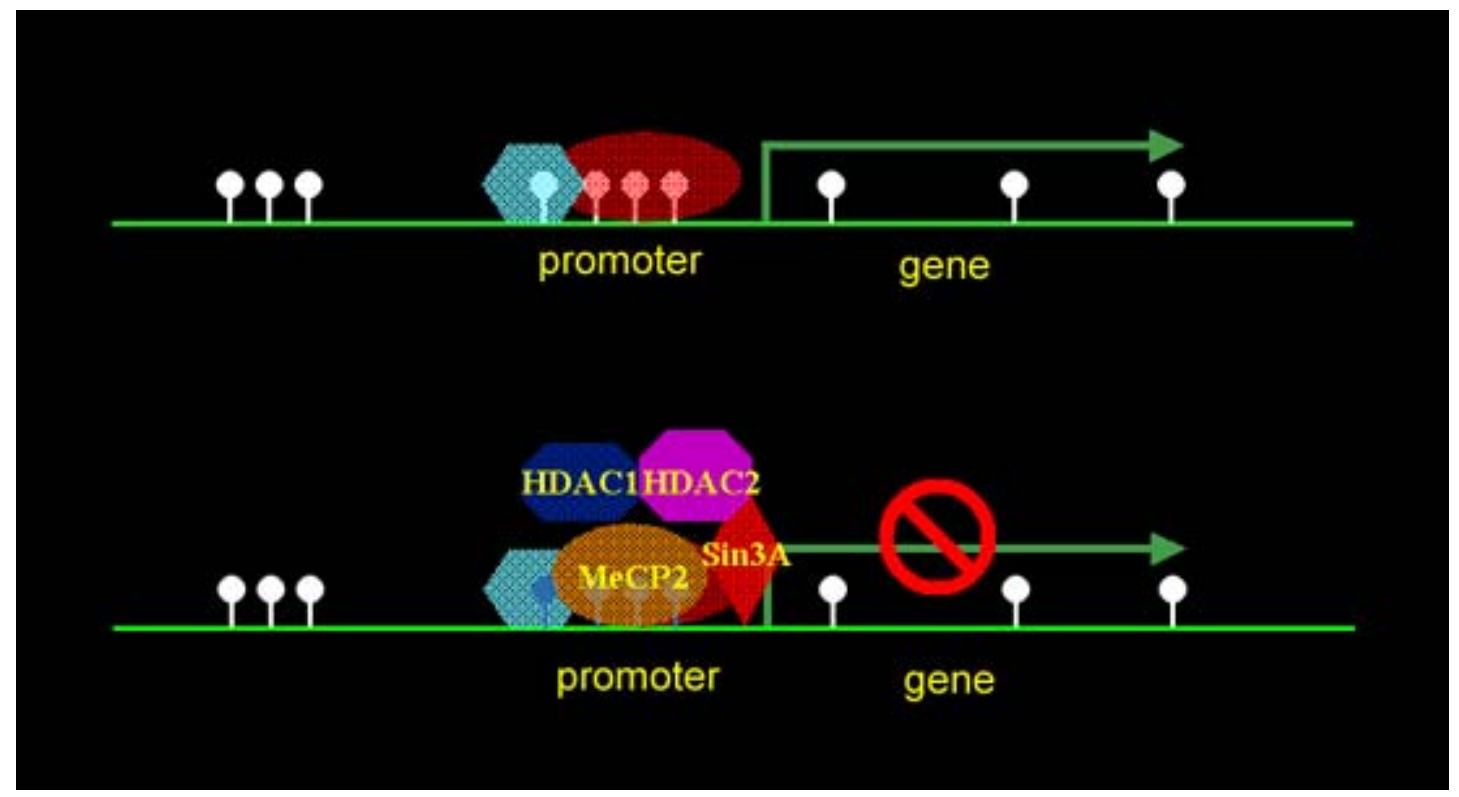

Abb. 1.4 Gensuppression durch MeCP2. Abkürzungen: HDAC1: Histondeacetylase 1, HDAC2: Histondeacetylase 2, $\operatorname{Sin} 3 A$ : Co-Repressor. Entnommen aus Preuss (2004), Seite 1

\subsection{Die verwendeten Mecp2-Mausmodelle}

Aufbauend auf dem Kenntnisstand, dass Mutationen im MECP2-Gen für das RettSyndrom beim Menschen verantwortlich sind, wurden Mausmodelle generiert, denen das funktionsfähige Mecp2-Gen fehlt - so genannte Knockout-Mäuse (Mecp2-/y Modelle). Die Mecp2-defizienten Mäuse der Arbeitsgruppe Viemari et al. (2005) zeigten im Alter von ein bis zwei Monaten nach anfänglich normaler Entwicklung plötzlich unregelmäßige Atemzyklen mit häufigen Apnoephasen, die sich verstärkten und schließlich in einem tödlichen Atemstillstand endeten. Experimentelle Analysen von Stettner et al. (2007) ergaben ebenso respiratorische Störungen bei Mecp2-ly Mäusen. Sie zeichneten simultane phrenische und efferente vagale Nervenaktivitäten auf, um das motorische Muster der Respiration zu analysieren. Es zeigte sich eine hoch variable postinspiratorische Aktivität, die eng mit Atemunregelmäßigkeiten wie zum Beispiel Apnoephasen korrelierte, wie sie auch bei Rett-Patienten auftreten und dort zu lebensbedrohlichen Zuständen führen können (Stettner et al. 2007).

Das transgene Mausmodell von Collins et al. (2004), bei dem das humane MECP2Gen auf Wildtyp-Mäuse übertragen wurde, zeigte Mäuse, die im Alter von zwanzig Wochen epileptische Anfälle bekamen, vermehrt hypoaktiv wurden und sogar zu 30 \% verstarben. Hypoaktivität und epileptische Anfälle zeigen sich auch in der Rett- 
Symptomatik bei Menschen. Der respiratorische Phänotyp dieses Mausmodells ist hingegen noch nicht charakterisiert worden. Das transgene Mausmodell dient zunächst der Grundlagenforschung.

Für die vorliegende Arbeit wurde sowohl ein $M e c p 2^{-/ y}$ - als auch ein transgenes Modell verwendet. Als Mecp2-defizientes Mausmodell diente die Stammlinie B6.129P2(C)-Mecp2 ${ }^{\mathrm{tm} 1-1 B i r d}$ (Guy et al. 2001), welche schon bei Stettner et al. (2007) Verwendung fand. Heterozygote Mecp2 ${ }^{+-}$-Weibchen wurden mit C57BL/6JMännchen (Wildtyp, WT) gekreuzt, um hemizygote Mecp2 $2^{-/ y}$-Mäuse zu erhalten.

In Anlehnung an das Mausmodell von Collins et al. (2004) wurden vom Humangenetikinstitut (Leitung von Prof. Dr. Engel) transgene Mäuse zur Verfügung gestellt, die neben dem X-chromosomal gekoppelten Mecp2-Gen durch ein weiteres EGFP-gekoppeltes (Enhanced Green Fluorescent Protein) Mecp2-Gen auf einem Autosom gekennzeichnet waren. Dieses Mausmodell wurde durch eine homologe Rekombinationstechnik, die so genannte GET-Rekombination, geschaffen. Ein BACKlon (bacterial artificial chromosomes), der ein Maus-Genom-Fragment umfasst, das die gesamte Länge des Mecp2-Gens mit den flankierenden Sequenzen beinhaltet, wurde mit einer Wildtyp-Maus verpaart. Dadurch entstanden transgene Mäuse vom Typ „T/-, +/y“. Die Schreibweise „T/-, +/y“ verdeutlich, dass sich eine zusätzliche Kopie auf einem Autosom (T) und das ursprüngliche Mecp2-Gen auf dem X-Chromosom (+) befinden. Der respiratorische Phänotyp dieses Modells wurde noch nicht charakterisiert.

Das Rett-Syndrom betrifft überwiegend Mädchen. Trotzdem konnten in der vorliegenden Arbeit, die der Grundlagenforschung dient, nur männliche Mäuse aufgrund des homogenen Phänotyps verwendet werden. Bei weiblichen Mäusen ist immer eins der X-Chromosome inaktiviert. Welches der beiden in einer Zelle aktiviert und welches inaktiviert vorliegt, ist Zufall. Um einen heterogenen Phänotyp durch die zufällige Verteilung der X-Chromosomeninaktivierung zu vermeiden, wurden nur männliche Knockout- und transgene Mäuse sowie die korrespondierenden männlichen Wildtypen verwendet.

Die Entwicklungsstadien P7 und P40 (postnatal 7 beziehungsweise 40 Tage alt) wurden für die vorliegende Dissertation ausgewählt. Mecp2-Knockout-Mäuse zeigen im frühen Entwicklungsstadium P7 Dysbalancen in der exzitatorischen und inhibitorischen Transmission in der ventrolateralen Medulla oblongata. Eine 
gefundene supprimierte GABAerge Transmission scheint spezifische Signalwege im Hirnstamm während der frühen postnatalen Entwicklung zu beeinflussen, ohne dass sich dadurch bei P7 bereits eine Verhaltensauffälligkeit zeigt. Dieses Ungleichgewicht soll mitverantwortlich für die Rett-Symptomatik beim Menschen sein (Medrihan et al. 2008). Im Entwicklungsstadium P40 konnten Stettner et al. (2007) den respiratorischen Phänotyp (Apnoephasen, prolongierte Postinspiration, irregulärer Atemrhythmus) von Mecp2-Knockout-Mäusen charakterisieren. Dieser Phänotyp ähnelt den Atemunregelmäßigkeiten bei Menschen mit Rett-Syndrom (Stettner et al. 2007).

\subsection{Das respiratorische Netzwerk}

Die Atmung, die bei manchen Rett-Patienten und auch in diversen RettMausmodellen in Mitleidenschaft gezogen wird, ist einer der fundamentalen Prozesse des menschlichen Lebens. Ihre Hauptaufgabe ist es, Sauerstoff für den Blutkreislauf des Organismus bereitzustellen, damit dieser inn am Zielorgan beziehungsweise am Zielgewebe zur Energiegewinnung verbrauchen kann. Die Atmung wird von einer Vielzahl von Neuronen in der Medulla oblongata geregelt. Diese werden als respiratorische Neurone bezeichnet und lassen sich in funktionell und anatomisch unterschiedliche Gruppen einteilen. Funktionell werden sie entsprechend den einzelnen Atemphasen in

- pre-I-Neurone (prä-inspiratorische Neurone, die während des Übergangs von Exspiration und Inspiration aktiv sind),

- early-I-Neurone (früh-inspiratorische Neurone feuern vom Beginn bis zur Mitte der Inspiration),

- ramp-I-Neurone (Rampen-inspiratorische Neurone, deren Aktivität während der ganzen Inspiration vorhanden ist),

- late-I-Neurone (spät-inspiratorische Neurone, die am Ende der Inspiration aktiv sind),

- post-I-Neurone (post-inspiratorische Neurone feuern während des Übergangs von Inspiration zur Exspiration) und

- $\quad E_{2}$-Neurone (exspiratorische Neurone entladen sich während der Exspiration) 


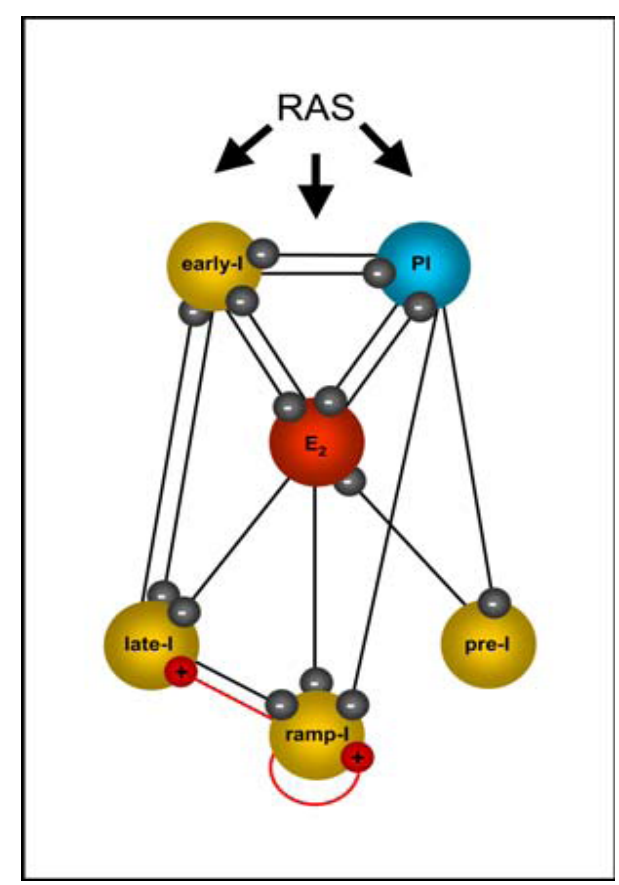

Abb. 1.5 Schematische Darstellung der Verschaltung des respiratorischen Netzwerkes: überwiegend inhibitorisch (grau -) reziproke Verschaltung innerhalb der respiratorischen Neurone durch Glycin und GABA, exzitatorische (rot +) Rückkopplungen durch Glutamat. Abkürzungen: pre-l: pre-l-Neurone, early-l: early-I-Neurone, ramp-l: ramp-I-Neurone, late-l: late-I-Neurone, post-I: post-I-Neurone, $E_{2}$ : $E_{2^{-}}$ Neurone, RAS: retikuläres Aktivierungssystem. Entnommen aus Manzke (2004), Seite 3

unterteilt, die durch ihr typisches Erregungsmuster den Atemrhythmus generieren (Schmidt RF et al. 2000). Entsprechend ihrer Lokalisation werden sie anatomisch in zwei große Neuronengruppen unterteilt, die als dorsale respiratorische Gruppe (DRG) und ventrale respiratorische Gruppe (VRG) bekannt sind. Die DRG befindet sich in den ventralen Anteilen des Nucleus tractus solitarius (NTS) und ist nicht für die Generierung eines Atemrhythmus notwendig (Smith et al. 1991). Die Interneurone des NTS bilden wesentliche Afferenzen aus den Atemwegen, der Lunge und dem Herz-Kreislaufsystem und sind so mit vagalen Reflexen assoziiert (Richter und Spyer 2001). Die VRG erstreckt sich als longitudinale Gewebesäule entlang des Nucleus ambiguus (NA) auf Höhe des kaudalen Pols des Nucleus facialis und des zweiten Zervikalsegments. Ferner wird sie in einen rostralen Teil, der den Bötzinger- und den Prä-Bötzinger-Komplex (preBotC) enthält, einen intermediären (Nucleus ambiguus, Nucleus paraambigualis) und einen kaudalen Teil (Nucleus retroambigualis) aufgeteilt (Preuße 2005). Die enge Lokalisation zum Nucleus ambiguus, der Motoneurone des Larynx und Pharynx enthält, ist sinnvoll, da Menschen nur während der Postinspiration und Exspiration die Phonation zur Kommunikation nutzen können. In ebenfalls enger räumlicher Beziehung befinden sich das kardiovaskuläre Netzwerk, das die Sympathikus-aktivität reguliert und die zentralen Chemo-rezeptoren, die empfindlich auf den $\mathrm{CO}_{2}$-Partialdruck und Protonen reagieren und so die Atemfrequenz modulieren (Schmidt RF et al. 2000). Das Prinzip der Verschaltung innerhalb des respiratorischen Netzwerkes basiert überwiegend auf einer reziproken Inhibition, das heißt, die oben genannten sechs respiratorischen Neuronengruppen hemmen sich untereinander gegenseitig, vermittelt durch die Neurotransmitter Glycin und GABA. Lediglich die ramp-I-Neurone wirken exzitatorisch durch Glutamatausschüttung auf sich selber und auf die late-I-Neurone 
(Richter et al. 1996). Von außen wird das respiratorische System durch das aufsteigende retikuläre Aktivierungssystem (RAS) angeregt.

\subsection{Der Prä-Bötzinger-Komplex}

Rett-Patienten können neben der mentalen Retardierung und dem Verlust von bereits erlernten Fähigkeiten unter lebensbedrohlichen Atemunregelmäßigkeiten leiden. Als Ort der Rhythmogenese der Atmung wird der Prä-Bötzinger-Komplex (preBotC) angesehen (Smith et al. 1991, Johnson et al. 2001, McCrimmon et al. 2001, Onimaru und Homma 2003). Er beinhaltet alle dafür notwendigen oben genannten Neuronengruppen (Smith et al. 1991, Feldman et al. 2003). Zwar kann der preBotC elektrophysiologisch identifiziert werden (Smith et al. 1991), für die anatomische Lokalisation müssen allerdings umgebende klar abgrenzbare Strukturen als Leitstrukturen zu Hilfe genommen werden. Hierzu dient die u-förmige Anordnung des prinzipalen Kerns der unteren Olive zur Bestimmung der korrekten Transversalebene. Die Sagittalebene wird mittels des Nucleus ambiguus, in dessen ventrolateraler Peripherie sich der preBotC befindet, identifiziert (Alheid et al. 2002, Schwarzacher et al. 1995). Auch durch Immunhistochemie kann der preBotC lokalisiert werden, denn der Neurokinin-1-Rezeptor (NK-1-R) für Substanz P wird überwiegend auf glutamatergen Neuronen der VRG exprimiert (Guyenet et al. 2002, Wang et al. 2001) und eine bilaterale Zerstörung von NK-1-Rezeptor-tragenden Neuronen im preBotC führt zu einer ataktischen Atmung (Gray et al. 2001). Daher etablierte sich der NK-1-R als Marker für die anatomische Identifizierung des preBotC, auch für den preBotC in der Embryogenese (Pagliardini et al. 2003). Des Weiteren ist auch der Neurotransmitter Somatostatin als preBotC-Marker bekannt (Stornetta et al. 2003), so dass in der vorliegenden Arbeit die Gene für den NK-1-R und für Somatostatin bezüglich ihres Expressionsmusters im preBotC hin untersucht werden. 

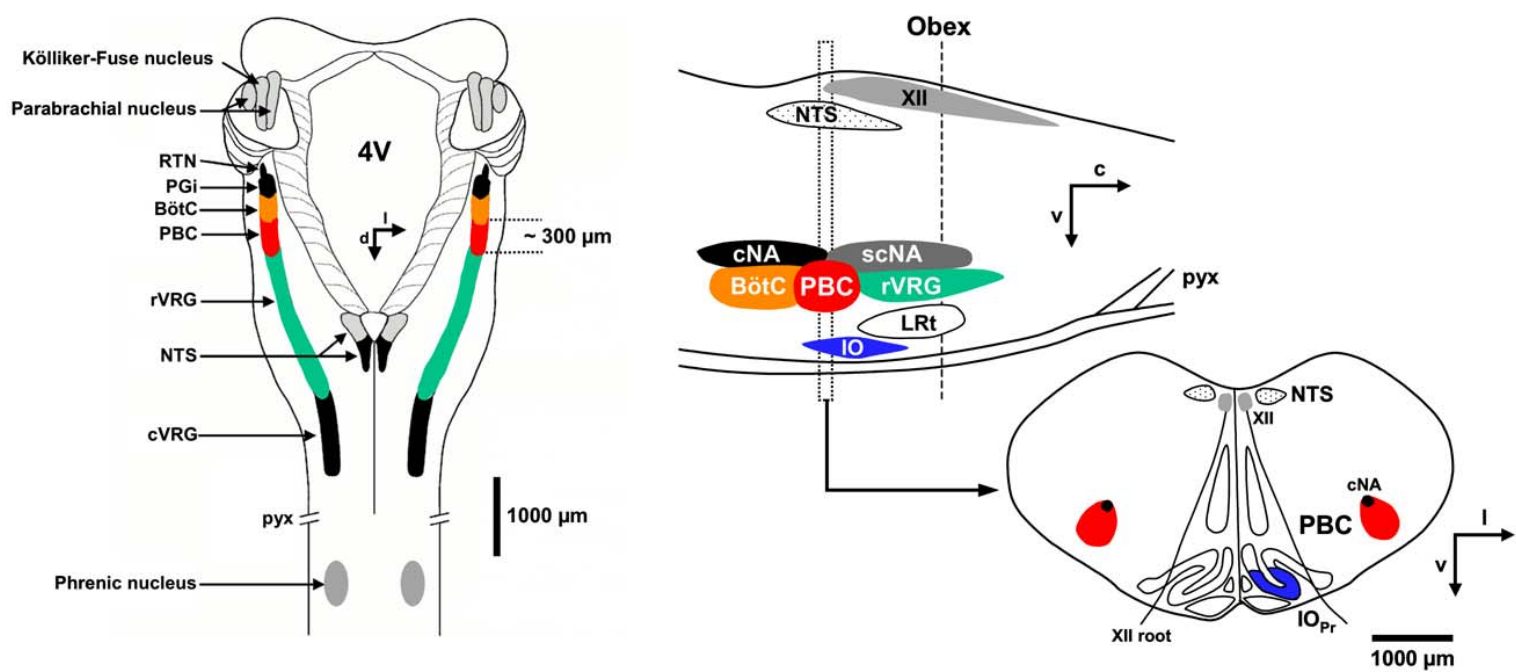

Abb. 1.6 Schematische Darstellung der Lokalisation des Prä-Bötzinger-Komplexes. Links Frontalschnitt. Mitte Sagittalschnitt. Rechts Transversalschnitt. Abkürzungen: BötC: Bötzinger-Komplex, c: caudal, cNA: kompakter Anteil des Nucleus ambiguus, $d$ : distal, $I_{P r}$ : Nucleus principalis der inferioren Olive, l: lateral, LRt: lateral reticular nucleus, NTS: Nucleus tractus solitarius, PBC: Prä-Bötzinger-Komplex, PGi: Nucleus paragigantocellularius pyx: Decussatio pyramidum, $r$ : rostral, scNA: semikompakter Anteil des Nucleus ambiguus, $v$ : ventral, VRG: ventrale respiratorische Gruppe, XII root: Nucleus nervi hypoglossi Ursprung, 4V: vierter Ventrikel. Entnommen aus Manzke (2004), Seite 2

\subsection{Das exzitatorische System}

Neben dem Prinzip der inhibitorisch reziproken Verschaltung der respiratorischen Neuronen fungiert Glutamat als exzitatorischer Neurotransmitter. In der vorliegenden Arbeit wird das Expressionsmuster von drei Genen für ionotrope NMDAGlutamatrezeptoren im preBotC untersucht. Die Relevanz ergibt sich aus der Tatsache, dass das glutamaterge System eins der wichtigsten Systeme im Zentralnervensystem ist, dass es an der respiratorischen Verschaltung beteiligt ist und dass eine Reduktion des Glutamatspiegels im Hirngewebe bei Rett-Patienten gefunden wurde (Jellinger 2003).

Glutamat ist der wichtigste Neurotransmitter des exzitatorisch zentralnervösen Systems und liegt als dissoziierte L-(+)-Glutaminsäure vor. Neben der Aufgabe als Neurotransmitter hat Glutamat weitere vielseitige Funktionen. Zum einen dient es als proteinogene Aminosäure selbst dem Aufbau von Eiweißen, zum anderen ist es in einer Transaminierungsreaktion ein $\mathrm{NH}_{2}$-Donor, um $\alpha$-Ketosäuren in $\alpha$-Aminosäuren umzuwandeln und so neue Aminosäuren zu synthetisieren. Enzyme hierfür sind die Glutamat-Oxalacetat-Transaminase (GOT) und Glutamat-Pyruvat-Transaminase (GPT). Für weitere im Stoffwechsel benötigte Aminogruppen wird Glutamin verwendet, das wiederum im Citratzyklus durch die Glutamin-Synthetase aus 
Glutamat und einem Ammoniumion gebildet wird (Kandel et al. 2000). Glutamat selbst wird auch im Citratzyklus gebildet, katalysiert von der Glutamatdehydrogenase

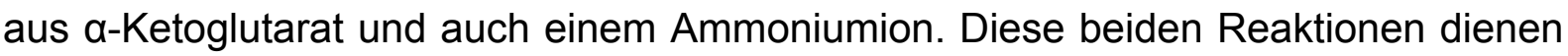
der Entgiftung von Ammoniak, welches in Form von Transaminierung auf Oxalacetat und durch die Glutamat-Dehydrogenase-Reaktion im Harnstoffwechsel weiter eliminiert wird und dann ausgeschieden werden kann. Ferner wird Glutamat in Lebensmitteln auch als Geschmacksverstärker ( $E$ 620) eingesetzt, das die Geschmacksrichtung Umami vermittelt. Im Zentralnervensystem kann Glutamat zu Y-Aminobuttersäure (GABA), ebenfalls ein Neurotransmitter, decarboxyliert werden. Somit ist Glutamat die einzige Aminosäure, die im Gehirn oxidiert, transaminiert, aminiert und decarboxyliert werden kann (Siegel und Albers 2006).

Als Neurotransmitter bindet Glutamat an ionotrope oder metabotrope Rezeptoren, die als Transmembranproteine fungieren. Die ionotropen Glutamatrezeptoren bestehen aus tetrameren (AMPA und NMDA) oder pentameren (Kainat) membranständigen Proteinuntereinheiten, die einen lonenkanal bilden und eine extrazelluläre Bindungsstelle für Glutamat besitzen. Sie werden aufgrund ihrer unterschiedlichen Affinität zu Glutamat-Agonisten in AMPA- ( $\alpha$-amino-3-hydroxy-5methyl-4-isoxazolepropionic acid), NMDA- (N-methyl-D-aspartic acid) und KainatRezeptoren unterteilt. Auch sind die Ionenkanäle unterschiedlich permeabel für Kationen. AMPA- und Kainat-Rezeptoren sind permeabel für Natrium, Kalium und eingeschränkt durchlässig für Calcium. NMDA-Rezeptoren hingegen sind nichtselektive Kationenkanäle, müssen aber bei negativen Membranpotentialen kleiner als $-30 \mathrm{mV}$ von einem Magnesium-lon entblockt werden und haben auch ein länger dauerndes EPSP (exzitatorisches postsynaptisches Potential) über einige hundert Millisekunden als AMPA-Rezeptoren (wenige Millisekunden). Das Besondere der NMDA-Rezeptoren ist, dass sie für Kationen erst leitfähig werden, wenn Prä- und Postsynapse ausreichend depolarisiert sind (Squire et al. 2008). Dieses gleichzeitige Auftreten von prä- und postsynaptischer Aktivität deutet darauf hin, dass diese Synapse besonders häufig verwendet wird. Man vermutet, dass die Leitfähigkeitserhöhung des NMDA-Rezeptors mit dem Phänomen des Bahnens von Nervenwegen und damit auch mit Lernen und Gedächtnis assoziiert ist. So lässt sich der Zusammenhang zwischen einer pathologischen Fehlsteuerung der NMDARezeptoren und der Krankheit Schizophrenie erklären. Die metabotropen Glutamatrezeptoren, auch G-Protein-gekoppelte Rezeptoren genannt, leiten Signale 
über GTP-bindende Proteine ins Zellinnere weiter und aktivieren dadurch je nach Untergruppe die Phosphorlipase $\mathrm{C}$ oder hemmen die Adenylatzyklase (Kandel et al. 2000, Siegel und Albers 2006 und Squire et al. 2008).

\subsection{Das inhibitorische System}

Eine wesentliche Eigenschaft des respiratorischen Netzwerkes basiert auf der inhibitorisch reziproken Verschaltung der respiratorischen Neuronen. Dabei spielen die Neurotransmitter Glycin und GABA eine wesentliche Rolle. Bei einer Blockade der GABAergen und glycinergen synaptischen Hemmung im respiratorischen Netzwerk kommt es zu einer Persistenz der rhythmischen Aktivität (Johnson et al. 2001). Das GABAerge System ist wichtig für die Aufrechterhaltung der Funktionalität des respiratorischen Netzwerkes. In der vorliegenden Dissertation werden speziell die Gene für die $G_{A B A}$-Rezeptoren mit den Untereinheiten Alpha 6 und Beta 1 untersucht. Ma et al. (2005) zeigten eine Assoziation dieser Rezeptoren mit der Erkrankung Autismus und, wie eingangs beschrieben, finden sich MECP2Mutationen bei dem Erkrankungsbild Autismus. Des Weiteren wird das bisher bekannte Zielgen DIx5 von MeCP2 in GABAergen Neuronen exprimiert (Horike et al. 2005), so dass die Untersuchung von Rezeptoren des inhibitorischen Systems relevant ist.

GABA ( $y$-Aminobuttersäure) ist das biogene Amin der Glutaminsäure. Es bildet eine $\gamma$-Aminosäure und ist somit keine proteinogene $\alpha$-Aminosäure. Durch die GlutamatDecarboxylase wird aus Glutamat GABA synthetisiert, wodurch der exzitatorische und der inhibitorische Neurotransmitter über Decarboxylierungsreaktionen im Gleichgewicht stehen.

Die GABA-Rezeptoren lassen sich in drei Gruppen einteilen, A, B und C. GABA $A^{-}$ und GABA $_{C}$-Rezeptoren sind ionotrop und formen aus pentameren membranständigen Proteinuntereinheiten Liganden-gesteuerte lonenkanäle für

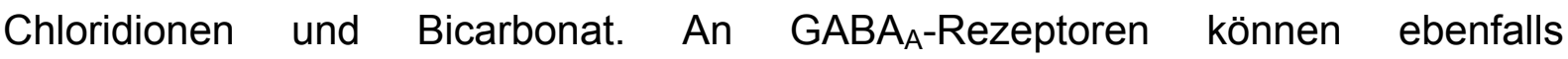
Benzodiazepine, Barbiturate und Neurosteroide binden, so dass sie an der Einleitung und Aufrechterhaltung des Schlafs mitwirken und in der Anästhesiologie zur Narkoseeinleitung benutzt werden. Besonders für Barbiturate und Benzodiazepine besteht durch Stimulierung der $G_{A B A}-$ Rezeptoren ein Suchtpotential. GABA $C^{-}$ 
Rezeptoren unterscheiden sich von $\mathrm{GABA}_{A}-$ Rezeptoren darin, dass sie nicht sensitiv gegenüber Benzodiazepinen, Barbituraten und Neurosteroiden reagieren, langsamer aktivieren und inaktivieren sowie kaum desensitivieren. Die GABA $A_{B}$-Rezeptoren sind metabotrop, haben sieben Transmembrandomänen und liegen als Dimere vor. Ihre Signaltransduktion erfolgt über $G_{i}$-Proteine, was eine Aktivierung von ligandengesteuerten Kalium-Kanälen und Hemmung von Calcium-Kanälen zur Folge hat und ein daraus resultierendes IPSP (inhibitorisches postsynaptisches Potential). Diese hemmende Wirkung von GABA dient besonders in den Basalganglien und im Kleinhirn der motorischen Kontrolle. Im Rückenmark auf den Motoneuronen ist es an der Verschaltung von Reflexen und an der Koordination von Bewegungsabläufen beteiligt (Kandel et al. 2000, Siegel und Albers 2006 und Squire et al. 2008).

\subsection{Serotonerges System}

Ramaekers et al. (2003) und Jellinger (2003) haben gezeigt, dass bei Patienten mit Rett-Syndrom verminderte Serotonin- und Dopaminspiegel vorliegen. Zudem fanden Paterson et al. (2005) bei Rett-Patienten eine Veränderung des Bindungsverhaltens von Serotonin an seinen Transporter. Aufgrund der neuromodulatorischen Wirkung auf das respiratorische Netzwerk wird in der vorliegenden Arbeit der Einfluss von MeCP2 auf das serotonerge System in Form von Genen für Syntheseenzymen, Rezeptoren und Transporter untersucht. Manzke (2004) zeigte, dass im preBotC auf inspiratorischen Neuronen Serotonin-4(a)-Rezeptorvarianten exprimiert werden. Ferner sind mit den Serotonin- und Opioidrezeptoren neurotrophe Wirkungen assoziiert (Lauder 1993, Jacobs und Azmitia 1992, Miller und Azmitia 1999), die mit Entwicklungsstörungen wie dem Rett-Syndrom und damit auch Hirnentwicklungsstörungen in Verbindung gebracht werden können.

Der Neurotransmitter Serotonin wurde ursprünglich als Faktor im Blutserum entdeckt. Da ihm die Fähigkeit zugesprochen wurde, den Blutdruck durch Kontraktion der Blutgefäße zu steigern, erhielt dieser Faktor den Namen Serotonin (Serum, Tonus). Serotonin wird aus der proteinogenen $\alpha$-Aminosäure Tryptophan synthetisiert. Im ersten Schritt hydroxyliert die Tryptophan-Hydroxylase Tryptophan, so dass die nichtproteinogene Aminosäure 5-Hydroxytryptophan entsteht. Die TryptophanHydroxylase (Tph) existiert in Form von zwei Isoenzymen. Die Tph1 befindet sich 
überwiegend im Darm, in der Glandula pinealis, in der Milz und im Thymus. Die Tph2 hingegen ist vorwiegend im Hirnstamm lokalisiert (Walther und Bader 2003). Im zweiten Schritt, die Decarboxylierung, wird durch die DOPA-Decarboxylase 5-Hydroxytryptamin (5-HT), das Serotonin genannt wird, gebildet. Vgl. Abb. 1.7. Diese Synthese findet entsprechend der Lokalisation der Tryptophan-Hydroxylase im Zentralnervensystem, in Leber, in Milz und in enterochromaffinen Zellen der Darmschleimhaut statt (Siegel und Albers 2006).

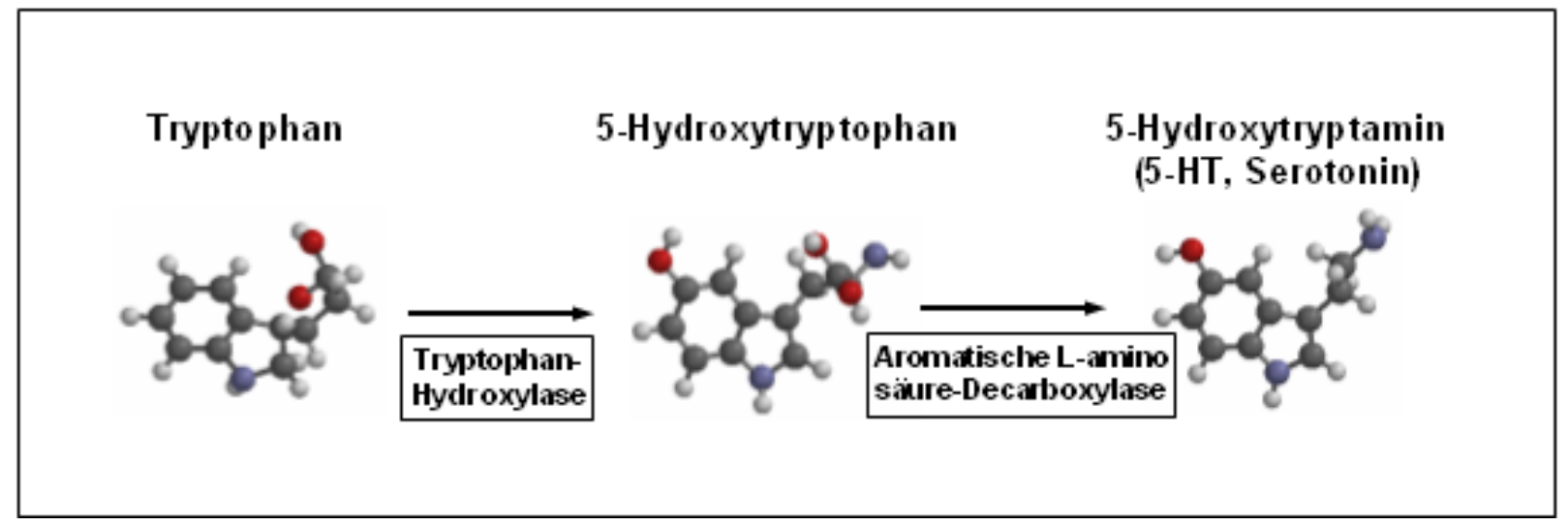

Abb. 1.7 Schematische Darstellung der Serotoninsynthese. Entnommen aus Preuße (2005), Seite 5

Serotonin selbst kann die Blut-Hirn-Schranke nicht passieren, Tryptophan schon, so dass ein Mangel an Serotonin durch nicht genügend verfügbares Tryptophan im Liquor cerebrospinalis entstehen kann. In diesem Zusammenhang wird das Phänomen des Heißhungers auf Süßigkeiten diskutiert. Denn die Aufnahme von Zucker und die damit verbundene Ausschüttung von Insulin ermöglichen unter anderem den Übertritt von Tryptophan in das zentrale Nervensystem. Normalerweise reguliert das Gehirn entsprechend der Aktivität der Raphe-Neuronen (siehe unten) die Serotoninsynthese bei ausreichender Verfügbarkeit von Tryptophan selbst (Squire et al. 2008).

Serotonin ist an vielen biologischen Prozessen beteiligt. Seine vielen Rezeptoren werden in Familien (1-7) unterteilt und international als 5-HT-R abgekürzt. Großbuchstaben sind den Rezeptorsubtypen und Kleinbuchstaben den jeweiligen Splicevarianten vorbehalten. Mit Ausnahme der 5-HT3-R sind alle Serotoninrezeptoren metabotrop und damit G-Protein gekoppelt (Hoyer et al. 2002). Ihre Signaltransduktionswege sind allerdings unterschiedlich. So bewirken die 5-HT2-R eine Aktivierung der Phosphorlipase $\mathrm{C}$, die 5-HT1-R und 5-HT5-R eine Hemmung der Adenylatzyklase und die 5-HT4-R, 5-HT6-R und 5-HT7-R eine Aktivierung der Adenylatzyklase. Die 5-HT3-R sind lonenkanäle, die selektiv für Natrium- und 


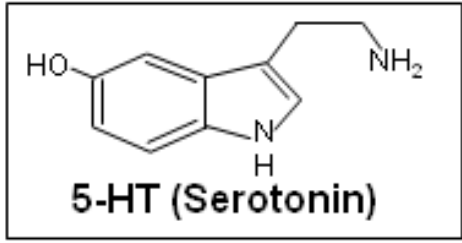

Serotoninrezeptoren

(5-HT...R)

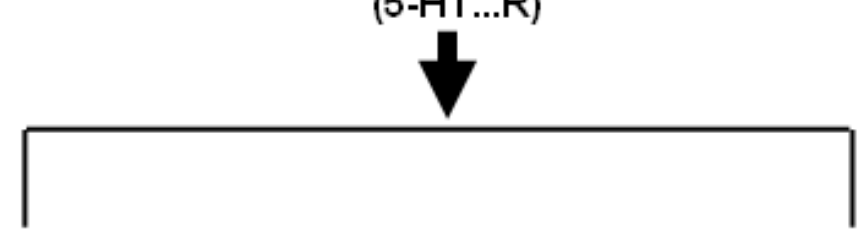

G-Protein gekop-

pelte Rezeptoren

$\mathrm{Na}^{+} / \mathrm{K}^{+}-\mathrm{Kanal}$

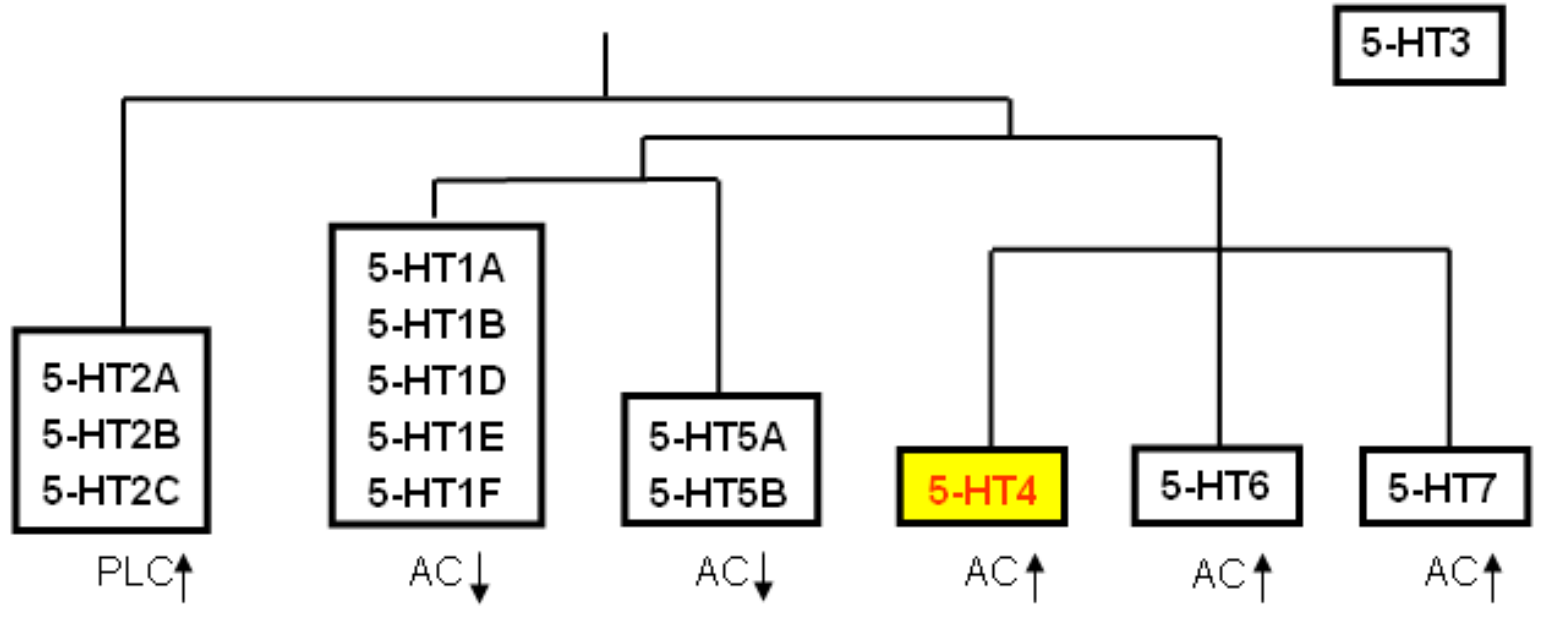

Abb. 1.8 Systematik der Serotoninrezeptoren. Entnommen aus Preuße (2005), Seite 6

$\uparrow$ Aktivierung $\downarrow$ Hemmung

Kaliumionen permeabel sind und sich nur auf zentralen und peripheren Neuronen befinden. Serotonin wird in den Interzellularraum und nicht direkt in den synaptischen Spalt sezerniert, so dass es die Aktivität 5-HT-R-tragender Neurone beeinflusst. Aufgrund der vielen verschiedenen Rezeptortypen und deren unterschiedlicher Signalwege kommt es in neuronalen und extraneuronalen Geweben durch Serotonin zu unterschiedlichen physiologischen Prozessen. Eine intravenöse Serotoningabe bewirkt zum Beispiel initial einen Blutdruckabfall, vermittelt durch $5-\mathrm{HT}_{3}-\mathrm{R}$, gefolgt von einem Blutdruckanstieg durch Aktivierung von $5-\mathrm{HT}_{2}-\mathrm{R}$ und schließlich zu einem erneuten prolongiert andauernden Blutdruckabfall durch 5- $\mathrm{HT}_{7}-\mathrm{R}$-Aktivierung (Kandel et al. 2000). Bezogen auf die Rezeptoren $5-\mathrm{HT}_{4}-\mathrm{R}$ und $5-\mathrm{HT}_{5 \mathrm{~B}}-\mathrm{R}$, deren Genexpression in der vorliegenden Arbeit untersucht werden, handelt es sich um metabotrope Rezeptoren, die die Adenylatzyklase über den 5- $\mathrm{HT}_{4}-\mathrm{R}$ aktivieren und über den $5-\mathrm{HT}_{5 \mathrm{~B}}-\mathrm{R}$ hemmen. Über den $5-\mathrm{HT}_{4}-\mathrm{R}$ ist bekannt, dass seine Rezeptorvariante $5-\mathrm{HT}_{4(\mathrm{a})}-\mathrm{R}$ auf inspiratorischen Neuronen im preBotC exprimiert wird (Manzke 2004). Ebenso wurde RNA des 5- $\mathrm{HT}_{4}-\mathrm{R}$ im Nucleus caudatus, Putamen, Nucleus accumbens und im Hippocampus durch Bonaventure et al. (2000) nachgewiesen. Der $5-\mathrm{HT}_{5 \mathrm{~B}}-\mathrm{R}$ wurde bisher zwar in Mäusen und Ratten gefunden, 
aber noch nicht im Menschen (Nelson 2004). Menschen besitzen zwar das Gen für den $5-\mathrm{HT}_{5 \mathrm{~B}}-\mathrm{R}$, aber dessen Translation ergibt kein funktionsfähiges Protein und damit auch keine intakten $5-\mathrm{HT}_{5 \mathrm{~B}}$-Rezeptoren (Grailhe et al. 2001). Serrats et al. (2004) fanden RNA-Expressionen in den Nuclei raphe dorsalis et medianus, Kinsey et al. (2001) in den Habenula, im Hippocampus und in der inferioren Olive.

Die serotonergen Neurone finden sich vornehmlich im medialen Hirnstamm, von wo aus sie durch weit verzweigte Axonsysteme jede Hirnregion erreichen (Jacobs und Azmitia 1992). Sie werden in zwei Gruppen unterteilt, wobei sich eine im Mesenzephalon (rostrale Gruppe) und die andere im Rhombenzephalon (kaudale Gruppe) in den Raphekernen befindet. Die rostrale Gruppe der serotonergen Neurone gliedert sich in die drei Kerne Nucleus linearis caudalis, Nucleus raphe dorsalis und Nucleus raphe medianus auf und projiziert hauptsächlich ins Vorderhirn. Die Projektion der kaudalen Gruppe erfolgt in den Hirnstamm und ins Rückenmark. Die kaudale Gruppe wird in die Nuclei raphe magnus, raphe obscurus, raphe pallidus und Teile der lateralen Formatio reticularis unterteilt. Die Raphe kann das globale Erregungsmuster im Gehirn durch unterschiedliche Beschickung der verschiedenen Gehirnregionen mit Serotonin beeinflussen. Antagonistisch hierzu würde eine Ausschüttung von Noradrenalin durch Neurone des Locus coeruleus wirken. Diese Steuerung der Aktivitätsverteilung ist nicht nur für Stresssituationen, sondern auch für den Schlaf notwendig. Eine Zerstörung der so genannten Hypnogenen Zone der Raphe, zuständig für die Auslösung des synchronen Schlafes, führt zur vollständigen Insomnie. Auch Depressionen, bipolare Störungen und Angststörungen sind mit dem Serotoninspiegel des Gehirns eng verbunden (Möller et al. 2008). Ob diese Störungen nun mit einem Mangel an Serotonin einhergehen oder durch diesen verursacht werden, ist noch umstritten. Sicher ist jedoch, dass die Symptomatik durch Erhöhung des Serotoninspiegels deutlich gelindert werden kann. Ein ausgeglichener beziehungsweise leicht erhöhter Spiegel vermittelt Wohlbefinden wodurch Serotonin auch als "Glückshormon" bezeichnet wird. MAO-Hemmer Monoaminooxidase-Hemmer - oder SSRI - selektive Serotonin-Reuptake-Inhibitoren - zum Beispiel erhöhen den Serotoninspiegel und werden so als wirksame Antidepressiva pharmakologisch eingesetzt (Siegel und Albers 2006 und Squire et al. 2008). 


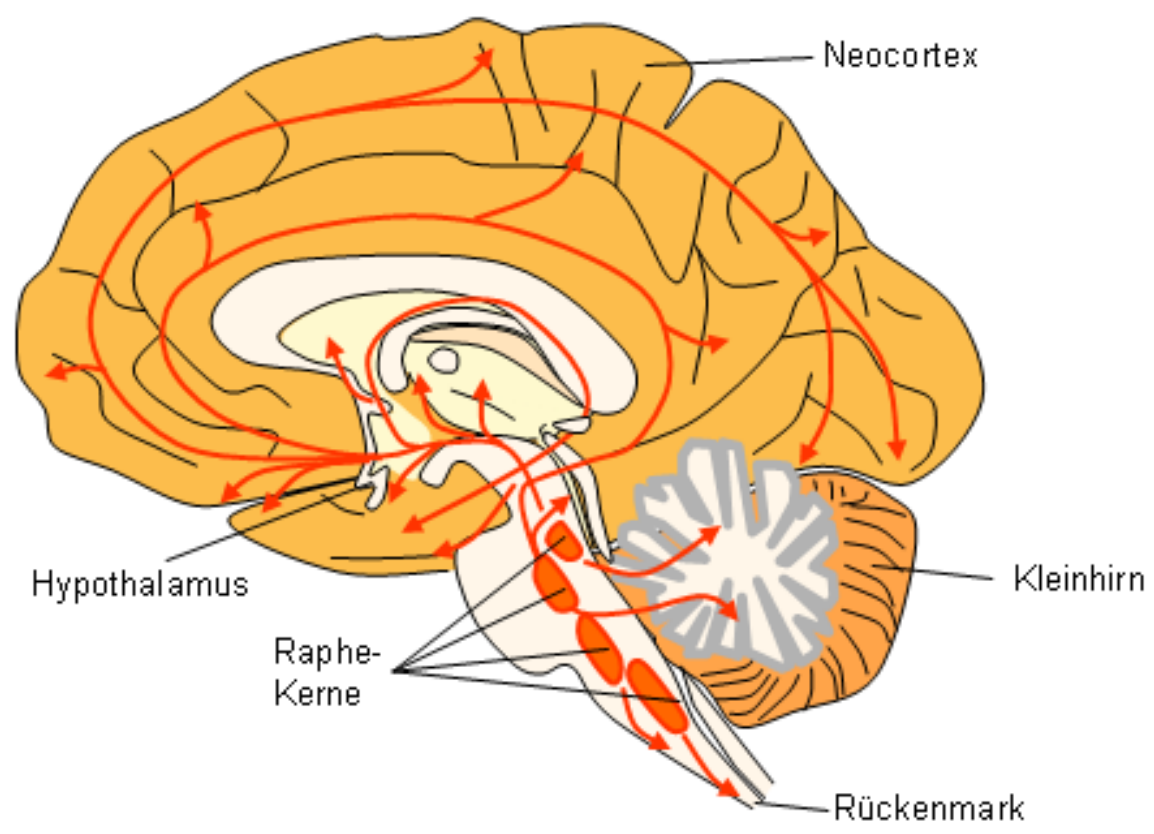

Abb. 2.9 Schematische Darstellung der Lokalisation serotonerger Leitungsbahnen anhand eines Mediansagittalschnittes. Das serotonerge System geht von Neuronenpopulationen der Raphekerne aus, die über weit verzweigte Axone praktisch jede Region des zentralen Nervensystems mit Serotonin versorgen. Entnommen aus Preuße (2005), Seite 7

\subsection{Das dopaminerge und opioiderge Transmittersystem}

Störungen im Dopaminhaushalt, zum Beispiel beim Morbus Parkinson und bei psychotischen Erkrankungen, lassen sich durch die anatomische Lokalisation der dopaminergen Neurone erklären, auf die im Folgenden eingegangen wird. Da bei Rett-Patienten geringere Dopaminspiegel im Hirngewebe vorliegen als bei Gesunden (Jellinger 2003), ist eine Beteiligung an der Pathogenese des Rett-Syndroms nicht auszuschließen.

Dopamin entsteht bei der Synthese von Adrenalin und wirkt ebenfalls als wichtiger Neurotransmitter. Die biogene Aminosäure Tyrosin wird durch die TyrosinHydroxylase in L-DOPA (Dihydroxyphenylalanin) umgewandelt und schließlich zu Dopamin decarboxyliert. Dopaminrezeptoren lassen sich in fünf Gruppen unterteilen (D1-D5), wobei alle metabotrop sind. D1 und D5 aktivieren über G-Proteine die Adenylatzyklase und führen so zu einem EPSP (exzitatorisches postsynaptisches Potential), wohingegen die Gruppen D2, D3 und D4 über Gi-Proteine die Adenylatzyklase hemmen und so ein IPSP (inhibitorisches postsynaptisches Potential) erzeugen. D1-Rezeptoren befinden sich hauptsächlich auf glatten Muskelzellen von Nieren- und Mesenterialgefäßen, in den Basalganglien, im Nucleus accumbens und in der Großhirnrinde. Im Corpus striatum, im Hypophysenvorder- 
lappen und in der Area postrema liegen Rezeptoren der Gruppe D2 vor. Das Kleinhirn besitzt D3- und der Frontallappen D4-Rezeptoren. Im Hippocampus und der Amygdala existieren die Gruppen D4 und D5. Entsprechend dazu befinden sich im Zentralnervensystem dopaminerge Neurone, die sich dem Nigro-Strialen-, dem Mesolimbischen und dem Mesokortikalen System zuschreiben lassen (Kandel et al. 2000, Siegel und Albers 2006 und Squire et al. 2008). Mrzljak et al. beschrieben schon 1996 eine Lokalisation von D4-Rezeptoren auf GABAergen Neuronen des cerebralen Cortex, im Hippocampus, im Nucleus reticularis des Thalamus, im Globus pallidus und in der Substantia nigra. Untersuchungen zur Lokalisation im preBotC stehen noch aus. Aber GABAerge Neuronen des respiratorischen Netzwerkes könnten auch D4-Rezeptoren tragen.

Die vorliegende Arbeit untersucht die Auswirkung von MeCP2 auf das Gen des $\mu$-Opioidrezeptors 1 ( $\mu$-OR1) im preBotC. Takita et al. (1997) haben gezeigt, dass Opioidrezeptoren an der Modulation der perinatalen Atemfrequenz beteiligt sind. In einer ontogenetisch angelegten Studie des preBotC konnte gezeigt werden, dass der $\mu$-Opioidrezeptor 1 stark mit dem $5-\mathrm{HT}_{4(\mathrm{a})}$-Rezeptor koexprimiert wird und dass ein differentielles Expressionsmuster vom Embryonaltag 16 bis zum vierten postnatalen Tag in Korrelation zur Atemrhythmusentwicklung vorliegt (Preuße 2005). Die durch Opioide hervorgerufene unerwünschte Atemdepression kann hingegen durch die Gabe von spezifischen $5-\mathrm{HT}_{4(\mathrm{a})^{-}}$und $5-\mathrm{HT}_{1 \mathrm{~A}}-\mathrm{Rezeptoragonisten} \mathrm{kompensiert} \mathrm{werden}$ (Manzke et al. 2003, Guenther et al. 2009). Zum Symptomkomplex von RettPatienten zählen unter anderem respiratorische Dysfunktionen, so dass ein potentieller Zusammenhang zwischen MeCP2 und dem $\mu$-Opioidrezeptor 1 vermutet werden kann.

Als Opioide werden natürliche und synthetische Substanzen bezeichnet, die Eigenschaften des Morphins aufweisen und an Opioidrezeptoren binden. Im Gegensatz dazu bezeichnet der Begriff Opiat einen im Opium - in der Milch des Schlafmohns - natürlich vorkommenden Stoff. Endogene Opioide - körpereigene schmerzdämpfende Substanzen - werden in Endorphine, die endogenen Morphine, Enkephaline und Dynorphine unterteilt. Sie werden als Oligopeptide in der Nebenniere, im Darm, im Hypophysenvorderlappen und im ZNS gebildet und können auf fünf verschiedene Opioidrezeptorsubtypen $(\mu, \kappa, \delta, \varepsilon$ und $\sigma)$ wirken. Alle genannten Subtypen sind metabotrop, wobei exogene Opioide (Pharmaka und 
Drogen) als reine Agonisten, gemischte Agonist-Antagonisten, Partialantagonisten und reine Antagonisten fungieren können. $\mathrm{Zu}$ den wichtigsten Wirkungen von Opioiden zählen Analgesie, Atemdepression, Obstipation und das Abhängigkeitspotential (Kandel et al. 2000, Siegel und Albers 2006 und Squire et al. 2008).

\subsection{Vokalisation}

Im 2. Stadium der Rett-Erkrankung gehen bereits erlernte Fähigkeiten verloren. Hierzu gehört insbesondere die Sprache, welche im Zusammenhang mit dem Gen FOXP2 steht, denn es spielt für den Spracherwerb und grammatikalische Fähigkeiten eine große Rolle (Enard et al. 2002). FOXP2 wurde erstmals 1995 bei einer Londoner Familie entdeckt, die unter schweren Sprachstörungen litt (Vargha-Khadem et al. 1995). Das Protein FoxP2 dient wie MeCP2 als Transkriptionsfaktor und gehört zur Familie der Forkhead-Box-Proteine (Spiteri et al. 2007). Mittlerweile wurde eine Vielzahl von Fox-Proteinen entdeckt, die zum Teil in verschiedenen Spezies völlig unterschiedliche Funktionen haben. Das menschliche FOXP2-Gen besitzt 17 Exons und liegt auf Chromosom 7. Das daraus translatierte FoxP2-Protein besteht aus 715 Aminosäuren und wird in vier Hauptbereiche unterteilt: 1. eine Polyglutamin-reiche Region, 2. eine Zinkfingerdomäne, 3. eine bZIP-Domäne (basic Leucine Zipper Domain) und 4. die Forkhead-Domäne. Für Protein-Protein-Interaktionen sind die Zinkfinger- und bZIP-Domänen zuständig. Lediglich die Forkhead-Domäne bindet an die DNA (MacDermot et al. 2005). Über die genaue Wirkungsweise von FoxP2 ist noch sehr wenig bekannt. Aber gesichert ist, dass Mutationen im FOXP2-Gen spezifische Sprach- und Sprechstörungen (Enard et al. 2002), sowie Artikulations- und Sprachverständnisstörungen auslösen (Spiteri et al. 2007). Frühere Studien fanden bei Mecp2-defizienten Mäusen respiratorische Störungen. Insbesondere zeigte sich eine prolongierte Postinspiration, die eng mit Atemunregelmäßigkeiten wie Apnoephasen korrelierte (Stettner et al. 2007). Dieser respiratorische Phänotyp ähnelt den bei Rett-Patienten auftretenden Atemdysfunktionen. Die Fähigkeit zur Vokalisation ist eng an den Atemzyklus gekoppelt, denn eine Phonation ist nur während der Postinspiration und Exspiration möglich. Ein potentieller Zusammenhang der beiden Transkriptionsfaktoren FoxP2 und MeCP2 kann durch die Rett-Symptomatik auf Sprachebene und 
der bekannten Funktion von FOXP2-Mutationen bei Vokalisationsstörungen vermutet werden.

\subsection{Neuroglia-Marker}

GFAP (glial fibrillary acidic protein, „Saures Gliafaserprotein“) ist ein zellspezifischer Marker für Astrozyten, welcher vom gleichnamigen Gen GFAP auf Chromosom 17 beim Menschen kodiert wird. GFAP befindet sich fast ausschließlich neben Schwann-Zellen der peripheren Nerven als zytoplasmatisches Intermediärfilament in Astrozyten. Daher wird es in der Hirntumordiagnostik (zum Beispiel für Astrozytome) eingesetzt (Setoguchi et al. 2006). Von Setoguchi et al. (2006) wird ein direkter Zusammenhang von MeCP2 und Gfap beschrieben, wodurch bei Bindung von MeCP2 und Gfap die Astrozytendifferenzierung gehemmt wird. Lipani et al. (2000) deckten eine Assoziation von niedrigen Spiegeln an Nervenwachstumsfaktoren, die wiederum mit GFAP verwandt sind, zum Rett-Syndrom auf. Aufgrund des dargestellten Zusammenhangs von MeCP2 und Gfap sowie der Tatsache, dass die Neuroglia im respiratorischen Netzwerk eine wichtige Rolle in der Regulierung und Differenzierung von Zellen spielt, ist eine Untersuchung der RNA-Expression von Gfap im Umfang dieser Arbeit nahe liegend.

Da in der vorliegenden Dissertation bestimmte Gene bezüglich des serotonergen Systems untersucht werden, bietet sich ein Wachstumsfaktor für Serotonin-bildende Zellen zur genaueren Untersuchung an. Einer dieser Faktoren ist das Protein S100B, dessen neurotrophe Eigenschaften bereits länger bekannt sind (Schmidt S 1998, Koppal et al. 2001). Die neurotrophe Wirkung speziell auf serotonerge Zellen zeigten Shapiro et al. (2004). Ebenso stellten Eriksen et al. (2002) und Tramontina et al. (2008) fest, dass die Gabe von Serotoninagonisten beziehungsweise von selektiven Serotonin-Wiederaufnahmehemmern (SSRI) eine gesteigerte Synthese von S100B bewirkten.

Das S100b-Gen kodiert für die $\beta$-Form des calciumbindenden S100-Proteins - „soluble in $100 \%$ saturated ammonium sulfate“ (sich auflösend in $100 \%$ igem Ammoniumsulfat) - kurz genannt S100B. Zu den S100 Proteinen zählen 19 Mitglieder, die zahlreiche Zellfunktionen wie zum Beispiel Phosphorylierungen übernehmen und in unterschiedlichen Zellen exprimiert werden. S100A1 findet sich 
überwiegend in Kardiomyozyten, Muskelzellen, Zellen der Speicheldrüsen, der Niere und in Nervenzellen des Hippocampus. Binde- und Muskelgewebe exprimieren S100A6 und S100B ist für Adipozyten, Melanozyten, Chondrozyten und insbesondere für Gliazellen spezifisch (Raponi et al. 2007). Diese Spezifität für bestimmte Zelltypen eignet sich besonders für die histopathologische Diagnostik von Tumorzellen, die eine Abgrenzung von S100-positiven (zum Beispiel Gliome) und S100-negativen Tumoren zulässt. Ferner dient die Bestimmung von Protein S100B in der Neurologie als Marker von Hirnschäden, da es bei Schlaganfällen oder Schädelhirntraumata von Gliazellen freigesetzt wird und im Liquor oder Blut nachgewiesen werden kann. Die in Studien gefundene hohe prädiktive Aussagekraft von S100B besagt, dass bei negativem S100B-Nachweis ein Schädelhirntrauma fast mit Sicherheit ausgeschlossen werden kann (Tanaka et al. 2008). 


\section{Material und Methoden}

\subsection{Material}

\subsubsection{Chemikalien}

\begin{tabular}{|c|c|c|}
\hline Chemikalie & Hersteller & Bestellnummer \\
\hline Aqua bidest & Roth & HN57.2 \\
\hline Chloroform & Roth & 7331.2 \\
\hline Cryomatrix & Therma Shandon & 6769006 \\
\hline DEPC- $\mathrm{H}_{2} \mathrm{O}$ & Roth & T143.2 \\
\hline Dnase I & Sigma-Aldrich & EC 3.1.21.1 \\
\hline Ethanol $70 \%$ & Roth & 9065.1 \\
\hline iQ SYBR Green Supermix & Bio-Rad & $170-8882$ \\
\hline $\begin{array}{l}\text { iScript cDNA Synthesis Kit inklusive } \\
-\quad \text { iScript Reaction Mix } \\
-\quad \text { iScript enzyme } \\
-\quad \text { nuclease-free water }\end{array}$ & Bio Rad & $170-8890$ \\
\hline iScript reverse Transkriptase & Bio-Rad & $170-8891$ \\
\hline Isoamylalkohol & Roth & T870.1 \\
\hline Isofluran & Baxter & 7311944 \\
\hline Isopropanol & Merk & 1.09634 .2500 \\
\hline lineare Acrylamide & Roth & L506.1 \\
\hline Magnesiumchlorid, $\mathrm{MgCl}_{2}$ & Roth & 2189.1 \\
\hline Natriumacetat & Roth & 6773.1 \\
\hline Phenol & Sigma & P-4758 \\
\hline Rnase Dekontaminationslösung Rnase ZAP & Sigma & R2020 \\
\hline Rnase Inhibitor & Sigma & $\mathrm{R} 2520$ \\
\hline Salzsäure, $\mathrm{HCl}(32 \%)$ & Merck & 1.00319 .2500 \\
\hline Tris & Roth & 4855.2 \\
\hline Trizol & Invitrogen & 15596018 \\
\hline
\end{tabular}




\subsubsection{Geräte}

\begin{tabular}{l|l}
\hline Gerät & Hersteller \\
\hline Cryostat CM 3050 S & Leica \\
\hline i-Cycler iQ system (Termocycler) & Bio Rad \\
\hline Nanodrop ND-1000, Spektrophotometer & A silent \\
\hline pH-Meter, InoLab & WTW \\
\hline RNA 6000 LabChip Kit, Nanochip & Agilent \\
\hline Thermomixer 5436 & Eppendorf \\
\hline Vortex Mixer & neoLab ${ }^{\circledR} 7-2020$ \\
\hline Zentrifuge 5415D & Eppendorf \\
\hline
\end{tabular}

\subsubsection{Verbrauchsmaterialien}

\begin{tabular}{l|l}
\hline Verbrauchsmaterial & Hersteller \\
\hline Cups, $2000 \mathrm{ml}$ & Eppendorf \\
\hline Menzel-Gläser $^{\circledR}$ SuperFrost Ultra Plus ${ }^{\circledR}$, Objektträger & Menzel GmbH \& Co KG \\
\hline Microseal $^{\circledR}$, Mikrotiterplatte $(96 \times 300 \mu$ l Näpfe $)$ & Bio Rad \\
\hline PP test tubes, $15 \mathrm{ml}$ & Cellstar $^{\circledR}$ \\
\hline
\end{tabular}

\subsubsection{Knockout- und transgene Mecp2-Mäuse}

Vom Humangenetikinstitut unter der Leitung von Prof. Dr. med. Engel wurden für die vorliegende Dissertation als Rett-Mausmodelle sowohl Mecp2-Knockout- (Mecp2 ${ }^{-/ y}$ ) als auch transgene Mecp2-Mäuse $\left(M e c p 2^{T /-,+/ y}\right)$ zur Verfügung gestellt. Das Mecp2 $^{-/ y}$-Modell des Rett-Syndroms, Stamm B6.129P2(C)-Mecp2 ${ }^{\text {tm1-1Bird }}$ (Guy et al. 2001), wurde schon für Stettner et al. (2007) von den Charles River Laboratories France and UK bereitgestellt. Hemizygote männliche $M e c p 2^{-/ y}$-Mäuse wurden durch die Kreuzung von heterozygoten Mecp2 $^{+/-}$-Weibchen und C57BL/6J-Männchen (Wildtyp, WT) generiert.

Das transgene Mausmodell wurde durch eine homologe Rekombinationstechnik, die so genannte GET-Rekombination, erschaffen. Ein BAC-Klon (bacterial artificial chromosomes), der ein Maus-Genom-Fragment umfasst, das die gesamte Länge 
des Mecp2-Gens mit den flankierenden Sequenzen beinhaltet, wurde mit einer FVBMaus (Wildtyp) verpaart, so dass unter anderem männliche transgene Mäuse vom Typ „T/-, +/y“ entstanden (Arunachalam 2007). Somit befand sich neben dem ursprünglichen X-chromosomal gekoppelten Mecp2-Gen (+) eine zusätzliche Kopie auf einem Autosom (T), welche EGFP-gekoppelt (Enhanced Green Fluorescent Protein) war.

Durch DNA-Isolierung aus den Mäuseschwänzen wurde eine Genotypisierung an allen verwendeten Mäusen durchgeführt. Es wurden nur hemizygote $M e c p 2^{-/ y}$ - und WT C57BL/6J- beziehungsweise Mecp2 $2^{T /-,+/ y}$ - und WT FVB-Männchen verwendet, weil heterozygote Weibchen einen unvorhersehbaren und heterogenen Phänotyp aufgrund der X-Inaktivierung des X-gekoppelten Mecp2-Gens besitzen. Unter Einhaltung der Richtlinien der „European community” und "National Institutes of Health“ bezogen auf die Haltung von Labortieren wurden die verwendeten Mäuse generiert und aufgezogen. Für die Real-time-PCR wurde jeweils ein DNA-Pool von Triplikaten (drei äquivalenten Tiere, gleich alt, gleicher Genotyp, gleicher Wurf, $n=3$ ) für jede Gruppe (P7 KO, P7 WT $\mathrm{WO}_{\mathrm{KO}} \mathrm{P} 7 \mathrm{~T}, \mathrm{P} 7 \mathrm{WT}_{\mathrm{T}}, \mathrm{P} 40 \mathrm{KO}, \mathrm{P} 40 \mathrm{WT}_{\mathrm{KO}}, \mathrm{P} 40 \mathrm{~T}$ und P40 WTT) gebildet.

\subsection{Methoden}

\subsubsection{Anästhesie}

Unter Einhaltung des Tierschutzgesetzes (TierSchG 3. Abschnitt § 4) wurden die für

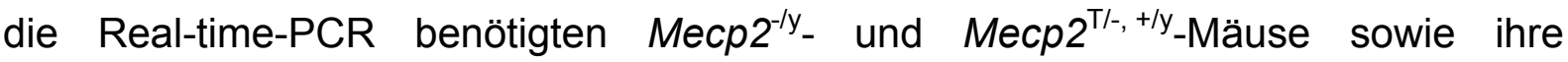
korrespondierenden Wildtypen der postnatalen Entwicklungsstufen P7 (postnatal 7 Tage alt) und P40 (postnatal 40 Tage alt) mit dem volatilen Anästhetikum Isofluran tief anästhesiert und schmerzunempfindlich gemacht. Nachdem eine deutliche Verlangsamung der Atmung und keine Bewegung der Tasthaare mehr zu sehen waren, wurden die Mäuse wie unter 2.2.2 beschrieben dekapitiert. 


\subsubsection{Präparation des Gehirns}

Die Präparation des Gehirns beziehungsweise des Hirnstammes muss äußerst sorgfältig ablaufen, um relevante Bereiche nicht zu zerstören. Die Maus wird möglichst weit kaudal dekapitiert. Nach Entfernen des Fells und der überschüssigen Nackenmuskeln wird der Schädel durch einen Longitudinal- und einen Transversalschnitt vorsichtig eröffnet und das Gehirn, der Hirnstamm und zervikale Rückenmarkspartien herauspräpariert. Stets zu beachten ist, dass die Spannung der noch bestehenden Dura mater vorsichtig gelöst wird, um wichtige Hirnstammgebiete nicht zu beschädigen.

Die Präparation erfolgte an vollnarkotisierten Mäusen. Anschließend wurden die Gehirne sofort bei $-80^{\circ} \mathrm{C}$ eingefroren.

\subsubsection{Präparation des Prä-Bötzinger-Komplexes aus dem Hirnstamm}

Zur Orientierung des Prä-Bötzinger-Komplexes (preBotC) dient die Anordnung des prinzipalen Kerns der unteren Olive. Bei seiner größten Ausbreitung in axialer Ebene kann der preBotC laterodorsal abgeschätzt und heraus gelöst werden (siehe Abb. 1.6, Seite 10).

Die bei $-80^{\circ} \mathrm{C}$ gelagerten Gehirne wurden parallel zur Axialebene frontal mit Cryomatrix durch Anfrieren fixiert und zervikal axial in $40 \mu \mathrm{m}$ dicke Scheiben mittels eines Cryostats geschnitten und auf Objektträgern der Reihe nach gesammelt. Es wurden die Schnitte ausgewählt, auf denen der prinzipale Kern der unteren Olive seine größte Ausdehnung hatte sowie weitere drei bis vier angrenzende Schnitte zervikal und kaudal. Auf diesen Schnitten wurden anschließend mit einem Skalpell Longitudinalschnitte um den Bereich des preBotC gesetzt.

\subsubsection{Isolierung von Gesamt-RNA aus Prä-Bötzinger-Komplex-Präparaten}

Das Isolieren von RNA aus Hirngewebe ist für die Untersuchungsmethode Real-time-PCR (quantitative Polymerasekettenreaktion) essentiell. Sämtliche Geräte, die mit RNA in Kontakt kommen, sollten mit Rnase Dekontaminationslösung Rnase ZAP (Sigma) behandelt werden. Ebenso sollten für sämtliche Arbeiten Rnase-freie 
Pipettenspitzen mit Filter benutzt werden. Die Isolierung mittels Trizol-Reagenz beruht auf der vollständigen Dissoziation der Nukleoproteinkomplexe, welche im Weiteren aufgetrennt werden.

Benötigte Lösungen:

Trizol

lineare Acrylamide

Chloroform

Isopropanol

$70 \%$ iges Ethanol

Aqua bidest.

Das preBotC-Gewebe wurde mit $360 \mu \mathrm{l}$ Trizol vermengt, durch kleine Mörser homogenisiert und bei Raumtemperatur für $15 \mathrm{~min}$ inkubiert, so dass eine vollständige Dissoziation der Nukleoproteinkomplexe ermöglicht wurde. Die anschließende Zentrifugation bei $13.200 \mathrm{rpm}$ für $10 \mathrm{~min}$ bei $4^{\circ} \mathrm{C}$ trennte unlösliche Bestandteile wie extrazelluläre Membrane, Polysaccharide und hochmolekulare DNA von gelösten Bestandteilen wie RNA, DNA und Proteinen. Zu dem Überstand wurden $5 \mu \mathrm{g}$ lineare Acrylamide hinzugegeben und für $10 \mathrm{sec}$ mit einem Vortex Mixer vermischt. Es folgten die Zugabe von $72 \mu \mathrm{l}$ Chloroform und das Vermischen in $30 \mathrm{sec}$ mit dem Vortex, so dass Proteine präzipitieren konnten. Bei erneuter Zentrifugation bei $13.200 \mathrm{rpm}$ für $5 \mathrm{~min}$ bei Raumtemperatur trennten sich eine hydrophobe rote Phenol-Chloroform Phase mit Proteinen, eine Interphase mit DNA und eine hydrophile Phase mit RNA auf. Letztere wurde in ein Eppendorf Cup überführt, mit $160 \mu$ l Isopropanol angereichert und bei $-80^{\circ} \mathrm{C}$ für 30 min inkubiert. Nach 30 min Zentrifugieren bei $13.200 \mathrm{rpm}$ und $4{ }^{\circ} \mathrm{C}$ wurde das Gel-artige Sediment mit $500 \mu \mathrm{l} 70$ \%igem Ethanol versetzt und erneut bei $13.200 \mathrm{rpm}$ für $10 \mathrm{~min}$ bei $4{ }^{\circ} \mathrm{C}$ zentrifugiert. Der Überstand wurde verworfen und die RNA an der Luft getrocknet, allerdings ohne diese komplett austrocknen zu lassen. $20 \mu$ Aqua bidest wurden hinzugegeben und eine Kontamination mit DNA wurde, wie unter 2.2.5 erklärt, durch einen Dnase-Verdau beseitigt. 


\subsubsection{Dnase-1-Behandlung und Aufreinigung}

DNA-Kontaminationen können nicht immer verhindert werden, so dass eine Reinigung der RNA-Eluaten durch Dnasen durchgeführt werden sollte. Hierfür eignet sich der Dnase-1-Standardansatz:

$5 \mu \mathrm{l} \quad$ Tris/HCl $1 \mathrm{M}, \mathrm{pH} 7,5$

$1 \mu \mathrm{l} \quad$ Magnesiumchlorid $1 \mathrm{M}$

$1 \mu \mathrm{l} \quad$ Dnase I $(10 \mathrm{U} / \mu \mathrm{l})$

$0,5 \mu l \quad$ Rnase Inhibitor $(40 U / \mu l)$

$20 \mu \mathrm{l} \quad$ RNA Eluat

$72,5 \mu \mathrm{I} \quad \mathrm{DEPC}-\mathrm{H}_{2} \mathrm{O}$.

Weitere benötigte Chemikalien:

Phenol

Chloroform

Isoamylalkohol

Isopropanol

Natriumacetat $3 \mathrm{M} \mathrm{pH} \mathrm{4,8}$

70 \%iges Ethanol

Rnase freies $\mathrm{H}_{2} \mathrm{O}$.

Nach Zugabe des Dnase-1-Standards wurden die Ansätze für 20 min bei $37^{\circ} \mathrm{C} \mathrm{im}$ Thermoblock inkubiert. Ein Volumen Phenol/ Chloroform/Isoamylalkohol $(25 / 24 / 1(v / v / v))$ wurde zu den Dnase-verdauten RNA-Eluaten gegeben und für 2 min bei 13.000 rpm bei Raumtemperatur zentrifugiert. Die wässrige obere Phase wurde in ein neues Eppendorf Cup überführt und mit 1 Volumen Isopropanol $(80 \mu \mathrm{l})$ und 1/10 Volumen $(8 \mu \mathrm{l}) 3 \mathrm{M}$ Natriumacetat $\mathrm{pH} 4,8$ versetzt. Die bei $-80{ }^{\circ} \mathrm{C}$ innerhalb von $15 \mathrm{~min}$ entstandenen Präzipitate wurden bei $13.000 \mathrm{rpm}$ in $15 \mathrm{~min}$ bei $4^{\circ} \mathrm{C}$ abzentrifugiert. Der Überstand wurde verworfen, dem Pellet wurde $1 \mathrm{ml} 70$ \%iges Ethanol zugesetzt und anschließend bei $4^{\circ} \mathrm{C}$ für $5 \mathrm{~min}$ bei $13.000 \mathrm{rpm}$ zentrifugiert. Dieser Schritt wurde dreimal wiederholt, um danach das Pellet vorsichtig bei $37^{\circ} \mathrm{C}$ an der Luft zu trocknen. Um das Pellet vollständig zu resuspendieren, wurde es in 20-100 $\mu$ l Rnase-freiem Wasser gelöst und für 10 min im Thermoblock bei $42{ }^{\circ} \mathrm{C}$ inkubiert. Zur Überprüfung der Qualität der RNA wurde ein Nanochip verwendet und 
die RNA-Konzentration wurde mittels Nanodrop photometrisch quantifiziert. In der Konzentration $50 \mathrm{ng} / \mu \mathrm{l}$ wurden die RNA-Proben verdünnt und bei $-80^{\circ} \mathrm{C}$ gelagert.

\subsection{6 cDNA-Synthese aus RNA}

Um später mittels Real-time-PCR die Expressivität von Genen untersuchen zu können, muss die extrahierte mRNA (messenger RNA) durch die reverse Transkriptase in komplementäre Einzelstrang-DNA (cDNA) umgeschrieben werden. Dies geschieht im Termocycler, wo in den ersten $5 \mathrm{~min}$ bei $25^{\circ} \mathrm{C}$ die reverse Transkriptase aktiviert wird, in den folgenden $30 \mathrm{~min}$ bei $42^{\circ} \mathrm{C}$ die Elongation stattfindet und in den anschließenden $5 \mathrm{~min}$ bei $85^{\circ} \mathrm{C}$ die reverse Transkriptase denaturiert. Bei der Elongation binden Primer mit einer poly-T-Sequenz (Thyminreiche Sequenz), die im iScript Reaction Mix enthalten sind, am poly-A-Ende (Adenin-reich) der mRNA und die reverse Transkriptase synthetisiert einen komplementären DNA-Strang. Die aus dem preBotC extrahierte RNA besteht nicht nur aus mRNA sondern auch aus tRNA (Transfer-RNA) und rRNA (ribosomale RNA). Allerdings besitzen $95 \%$ der mRNA ein poly-A-Ende, so dass durch die poly-TPrimer gesichert wird, dass komplett mRNA revers transkriptiert wird.

Hierfür wurde folgender Master Mix verwendet:

$\begin{array}{ll}4 \mu \mathrm{l} & 5 x \text { iScript Reaction Mix } \\ 1 \mu \mathrm{l} & \text { iScript reverse Transkriptase } \\ 10 \mu \mathrm{l} & \text { Nuklease-freies Wasser. }\end{array}$

Jeweils $15 \mu \mathrm{l}$ des Master Mixes wurden mit $5 \mu \mathrm{l}$ RNA eines Tieres mit der Konzentration $50 \mathrm{ng} / \mu \mathrm{l}$ vermengt und durch den Vortex für einige Sekunden vermischt. Auf eine Mikrotiterplatte wurden die entstandenen $20 \mu \mathrm{l}$ vorsichtig pipettiert und die RT-PCR (reverse Transkriptase Polymerasekettenreaktion) wurde im Termocycler gestartet. Von den entstandenen Einzelstrang-DNA-Proben wurde ein „Pooling“ der DNA-Konzentrationen durchgeführt. Die gleiche Konzentration an DNA von drei äquivalenten Tieren - also gleich alt und von den selben Elterntieren entweder aus dem Mecp2 $2^{-/ y}$ - oder aus dem Mecp2 $2^{T /-,+/ y}-$ Modell wurden vermengt, um einen Querschnitt zu erhalten und um Faktoren wie den Genotyp oder biologische Einflüsse auf die Individualität jeder einzelnen Maus zu minimieren. Die Anzahl der 
verwendeten Tiere betrug daher drei pro Experiment $(n=3)$. Die DNA-Mixturen wurden bei $-80^{\circ} \mathrm{C}$ aufbewahrt.

\subsubsection{Primer-Design}

Zur Amplifikation von bestimmten Genabschnitten sind spezifische Primer notwendig. Alle verwendeten Primer wurden daher mit der in Fachkreisen etablierten BLASTDatenbank verglichen. Die BLAST-Datenbank (Basic Local Alignment Search Tool) ist eine Sammlung an Programmen zur Analyse biologischer Sequenzdaten. Experimentell ermittelte DNA-, Protein- oder Primer-Sequenzen werden mit den in der Datenbank vorhandenen Sequenzen verglichen. Somit kann aufgrund der Sequenzübereinstimmung eine Aussage über die Spezifität der Primer gemacht werden.

Die Sequenzierung des Amplifikates erfolgte durch Auftragung der bei einer Standard-Polymerasekettenreaktion entstandenen Produkte auf einem Agarose-Gel. Zusätzlich wurde beachtet, dass die Länge des zu amplifizierenden Segments zwischen 150 und 250 Basenpaaren lag und dass die Primerpaare - ein Primer für den kodierenden Strang (forward) und ein Primer für den kodogenen Strang (reverse) - die gleiche Schmelztemperatur $\left(55^{\circ} \mathrm{C}\right)$ wie das zu amplifizierende Gen besitzen. Die folgende Tabelle zeigt die zu den untersuchten Genen korrespondierenden Primer-Sequenzen.

\begin{tabular}{l|l|l|l|l}
\hline Genname & Primer forward & Primer reverse & Akzessionsnr. & Größe \\
\hline Mecp2 & TCCTTGGACCCTAATGATTT & TTTCACCTGAACACCTTCTG & NM 010788.2 & 186 \\
\hline Tacr1 & TGGTACTACGGCCTCTTTTA & ACCCAGATGACAAAGATGAC & NM 009313.4 & 176 \\
\hline Sst & CCAACCAGACAGAGAATGAT & AGGATGTGAATGTCTTCCAG & NM 009215.1 & 168 \\
\hline Grin1 & GTGGAGTTGAGCACCATGTA & GGGACTTGAGTATGGACAGG & NM 008169.2 & 250 \\
\hline Grin2a & AACACTCATTGCCATCACAG & ATTTAAAACCCTGGGGGTAG & NM 008170.2 & 176 \\
\hline Grin2d & CGACTTCCCCTACCCGTAT & GGCAGGTAGTCCCAGCTAC & NM 008172.1 & 105 \\
\hline Gabra6 & CCTTGCTGTGTTCTTTTACC & CAAGTGACCTTGCTAGAACC & NM 008068.1 & 188 \\
\hline Gabrb1 & TGACGTGAACTCCATAGACAA & TAGTCTAAACCGAACCACGAG & NM 008069.3 & 122 \\
\hline Tph2 & CAGGGTCGAGTACACAGAAG & CTTTCAGAAACATGGAGACG & NM 173391.1 & 182 \\
\hline Ddc & GCAGTGCCTTTATCTGTCCT & GAATCCTGAGTCCTGGTGAC & NM 016672.1 & 200 \\
\hline Slc6a4 & AAGCCAAGCTGATGATGTAA & TCCTCACATATCCCAGTCAG & NM 010484.1 & 162 \\
\hline$H$ tr4 & CCTCACAGCAACTTCTCCTT & TCCCCTGACTTCCTCAAATA & NM 008313.2 & 233 \\
\hline$H$ tr5b & GGAGTCTGAGATGGTGTTCA & AATATCCAAGCCACAGGAAT & NM 010483.2 & 230
\end{tabular}




\begin{tabular}{l|l|l|l|l} 
Drd4 & ACCTGGCTAGGCTATGTCAA & ACTCTGCACACAAGTCTTGGA & NM 012944.1 & 152 \\
\hline Oprm1 & CCAGTTCTTTATGCGTTCCT & CAGCTTTTTCTTCTGGTGGT & NM 001039652.1 & 174 \\
\hline Foxp2 & TCATGGAGTCATCTGACAGG & TCCACACTGCTCCTTTAACA & NM 053242.3 & 171 \\
\hline Gfap & ACCAAACTGGCTGATGTCTA & GGTTTCATCTTGGAGCTTCT & NM 010277.2 & 150 \\
\hline S100b & ACAAGCACAAGCTGAAGAAG & TGAACTCCTGGAAGTCACAC & NM 009115.2 & 153
\end{tabular}

\subsubsection{Real-time-PCR}

Die Polymerasekettenreaktion (PCR) ist eine etablierte von Dr. Kary Banks Mullis und Michael Smith schon 1983 entwickelte Methode zur Vervielfältigung von Nukleinsäuren, für die Dr. Mullis mit dem Nobelpreis in Chemie 1993 honoriert wurde. Russell G. Higuchi verfeinerte dieses Verfahren und veröffentlichte 1993 „Kinetic PCR analysis: real-time monitoring of DNA amplification reactions“, wodurch er als Erfinder der Real-time-PCR angesehen wird. Hierbei handelt es sich um ein Verfahren, bei dem amplifizierte DNA-Sequenzen während der Polymerasekettenreaktion gemessen werden. Das Verfahren ist eine der wichtigsten Amplifikations- und Analysetechniken von DNA und RNA und bildet einen Standard in der molekularen Diagnostik und Forschung. Der Vorteil ihrer hohen Sensitivität, dass nur geringe Anfangsmengen an DNA benötigt werden, ist auch gleichzeitig der größte Angriffspunkt für Fehlerquellen. Die Polymerasekettenreaktion verläuft in Zyklen. Jeder Zyklus ist wiederum in drei Schritte unterteilt. Im 1. Schritt findet die Denaturierung statt. Bei $95{ }^{\circ} \mathrm{C}$ ist die DNA aufgeschmolzen und liegt als Einzelstrang vor. Im 2. Schritt, die Primerhybridisierung, binden bei $55^{\circ} \mathrm{C}$ die spezifischen Primer an die DNA-Einzelstränge. Die Elongation, der 3. Schritt, erfolgt bei $72{ }^{\circ} \mathrm{C}$. Hierbei bildet die DNA-Polymerase, beginnend am 3'-Ende des angelagerten Primers, aus freien Nukleotiden einen komplementären DNA-Strang. Das Fluoreszenzmolekül SYBR-Green interkaliert mit der neu entstandenen Doppelstrang-DNA, so dass die Fluoreszenz in dem Maße zunimmt, wie es zur Bildung von PCR-Produkten pro Amplifikationszyklus kommt. Durch die Messung der Fluoreszenz kann ein Fluoreszenzschwellenwert definiert werden, bei dem die DNA exponentiell amplifiziert wird. Die Menge der cDNA-Moleküle im Ausgangsmaterial lässt sich ermitteln, indem das Erreichen dieses Schwellenwertes mit dem Schwellenwert der Standardreihe verglichen wird. Jedes untersuchte Gen wird mit einem Referenzgen, ein so genanntes „Housekeeping Gene“, verglichen. Dieses Referenzgen ist ein Gen, 
welches nicht reguliert und homogen ubiquitär exprimiert wird. Insbesondere sollte dessen Expression in den $\mathrm{Mecp}^{-/ y_{-}}, \mathrm{Mecp}^{\mathrm{T} /-,+/ y_{-}}$und ihren korrespondierenden Wildtyp-Mäusen homogen sein. Häufige „Housekeeping Genes“ sind Gene für GAPDH, ribosomale Untereinheiten (18S und 28S), Ubiquitin, Histon Untereinheiten und $\beta$-Aktin. Im vorliegenden Fall wurde das Gen Gapdh, welches für die Glycerinaldehyd-3-phosphat-Dehydrogenase (GAPDH) kodiert, verwendet. Es wurde in allen Entwicklungsstadien und allen verwendeten Modellen stets gleich stark exprimiert. Für die Datenerfassung der Schmelzkurven wurde die Temperatur nach jedem 2. Zyklus um $0,5^{\circ} \mathrm{C}$ erhöht, bis $95^{\circ} \mathrm{C}$ erreicht wurden. Diese stufenweise Erhöhung der Temperatur diente der Schmelzpunktgewinnung, das heißt der Gewinnung des Temperaturpunktes, bei dem die Doppelstrang-DNA denaturiert und damit aufschmilzt. SYBR-Green interkaliert nur mit Doppelstrang-DNA, so dass bei der Denaturierung ein Fluoreszenzabfall gemessen werden kann. Die Emission an Fluoreszenz steigt exponentiell bei jedem PCR-Zyklus, da stets neu der Farbstoff SYBR-Green in Doppelstrang-DNA eingebaut wird. Spaltet sich also die Doppelstrang-DNA bei einer für das amplifizierte Fragment spezifischen Schmelztemperatur auf, fällt augenblicklich die Fluoreszenzemission ab. Passiert dies aber bei verschiedenen Temperaturpunkten, liegen mehrere Amplifikationsprodukte und damit auch mehrere Schmelztemperaturen vor, was einer Kontamination entspricht. Diese Schmelzkurvenanalyse ist eine weitere Kontrolle dafür, dass die gewählten Primer spezifisch sind und die Probe nicht kontaminiert ist. Für die Real-time-PCR wurde folgender Master Mix:

$12,5 \mu l \quad$ iQ SYBR Green Supermix

$0,4 \mu \mathrm{l} \quad$ Primer forward $10 \mu \mathrm{M}$

$0,4 \mu \mathrm{l} \quad$ Primer reverse $10 \mu \mathrm{M}$

6,7 $\mu \mathrm{l} \quad$ Aqua bidest

und folgendes Real-time-PCR-Programm verwendet:

1. Zyklus

$3 \min$ bei $95^{\circ} \mathrm{C}$

2. Zyklus

$15 \mathrm{sec}$ bei $95^{\circ} \mathrm{C}, 15 \mathrm{sec}$ bei $55^{\circ} \mathrm{C}$ und 30 sec bei $72^{\circ} \mathrm{C}$

3. Zyklus $1 \mathrm{~min}$ bei $95^{\circ} \mathrm{C}$

4. Zyklus

$1 \min$ bei $55^{\circ} \mathrm{C}$

5. Zyklus

10 sec bis $55^{\circ} \mathrm{C}$. 
$20 \mu \mathrm{l}$ des Master Mixes wurden zu jeweils $5 \mu \mathrm{l}$ cDNA des DNA-Pools gegeben. Die Expressivität jedes untersuchten Genes ermittelte sich aus dem Durchschnitt der Expressionswerte von drei Proben des DNA-Pools. Darüber hinaus wurde zur Vergleichbarkeit jedes Gen mit dem Referenzgen Gapdh in Relation gesetzt. So kann eine relative Quantifizierung ermittelt werden. Diese Standardreihe mit dem Referenzgen wurde anfangs mit $5 \mu \mathrm{l}$ cDNA aller Tiere begonnen und sukzessiv in ihrer Konzentration um 1/10 reduziert. Der Standardreihe wurden ebenfalls jeweils 20 l Master Mix hinzugeführt. Jedes Gen wurde mit der Methode Real-time-PCR in drei Proben jeweils zweimal quantifiziert.

\subsubsection{Datenanalyse}

Es wurden DNA-Pools von jeweils drei äquivalenten Tieren $(n=3)$ für jede Gruppe (WT KO P7, KO P7, WT T P7, T P7, WT KO P40, KO P40, WT T P40 und T P40) hergestellt, so dass sich die Gesamtanzahl an Tieren auf vierundzwanzig $\left(n_{\text {total }}=24\right)$ beläuft.

\begin{tabular}{l|l|l|l}
\multicolumn{2}{c|}{$\mathrm{P7}$} & \multicolumn{2}{c}{$\mathrm{P} 40$} \\
\hline Gruppe & Tieranzahl & Gruppe & Tieranzahl \\
\hline $\mathrm{WT}_{\mathrm{KO}}$ & $\mathrm{n}=3$ & $\mathrm{WT}_{\mathrm{KO}}$ & $\mathrm{n}=3$ \\
\hline $\mathrm{KO}$ & $\mathrm{n}=3$ & $\mathrm{KO}$ & $\mathrm{n}=3$ \\
\hline $\mathrm{WT} \mathrm{T}_{\mathrm{N}}$ & $\mathrm{n}=3$ & $\mathrm{WT}_{\mathrm{T}}$ & $\mathrm{n}=3$ \\
\hline $\mathrm{T}$ & $\mathrm{n}=3$ & $\mathrm{~T}$ & $\mathrm{n}=3$ \\
\hline & $\mathrm{n}_{\mathrm{P} 7}=12$ & & $\mathrm{n}_{\mathrm{P} 40}=12$ \\
\hline & & & $\mathrm{n}_{\text {total }}=\mathbf{2 4}$
\end{tabular}

Die Daten der Genexpression der DNA-Proben wurden auf das nicht regulierte „Housekeeping Gene“ (Referenzgen) Gapdh bezogen und so relativ quantifiziert (quantitative Real-time-PCR). Als Maß für die Quantifizierung der Startmenge wurden nicht die DNA-Produktmengen, sondern die so genannten Ct- oder CP(Crossing Point) Werte herangezogen. Der CP-Wert entspricht der Anzahl an PCRZyklen, die nötig sind, ein konstant definiertes Fluoreszenzniveau zu erreichen und in 
allen Reaktionsgefäßen die gleiche Menge an neu synthetisierter DNA zu haben. Bei einer Effizienz der PCR von 100 \% verdoppelt sich die DNA-Menge mit jedem Zyklus und damit auch das Fluoreszenzsignal. Genau der doppelten Menge der eingesetzten cDNA und demnach auch der mRNA-Startmenge entspricht der um genau eine Einheit verringerte CP-Wert. Über die so genannte $\triangle \triangle C P$-Methode (Delta-deltaCt-Methode) kann die Berechnung des Expressionsunterschiedes (Ratio) erfolgen. Zuerst muss von dem CP-Wert des Zielgens der CP-Wert des Referenzgens subtrahiert werden (Beispiel: $\Delta \mathrm{CP}_{\text {Mecp2 }}=\mathrm{CP}_{\text {Zielgen (Mecp2) }}-\mathrm{CP}_{\text {Referenzgen (Gapdh) }}$ ). Nach dieser relativen Quantifizierung wird nun vom $\triangle \mathrm{CP}$-Wert der Mecp2-/y - beziehungsweise der $M e c p 2^{T /-,+/ y}$-Probe der $\triangle \mathrm{CP}$-Wert des korrespondierenden Wildtypens abgezogen $\left(\Delta \Delta \mathrm{CP}=\Delta \mathrm{CP}_{\text {Mecp 2 }}-\Delta \mathrm{CP}_{\text {Wildtyp }}\right)$. Der relative Expressionsunterschied einer Mecp2 $2^{-/ y}$ - beziehungsweise einer Mecp2 $2^{T /,++/ y}$-Probe und des korrespondierenden Wildtyps (Ratio), relativ quantifiziert zum Referenzgen und bezogen auf eine Standardprobe, ergibt sich aus der arithmetischen Formel $2^{\triangle \triangle C P}$. Diese Berechnung gilt jedoch nur, wenn die Effizienz der PCR $100 \%$ beträgt. Um diese Optimalbedingungen den Laborbedingungen anzupassen, wird das „Effizienzkorrigierte relative Quantifizierungsmodell“ verwendet.

$$
\text { Ratio }=\frac{\left(E_{\text {Zielgen }}\right)^{\Delta C P_{\text {Zielgen }}}}{\left(E_{\text {Referenzgen }}\right)^{\Delta C P} \text { Referenzgen }}
$$

Idealerweise stimmen die CP-Werte des Refrenzgens, da es nicht reguliert wird, überein, so dass der Nenner 1 ergibt und sich folgende Formel ableiten lässt (Pfaffl 2001):

Ratio $=\left(E_{\text {Zielgen }}\right)^{\Delta C P_{\text {Zielgen }}}$

Zur statistischen Auswertung dieser Daten wurde die freie Programmiersprache und Statistik-Software "R“ verwendet. Das von Ross Ihaka und Robert Gentleman entwickelte GNU-Projekt („GNU is not Unix“) orientiert sich an den in den Bell Laboratories entwickelten Sprachen $S$ und S-Plus zur Verarbeitung statistischer Daten (http://www.r-project.org). Mittels dieser Software wurden, aus den durch die Pfaffl-Methode berechneten Ratio-Werten, der Mittelwert ( $\mathrm{m})$ und die Standardabweichung (sd) - Streuung um den Mittelwert - berechnet ( $m \pm s d$ ).

Ferner wurde der $\mathrm{p}$-Wert für die $M e c p 2^{-/ y}$-Ergebnisse gegenüber den korrespondierenden Wildtypergebnissen und entsprechend für das 
Mecp $2^{T /,++/ y}$-Modell separat für die postnatalen Entwicklungsstadium P7 und P40 berechnet, um eine Aussage über die Signifikanz einer Expressionsänderung treffen zu können. Die $p$-Wertberechnung erfolgte durch einen t-Test für gepaarte Stichproben, dem als Wahrscheinlichkeitsverteilung eine „studentsche t-Verteilung“ zugrunde liegt. „Der t-Test arbeitet mit den Populationsparametern der Streuung und des arithmetischen Mittels, die mit Hilfe der Stichprobe geschätzt werden. Er liefert eine Entscheidungshilfe dafür, ob ein gefundener Mittelwertsunterschied rein zufällig entstanden ist, oder ob es wirklich bedeutsame Unterschiede zwischen den zwei untersuchten Gruppen gibt. Mathematisch gesprochen beurteilt dieses Verfahren, ob sich zwei untersuchte Gruppen systematisch in ihren Mittelwerten unterscheiden oder nicht" (Rasch et al. 2006, Seite 44). Als Signifikanzwert wurde $p=0,05$ bestimmt, so dass mit einer Wahrscheinlichkeit von 95\% der Wert innerhalb des Konfidenzintervalls liegt. Falsch positive Werte treten mit einer Wahrscheinlichkeit von 5\% auf. Innerhalb der Gruppenpaare (zum Beispiel P7 KO versus P7 WTKO) wurde der t-Test angewendet, da die Mecp2-Mäuse bezüglich eines Gens nur mit ihren korrespondierenden Wildtypen verglichen werden können (gepaarte Stichproben). Um biologische Varianzen zu minimieren, wurden stets Mäuse des gleichen Wurfs, Alters und Genotyps für einen DNA-Pool verwendet. Zur Reduktion falsch positiver Werte wurde jedes Gen zweimal mit einem DNA-Pool von drei Tieren quantifiziert. Ein t-Test zur Bestimmung der Signifikanz ist in dieser Dissertation zur Darstellung von Veränderungen in der relativen Expression zwischen zum Beispiel P7 KO und P7 WT Ko ausreichend. 


\section{Ergebnisse}

\subsection{Relative Genexpression von Mecp2}

Zunächst wird durch quantitative Polymerasekettenreaktion (Real-time-PCR) die Expression des Gens Mecp2 im postnatalen Entwicklungsstadium P7 (7 Tage alt postnatal) des $M e c p 2^{-1 /}$ - und des Mecp2 $2^{T /-,+/ y}$-Modells und den korrespondierenden Wildtyp-Mäusen ( $\left(\mathrm{WT}_{\mathrm{KO}}\right.$ und $\mathrm{WT}_{\mathrm{T}}$ ) dargestellt. Im Knockout-Mausmodell (KO, Mecp2-/y-Modell), welches gekennzeichnet ist durch das Fehlen des natürlich vorkommenden X-chromosomal gekoppelten Mecp2-Gens, zeigten sich für $\mathrm{WT}_{\mathrm{KO}} \mathrm{P} 7$ ein Mittelwerte von 2,04 $\pm 0,15$ als Standardabweichung und für KO keine Genexpression. Im transgenen Modell ( $\mathrm{T}, \mathrm{Mecp} 2^{\mathrm{T} /,+/ / \mathrm{y}}$-Modell) befand sich neben dem X-chromosomal gekoppelten Mecp2-Gen ein weiteres EGFP-gekoppeltes (Enhanced Green Fluorescent Protein) Mecp2-Gen auf einem Autosom. Für WT T P7 betrug die relative Genexpression 0,41 $\pm 0,03$ und für die transgenen Mäuse T P7 $1,29 \pm 0,16$, so dass sich eine signifikante $\left(p=2.9 \times 10^{-5}\right)$ Steigerung um $211 \%$ ergab. Vgl. Abb. 3.1A.

Im postnatalen Entwicklungsstadium P40 (40 Tage alt postnatal) ergab sich für WT $_{\text {KO }} \mathrm{P} 40$ 1,04 \pm 0,09 als relative Expression und für KO P40 keine RNAExpression. Bezogen auf das Mecp $2^{T /-,+/ y}-$ Modell wurden Werte von 0,64 $\pm 0,02$ für $\mathrm{WT}_{\mathrm{T}} \mathrm{P} 40$ und von 1,41 $\pm 0,12$ für T P40 gemessen. Die signifikante $\left(p=5.9 \times 10^{-5}\right)$ Steigerung betrug hier $120 \%$. Vgl. Abb. 3.1B. 
A

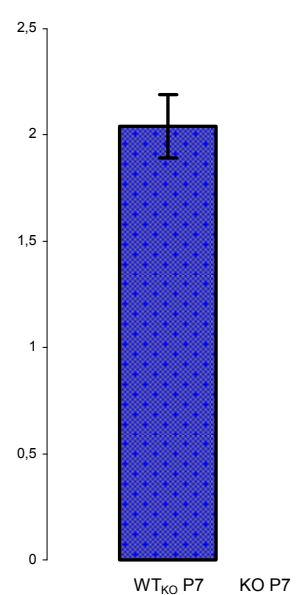

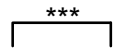

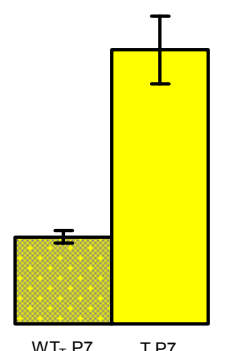

B

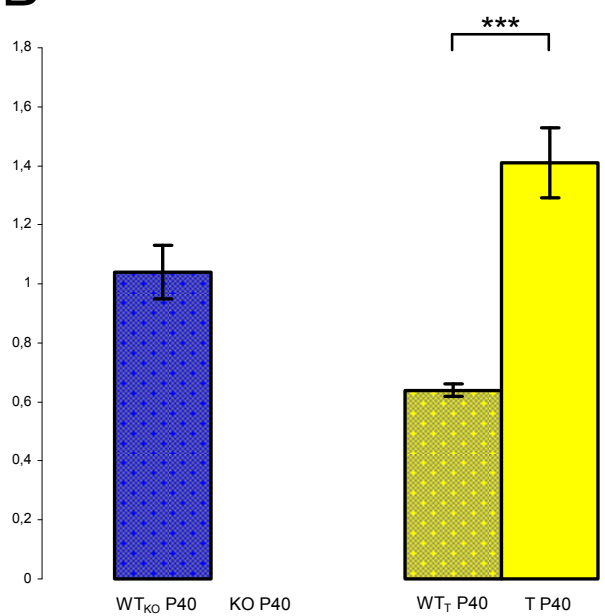

Abb. 3.1 Relative Genexpression von Mecp2 im Mecp2 $2^{-/ y}$ (KO) und Mecp2 $2^{T /-,+/ y}$-Modell (T) gegenüber Wildtyp (WT ${ }_{\mathrm{KO}}$ beziehungsweise $\mathrm{WT}_{\mathrm{T}}$ ) in den postnatalen Entwicklungsstadien P7 und P40. (A) Relative Genexpression von Mecp2 im postnatalen Entwicklungsstadium P7; Mittelwert \pm Standardabweichung für $\mathrm{WT}_{\mathrm{KO}} \mathrm{P} 72,04 \pm 0,15, \mathrm{KO}$ P7 $0 \pm 0, \mathrm{WT}_{\mathrm{T}} \mathrm{P} 70,41 \pm$ 0,03 , T P7 1,29 $\pm 0,16$. (B) Relative Genexpression von Mecp2 im postnatalen Entwicklungsstadium P40; Mittelwert \pm Standardabweichung für $\mathrm{WT}_{\mathrm{KO}} \mathrm{P} 40$ 1,04 \pm 0,09, KO P40 $0 \pm$ 0, WT $\mathrm{T} 40$ 0,64 \pm 0,02, T P40 1,41 \pm 0,12.

Abkürzungen: ${ }^{* \star *}: p<0,001$, Mecp2: Methyl-Cytosin-phosphatidyl-Guanin-Bindungsprotein 2, P7: postnatal 7 Tage alt, P40: postnatal 40 Tage alt; $n=3$ in jeder der acht Gruppen. Quelle: Eigene Entwicklung

\subsection{Ergebnisse der Real-time-PCR}

Im Folgenden werden die durch Real-time-PCR gemessenen relativen Genexpressionen von transgenen Mäusen (T, Mecp2 $2^{T /,+1 / y}$-Modell) in Relation zu Wildtyp-Mäusen $\left(\mathrm{WT}_{\mathrm{T}}\right)$ beziehungsweise von Knockout-Mäusen (KO, Mecp- $2^{-1 y}$-Modell) zu korrespondierenden Wildtyp-Mäusen ( $\mathrm{WT}_{\mathrm{Ko}}$ ) im frühen postnatalen Entwicklungsstadium P7 (7 Tage alt postnatal) und im späten postnatalen Altersstadium P40 (40 Tage alt postnatal) beschrieben. In Anlehnung an die Einleitung werden die Genexpressionen gruppiert dargestellt. 


\subsubsection{Relative Genexpression der Prä-Bötzinger-Komplex-Marker}

Als Prä-Bötzinger-Komplex-Marker wurden Tacr1 - Tachykinin-Receptor 1 - und Sst

- Somatostatin - verwendet.

Die relative Genexpression für Tacr1 im postnatalen Entwicklungsstadium P7 des Mecp2 $^{-/ y}$-Modells lag für $\mathrm{WT}_{\mathrm{KO}} \mathrm{P} 7$ bei $1,22 \pm 0,04$ und für KO P7 bei 1,17 $\pm 0,17$, somit ergab sich eine nicht signifikante $(p=0,62)$ Verminderung von $4 \%$. Im Mecp $2^{T /-,+/ y}$-Modell wurde für WT $_{\mathrm{T}}$ P7 1,44 $\pm 0,11$ und für T P7 1,18 $\pm 0,25$ gemessen, so dass sich eine nicht signifikante $(p=0,19)$ Reduzierung von $18 \%$ ergab. Vgl. Abb. 3.2A.

Dem gegenüber stellten sich die relativen Tacr1-Expressionen im späten postnatalen Entwicklungsstadium bei $\mathrm{WT}_{\text {KO }} \mathrm{P} 40$ mit 0,64 $\pm 0,09$ und bei KO P40 mit 0,28 $\pm 0,08$ durch eine signifikante ( $p=0,007)$ Verringerung um $56 \%$ dar. Werte von 0,66 0,12 wurden bei $\mathrm{WT}_{\mathrm{T}} \mathrm{P} 40$ und $0,65 \pm 0,14$ bei T P40 gemessen. Eine nicht signifikante $(p=0,96)$ Abnahme lag hier von $2 \%$ vor. Vgl. Abb. 3.2B.
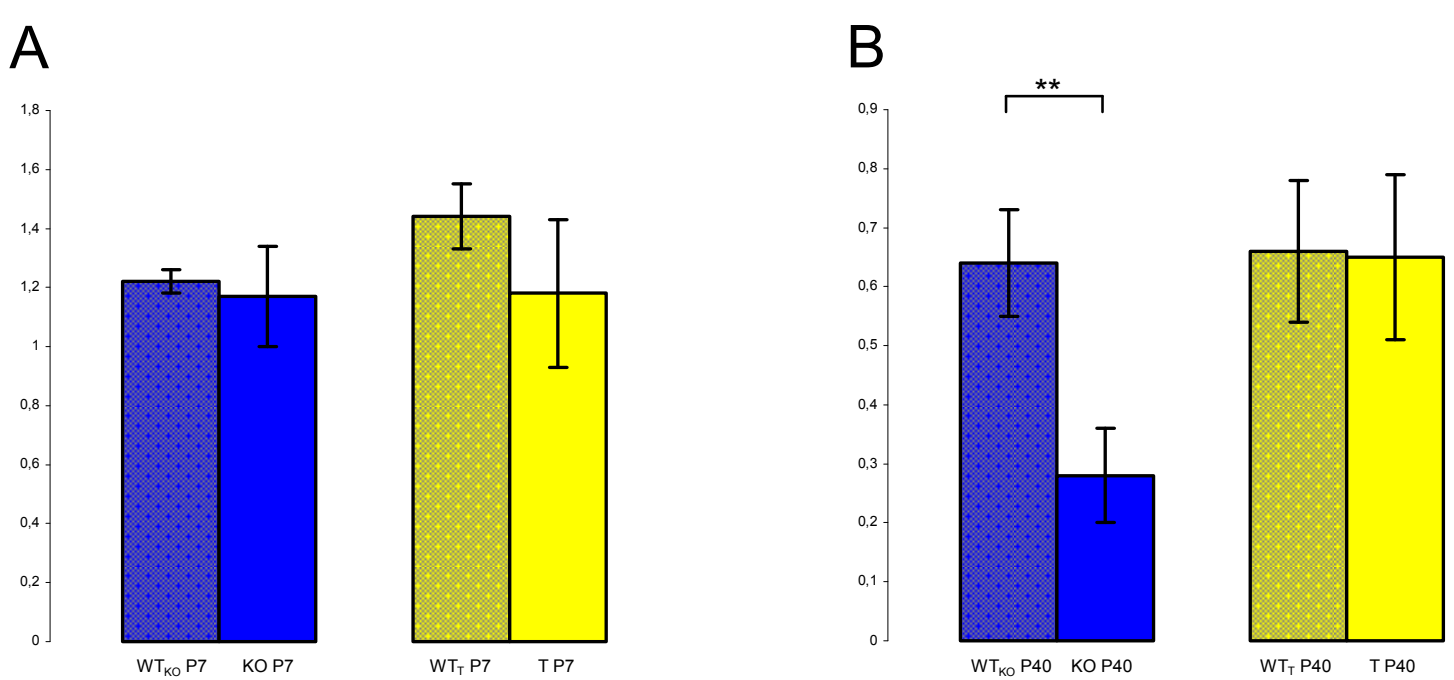

Abb. 3.2 Relative Genexpression von Tacr1 im Mecp2/ly $(\mathrm{KO})$ und Mecp2 $2^{T /-,+/ y}$-Modell (T) gegenüber Wildtyp (WTKO beziehungsweise $\mathrm{WT}_{\mathrm{T}}$ ) in den postnatalen Entwicklungsstadien P7 und P40. (A) Relative Genexpression von Tacr1 im postnatalen Entwicklungsstadium P7; Mittelwert \pm Standardabweichung für $\mathrm{WT}_{\mathrm{KO}} \mathrm{P} 7 \mathrm{1,22} \pm$ 0,04, KO P7 1,17 $\pm 0,17, \mathrm{WT}_{\mathrm{T}} \mathrm{P} 7$ $1,44 \pm 0,11$, T P7 1,18 $\pm 0,25$. (B) Relative Genexpression von Tacr1 im postnatalen Entwicklungsstadium P40; Mittelwert \pm

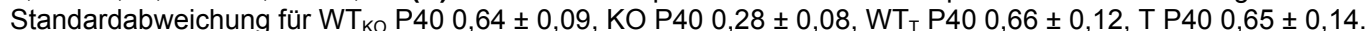

Abkürzungen: **: $p<0,01$, Mecp2: Methyl-Cytosin-phosphatidyl-Guanin-Bindungsprotein 2, P7: postnatal 7 Tage alt, $P 40$ : postnatal 40 Tage alt, Tacr1: Tachykinin-Receptor $1 ; n=3$ in jeder der acht Gruppen. Quelle: Eigene Entwicklung 
Für das Gen Sst wurden für WT $\mathrm{WO}_{\mathrm{KO}} \mathrm{P} 7 \mathrm{1,02} \pm 0,09, \mathrm{KO}$ P7 1,5 \pm 0,07, $\mathrm{WT}_{\mathrm{T}} \mathrm{P} 7$ $0,97 \pm 0,29$ und für T P7 1,17 $\pm 0,18$ als relative Expressionen gemessen. Daraus ergaben sich für KO P7 ein signifikanter $(p=0,003)$ Anstieg um $47 \%$ und für T P7 ein nicht signifikanter $(p=0,49)$ um $21 \%$. Vgl. Abb. 3.3A.

Die relativen Sst-Expressionen im postnatalen Entwicklungsstadium P40 ergaben bei WT KO $_{\text {KO }}$ 0,69 $\pm 0,05$ und bei KO P40 0,42 $\pm 0,03$. Es zeigte sich daher eine signifikante $(p=0,002)$ Verringerung um $39 \%$. Bei WT T $P 40$ wurden 0,69 $\pm 0,19$ und bei T P40 0,72 $\pm 0,03$ gemessen. Hier stellte sich eine nicht signifikante $(p=0,86)$ Steigerung von $4 \%$ dar. Vgl. Abb. 3.3B.

A

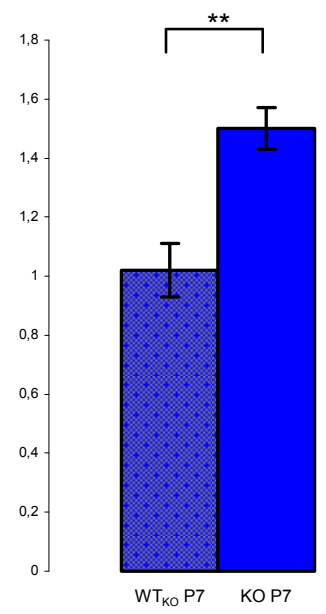

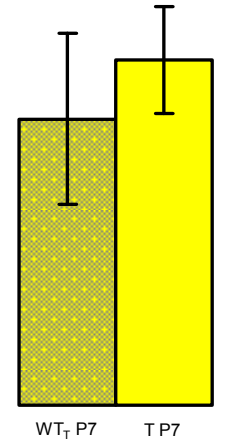

B

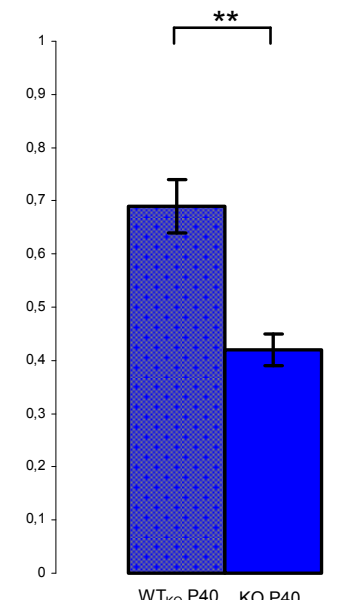

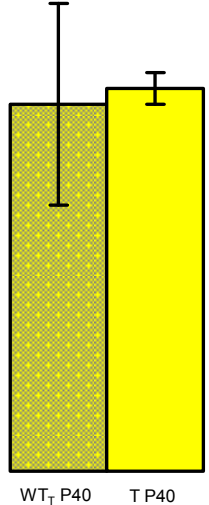

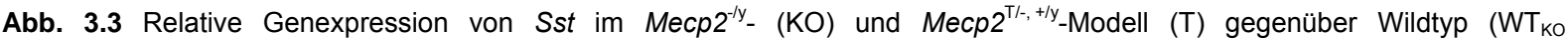
beziehungsweise $\mathrm{WT}_{\mathrm{T}}$ ) in den postnatalen Entwicklungsstadien $\mathrm{P} 7$ und P40. (A) Relative Genexpression von Sst im postnatalen Entwicklungsstadium P7; Mittelwert \pm Standardabweichung für $\mathrm{WT}_{\mathrm{KO}} \mathrm{P7} 1,02 \pm 0,09, \mathrm{KO} \mathrm{P} 71,5 \pm 0,07, \mathrm{WT} \mathrm{T} 7$ $0,97 \pm 0,29$, T P7 1,17 $\pm 0,18$. (B) Relative Genexpression von Sst im postnatalen Entwicklungsstadium P40; Mittelwert \pm Standardabweichung für WT $\mathrm{WO}_{\mathrm{K}} \mathrm{P} 40$ 0,69 \pm 0,05, KO P40 0,42 \pm 0,03, WT T P40 0,69 \pm 0,19, T P40 0,72 \pm 0,03.

Abkürzungen: ${ }^{* *}: p<0,01$, Mecp2: Methyl-Cytosin-phosphatidyl-Guanin-Bindungsprotein 2, P7: postnatal 7 Tage alt, $P 40$ : postnatal 40 Tage alt, Sst: Somatostatin; $n=3$ in jeder der acht Gruppen. Quelle: Eigene Entwicklung 


\subsubsection{Das exzitatorische System}

Bezogen auf das exzitatorische System wurden drei Gene für Glutamat-Rezeptoren untersucht.

Für Grin1 - Glutamat-Rezeptor, ionotroph, NMDA1 - ergaben sich folgende Zahlenwerte der relativen Expressionen: $\mathrm{WT}_{\mathrm{KO}} \mathrm{P} 7$ 1,13 \pm 0,08, KO P7 1,36 \pm 0,17, $\mathrm{WT}_{\mathrm{T}} \mathrm{P} 7$ 1,22 $\pm 0,09$ und T P7 1,08 \pm 0,18. Daraus errechneten sich eine nicht signifikante $(p=0,07)$ Steigerung von $\mathrm{WT}_{\mathrm{KO}}$ auf $\mathrm{KO}$ um $20 \%$ und eine nicht signifikante $(p=0,45)$ Verminderung von $\mathrm{WT}_{\mathrm{T}}$ auf T um $11 \%$. Vgl. Abb. 3.4A.

Die Ergebnisse des späteren postnatalen Entwicklungsstadiums bezüglich Grin1 beliefen sich für $\mathrm{WT}_{\mathrm{KO}} \mathrm{P} 40$ auf 1,74 $\pm 0,11$ und KO P40 auf 0,89 $\pm 0,08$ sowie im Mecp $2^{T /-,+/ y}-$ Modell für $\mathrm{WT}_{\mathrm{T}} \mathrm{P} 40$ auf 0,85 $\pm 0,06$ und $\mathrm{T} \mathrm{P} 40$ auf 0,85 0,16. Das heißt, von $\mathrm{WT}_{\mathrm{KO}} \mathrm{zU} \mathrm{KO}$ verringerte sich die relative Genexpression signifikant ( $p=0,0001)$ um $49 \%$ und von $\mathrm{WT}_{\mathrm{T}}$ zu T blieb sie nahezu gleich. Vgl. Abb. 3.4B.

A

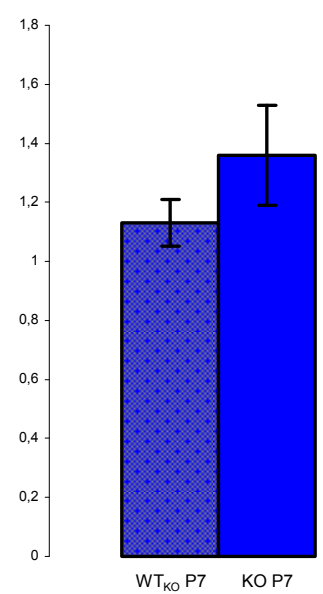

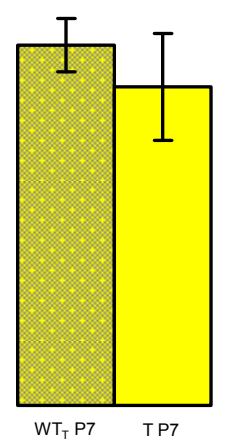
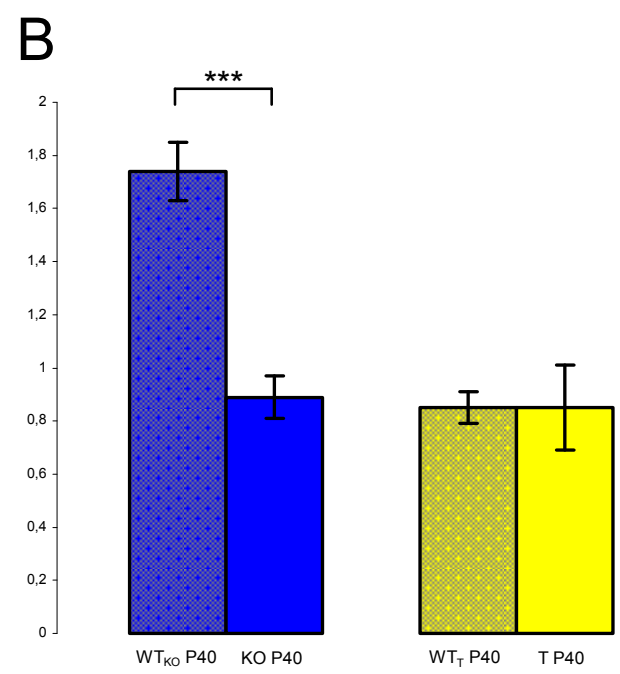

Abb. 3.4 Relative Genexpression von Grin1 im Mecp2/y- (KO) und Mecp2 $2^{T /-,+/ y}$-Modell (T) gegenüber Wildtyp (WT ${ }_{\text {KO }}$ beziehungsweise $\mathrm{WT}_{\mathrm{T}}$ ) in den postnatalen Entwicklungsstadien P7 und P40. (A) Relative Genexpression von Grin1 im postnatalen Entwicklungsstadium $\mathrm{P} 7$; Mittelwert \pm Standardabweichung für $\mathrm{WT}_{\mathrm{KO}} \mathrm{P} 71,13 \pm 0,08, \mathrm{KO} \mathrm{P} 71,36 \pm 0,17, \mathrm{WT} \mathrm{P}_{\mathrm{T}}$ $1,22 \pm 0,09$, T P7 1,08 \pm 0,18. (B) Relative Genexpression von Grin1 im postnatalen Entwicklungsstadium P40; Mittelwert \pm Standardabweichung für WT $\mathrm{WO}_{\mathrm{O}} \mathrm{P} 401,74 \pm 0,11, \mathrm{KO}$ P40 0,89 \pm 0,08, WT $\mathrm{T}$ P40 0,85 \pm 0,06, T P40 0,85 $\pm 0,16$.

Abkürzungen: ***: p<0,001, Mecp2: Methyl-Cytosin-phosphatidyl-Guanin-Bindungsprotein 2, P7: postnatal 7 Tage alt, P40: postnatal 40 Tage alt, Grin1: Glutamat-Rezeptor, ionotroph, NMDA1; $n=3$ in jeder der acht Gruppen. Quelle: Eigene Entwicklung 
Bei Grin2a - Glutamat-Rezeptor, ionotroph, NMDA2A - lagen die relativen Expressionen für $\mathrm{WT}_{\mathrm{KO}} \mathrm{P} 7$ bei 1,28 $\pm 0,01$ und für $\mathrm{KO} \mathrm{P} 7$ bei 1,37 $\pm 0,19$. Daraus ergab sich eine nicht signifikante $(p=0,82)$ Erhöhung um $7 \%$. Für $\mathrm{WT}_{\mathrm{T}} \mathrm{P} 7$ wurden $1,01 \pm 0,14$ und für T P7 0,85 $\pm 0,17$ gemessen, so dass sich eine nicht signifikante $(p=0,35)$ Verminderung von $16 \%$ darstellte. Vgl. Abb. 3.5A.

Relative Expressionsergebnisse in der späteren Altersgruppe für Grin2a ergaben folgende Zahlenwerte: $\mathrm{WT}_{\mathrm{KO}} \mathrm{P} 40$ 1,16 \pm 0,28, KO P40 0,75 \pm 0,04, WT $\mathrm{T} 40$ $0,71 \pm 0,06$, T P40 0,54 $\pm 0,07$. Daraus errechnete sich ein nicht signifikantes Absinken im Mecp2 ${ }^{-l y}-$ Modell von WT $_{K O}$ auf KO um $35 \%(p=0,08)$ sowie im transgenen Modell von $\mathrm{WT}_{\mathrm{T}}$ auf T um $24 \%(p=0,35)$. Vgl. Abb. 3.5B.

A

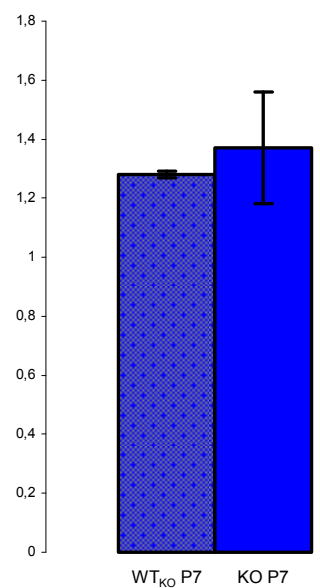

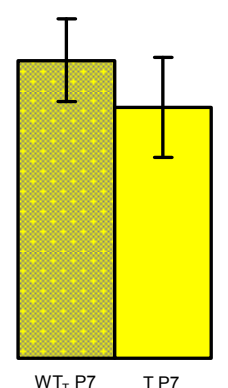
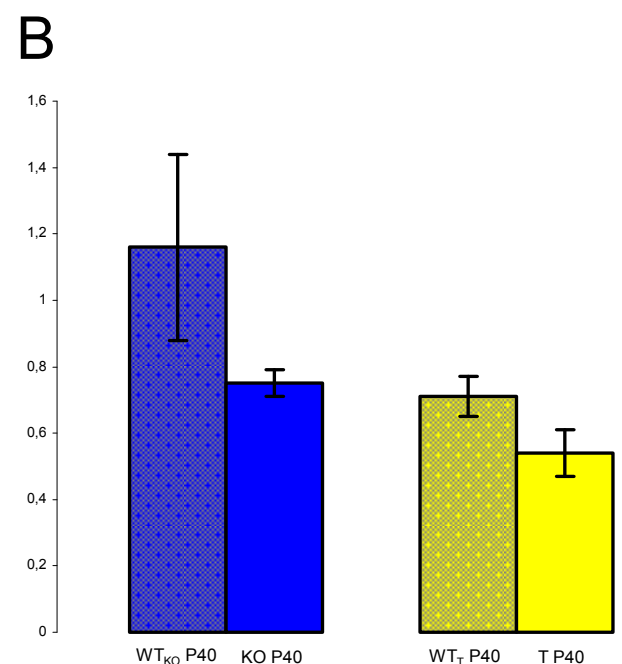

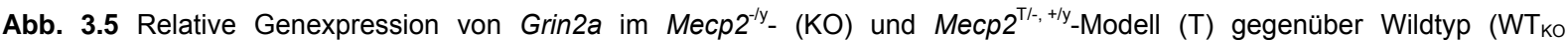
beziehungsweise $\mathrm{WT}_{\mathrm{T}}$ ) in den postnatalen Entwicklungsstadien P7 und P40. (A) Relative Genexpression von Grin2a im postnatalen Entwicklungsstadium P7; Mittelwert \pm Standardabweichung für $\mathrm{WT}_{\mathrm{KO}} \mathrm{P} 71,28 \pm 0,01, \mathrm{KO} \mathrm{P7} 1,37 \pm 0,19, \mathrm{WT} \mathrm{P}_{\mathrm{T}} \mathrm{P}$ $1,01 \pm 0,14$, T P7 0,85 \pm 0,17. (B) Relative Genexpression von Grin2a im postnatalen Entwicklungsstadium P40; Mittelwert \pm Standardabweichung für $\mathrm{WT}_{\mathrm{KO}} \mathrm{P} 401,16 \pm 0,28$, KO P40 0,75 \pm 0,04, WT T P40 0,71 \pm 0,06, T P40 0,54 \pm 0,07.

Abkürzungen: Mecp2: Methyl-Cytosin-phosphatidyl-Guanin-Bindungsprotein 2, P7: postnatal 7 Tage alt, $P 40$ : postnatal 40 Tage alt, Grin2a: Glutamat-Rezeptor, ionotroph, NMDA2A; $n=3$ in jeder der acht Gruppen. Quelle: Eigene Entwicklung 
Für das Gen Grin2d - Glutamat-Rezeptor, ionotroph, NMDA2D - ergaben sich für $\mathrm{WT}_{K O} \mathrm{P} 7$ 1,52 $\pm 0,11$ und für KO P7 1,22 $\pm 0,22$ sowie für $\mathrm{WT}_{\mathrm{T}} \mathrm{P} 7$ 1,67 $\pm 0,28$ und für T P7 1,95 $\pm 0,31$. Daraus zeigten sich eine signifikante $(p=0,047)$ Verminderung innerhalb des Knockout-Modells für P7 von $20 \%$ und eine nicht signifikante ( $p=0,31)$ Erhöhung innerhalb des transgenen Modells für P7 von $16 \%$. Vgl. Abb. 3.6A.

Messdaten für Grin2d im postnatalen Entwicklungsstadium P40 beliefen sich bei $\mathrm{WT}_{\text {KO }} \mathrm{P} 40$ auf $0,88 \pm 0,15, \mathrm{KO}$ P40 auf 0,31 $\pm 0,03, \mathrm{WT}_{\mathrm{T}} \mathrm{P} 40$ auf 0,63 $\pm 0,02$ und bei T P40 auf 0,64 $\pm 0,10$. Somit lagen die Messwerte innerhalb des Mecp2 ${ }^{-/ y}$-Modells signifikant $(p=0,005)$ um $65 \%$ niedriger. Darüber hinaus stellte sich eine nicht signifikante $(p=0,93)$ Erhöhung innerhalb des transgenen Modells von $2 \%$ dar. Vgl. Abb. 3.6B.

A

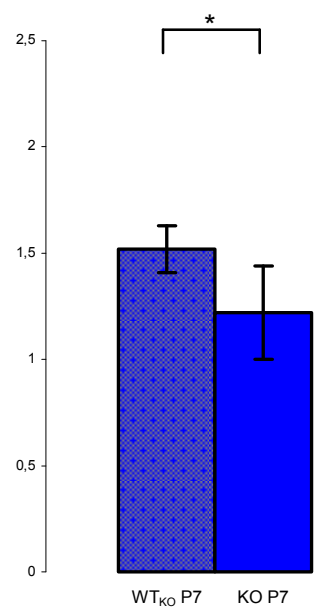

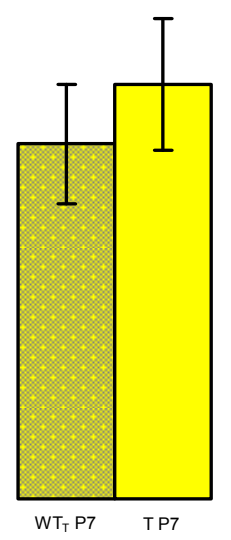

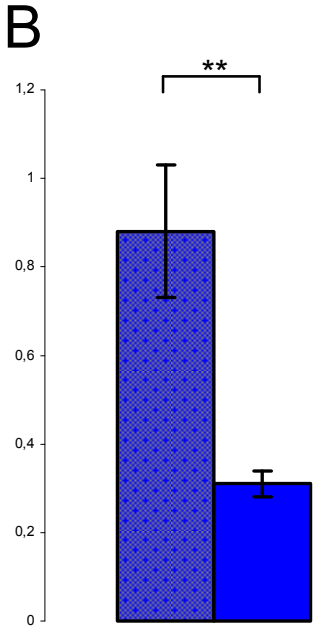

$W T_{K O} P 40 \quad K O P 40$

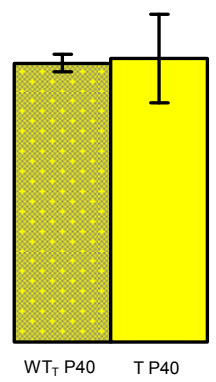

Abb. 3.6 Relative Genexpression von Grin2d im $\operatorname{Mecp}^{-/ y}$ - (KO) und Mecp2 $2^{T /,+1 / y}$-Modell (T) gegenüber Wildtyp (WTKo beziehungsweise $\mathrm{WT}_{\mathrm{T}}$ ) in den postnatalen Entwicklungsstadien P7 und P40. (A) Relative Genexpression von Grin2d im postnatalen Entwicklungsstadium P7; Mittelwert \pm Standardabweichung für WT $\mathrm{W}_{\text {Ko }} \mathrm{P7}$ 1,52 $\pm 0,11, \mathrm{KO}$ P7 1,22 $\pm 0,22, \mathrm{WT}_{\mathrm{T}} \mathrm{P7}$ $1,67 \pm 0,28$, T P7 1,95 $\pm 0,31$. (B) Relative Genexpression von Grin2d im postnatalen Entwicklungsstadium P40; Mittelwert \pm Standardabweichung für WT $\mathrm{WO}_{\mathrm{K}} \mathrm{P} 40 \mathrm{0,88} \pm 0,15$, KO P40 0,31 $\pm 0,03, \mathrm{WT}_{\mathrm{T}} \mathrm{P} 400,63 \pm 0,02$, T P40 0,64 $\pm 0,1$.

Abkürzungen: *: $p<0,05,{ }^{* *}$ : $p<0,01$, Mecp2: Methyl-Cytosin-phosphatidyl-Guanin-Bindungsprotein 2, P7: postnatal 7 Tage alt, P40: postnatal 40 Tage alt, Grin2d: Glutamat-Rezeptor, ionotroph, NMDA2D; $n=3$ in jeder der acht Gruppen. Quelle: Eigene Entwicklung 


\subsubsection{Das inhibitorische System}

Zwei Gene für $\mathrm{GABA}_{A}-$ Rezeptoren werden exemplarisch für das inhibitorische System dargestellt.

Das Gabra6-Gen steht für $Y$-Aminobuttersäure(GABA) $)_{A}$-Rezeptor Untereinheit Alpha 6. Hierfür ergaben sich Messergebnisse im frühen postnatalen Entwicklungsstadium $\mathrm{P7}$ von 0,58 \pm 0 für $\mathrm{WT}_{\mathrm{KO}} \mathrm{P} 7,1,07 \pm 0,03$ für KO P7, 0,84 \pm 0,07 für $\mathrm{WT}_{\mathrm{T}} \mathrm{P} 7$ sowie 1,96 $\pm 0,41$ für T P7. Für das Mecp2 $2^{-/ y}$-Modell zeigte sich somit eine signifikante ( $p=0,0013)$ Erhöhung der relativen Expression um $84 \%$ und für das Mecp2 $2^{T /-,+/ y}$-Modell eine signifikante $(p=0,004)$ Steigerung um $134 \%$. Vgl. Abb. 3.7A.

Die Daten im späten postnatalen Entwicklungsstadium P40 für Gabra6 wurden für $\mathrm{WT}_{\mathrm{KO}} \mathrm{P} 40$ mit $2 \pm 0,21$ und für KO P40 mit 1,14 \pm 0,07 bestimmt. Somit belief sich die signifikante $\left(p=5 \times 10^{-5}\right)$ Minderung auf $43 \%$ innerhalb des Knockout-Modells. Für $\mathrm{WT}_{\mathrm{T}} \mathrm{P} 40$ ließen sich Zahlenwerte von 1,55 \pm 0,27 und für T P40 von 0,64 \pm 0,18 messen und daraus eine signifikante $(p=0,012)$ Verringerung von $\mathrm{WT}_{T}$ auf $T$ um $58 \%$ errechnen. Vgl. Abb. 3.7B.

A

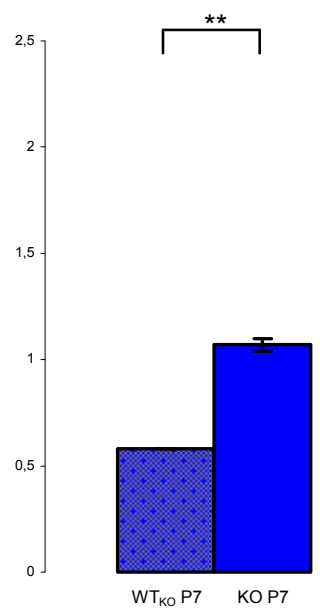

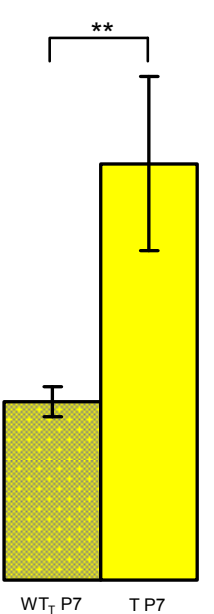

B

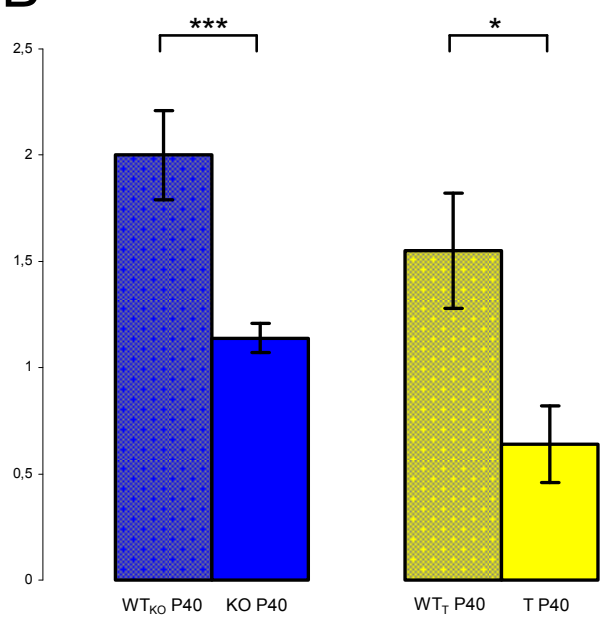

Abb. 3.7 Relative Genexpression von Gabra6 im Mecp2 $2_{-}^{-1 y}$ (KO) und Mecp2 $2^{T /,+/ y}$-Modell (T) gegenüber Wildtyp (WTKO beziehungsweise $\mathrm{WT}_{\mathrm{T}}$ ) in den postnatalen Entwicklungsstadien P7 und P40. (A) Relative Genexpression von Gabra6 im postnatalen Entwicklungsstadium $\mathrm{P} 7$; Mittelwert \pm Standardabweichung für $\mathrm{WT}_{\mathrm{KO}} \mathrm{P} 7 \mathrm{0,58 \pm 0, \textrm {KO }} \mathrm{P} 71,07 \pm 0,03, \mathrm{WT}_{\mathrm{T}} \mathrm{P} 7$ $0,84 \pm 0,07$, T P7 1,96 $\pm 0,41$. (B) Relative Genexpression von Gabra6 im postnatalen Entwicklungsstadium P40; Mittelwert \pm Standardabweichung für WT Kо P40 $2 \pm 0,21, \mathrm{KO}$ P40 1,14 \pm 0,07, WT T P40 1,55 \pm 0,27, T P40 0,64 \pm 0,18.

Abkürzungen: *: $p<0,05,{ }^{* *}: p<0,01,{ }^{* * *}: p<0,001$, Mecp2: Methyl-Cytosin-phosphatidyl-Guanin-Bindungsprotein 2, P7: postnatal 7 Tage alt, P40: postnatal 40 Tage alt, Gabra6: GABA $A_{A}$ Rezeptor Untereinheit Alpha 6; $n=3$ in jeder der acht Gruppen. Quelle: Eigene Entwicklung 
Im postnatalen Entwicklungsstadium $\mathrm{P} 7$ lag die relative Expression für Gabrb1

- $\mathrm{GABA}_{A}-\mathrm{Rezeptor}$ Untereinheit Beta 1 - für $\mathrm{WT}_{\mathrm{KO}} \mathrm{P7}$ bei 0,94 $\pm 0,12$ und für KO P7 bei $1,21 \pm 0,18$. Daraus folgte eine nicht signifikante $(p=0,48)$ Steigerung um $29 \%$. Für $\mathrm{WT}_{\mathrm{T}} \mathrm{P} 7$ lagen die Werte bei 1,43 $\pm 0,23$ und für T P7 bei 1,15 $\pm 0,17$. Hier zeigte sich eine nicht signifikante ( $p=0,24)$ Verminderung um $20 \%$. Vgl. Abb. 3.8A.

Die relativen Gabrb1-Expressionen im postnatalen Entwicklungsstadium P40 ergaben bei $\mathrm{WT}_{\mathrm{KO}} \mathrm{P} 401,09 \pm 0,05$ und bei KO P40 1,08 \pm 0,24. Es errechnete sich eine nicht signifikante $(p=1)$ Reduktion um $1 \%$ der Werte. Bei WTT P40 fanden sich Werte von 0,94 $\pm 0,17$ und bei T P40 von 0,79 $\pm 0,09$. Auch hier lagen die Werte von T gegenüber $\mathrm{WT}_{\mathrm{T}}$ nicht signifikant $(\mathrm{p}=0,35)$ um $16 \%$ niedriger. Vgl. Abb. 3.8B.

A

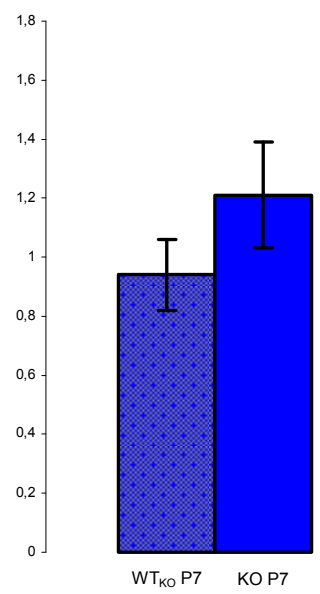

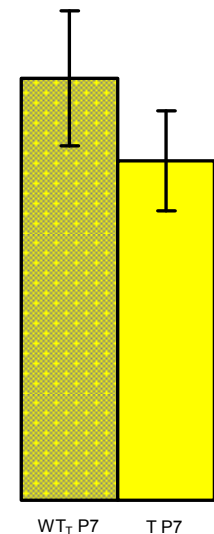

B

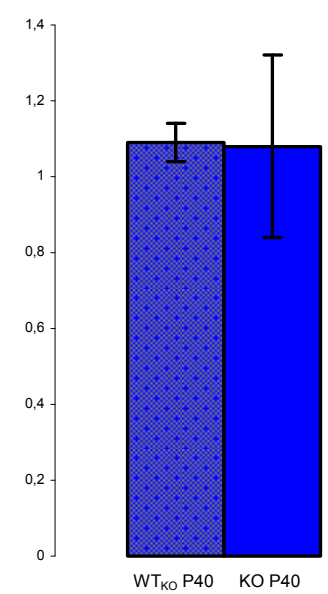

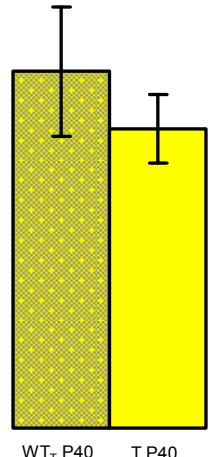

Abb. 3.8 Relative Genexpression von Gabrb1 im Mecp2/y - (KO) und Mecp2 ${ }^{T /,-+/ y}$-Modell (T) gegenüber Wildtyp (WTKO beziehungsweise $\mathrm{WT}_{\mathrm{T}}$ ) in den postnatalen Entwicklungsstadien P7 und P40. (A) Relative Genexpression von Gabrb1 im

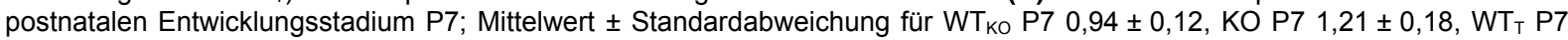
1,43 \pm 0,23, T P7 1,15 \pm 0,17. (B) Relative Genexpression von Gabrb1 im postnatalen Entwicklungsstadium P40; Mittelwert \pm Standardabweichung für WT $\mathrm{WO}_{\mathrm{K}} \mathrm{P} 401,09 \pm 0,05, \mathrm{KO}$ P40 1,08 \pm 0,24, WT T P40 0,94 \pm 0,17, T P40 0,79 \pm 0,09.

Abkürzungen: Mecp2: Methyl-Cytosin-phosphatidyl-Guanin-Bindungsprotein 2, P7: postnatal 7 Tage alt, $P 40$ : postnatal 40 Tage alt, Gabrb1: GABA $A-$ Rezeptor Untereinheit Beta 1; $\mathrm{n}=3$ in jeder der acht Gruppen. Quelle: Eigene Entwicklung 


\subsubsection{Das serotonerge System}

Bezogen auf das serotonerge System wurden fünf unterschiedliche Gene untersucht. Zwei kodieren für Enzyme der Serotoninsynthese $(T p h 2, D d c)$, eins für einen Serotonintransporter (S/c6a4) und zwei Gene kodieren für Serotoninrezeptoren (Htr4, Htr5b).

Für Tph2 - Tryptophanhydroxylase 2 - ergaben sich folgende relative Expressionsdaten: $\mathrm{WT}_{\text {KO }} \mathrm{P} 7$ 0,56 \pm 0,06, KO P7 0,95 \pm 0,02, $\mathrm{WT}_{\mathrm{T}} \mathrm{P} 7$ 1,06 \pm 0,03 sowie T P7 0,91 $\pm 0,07$. Hieraus folgte eine signifikante $(p=0,04)$ Erhöhung für das Mecp $2^{-/ y}$-Modell von $\mathrm{WT}_{\mathrm{KO}}$ auf $\mathrm{KO}$ um $70 \%$ und ein nicht signifikantes $(p=0,42)$ Absinken für das Mecp2 $2^{T /,++/ y}$-Modell von T gegenüber $\mathrm{WT}_{\mathrm{T}}$ um $14 \%$. Vgl. Abb. 3.9A. Die auf das spätere Entwicklungsstadium P40 bezogenen Tph2-Ergebnisse beliefen sich bei $W_{\text {KO }} P 40$ auf $1,13 \pm 0,09$ und bei KO P40 auf 2,35 $\pm 0,3$. Somit errechnete sich eine signifikante $\left(p=6 \times 10^{-5}\right)$ Erhöhung innerhalb des Mecp2-/y - Modells um $108 \%$. Zudem zeigten sich bei $\mathrm{WT}_{\mathrm{T}} \mathrm{P} 40$ Zahlenwerte von 1,03 \pm 0,03 sowie bei T P40 von 1,31 $\pm 0,2$. Hieraus ließ sich eine nicht signifikante $(p=0,07)$ Steigerung für das Mecp2 $2^{T /,-+/ y}$-Modell von WT T auf T um 27 \% ermitteln. Vgl. Abb. 3.9B.
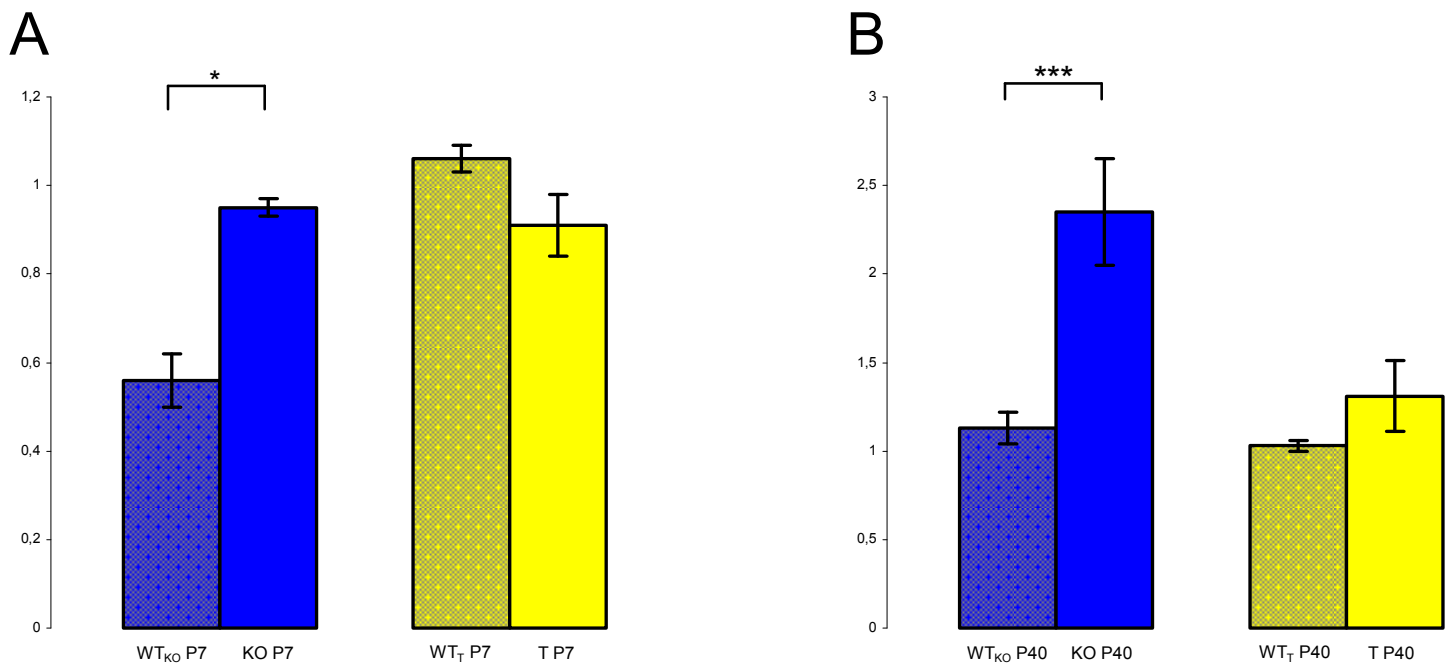

Abb. 3.9 Relative Genexpression von Tph2 im Mecp2 $2^{-1 /}$ - (KO) und Mecp2 $2^{T /,+/ y}$-Modell (T) gegenüber Wildtyp (WTKO beziehungsweise $\mathrm{WT}_{\mathrm{T}}$ ) in den postnatalen Entwicklungsstadien P7 und P40. (A) Relative Genexpression von Tph2 im postnatalen Entwicklungsstadium P7; Mittelwert \pm Standardabweichung für $\mathrm{WT}_{\text {Ko }} \mathrm{P} 7$ 0,56 $\pm 0,06, \mathrm{KO}$ P7 0,95 $\pm 0,02$, WT $\mathrm{P} 7$ $1,06 \pm 0,03$, T P7 0,91 $\pm 0,07$. (B) Relative Genexpression von Tph2 im postnatalen Entwicklungsstadium P40; Mittelwert \pm Standardabweichung für WT Ko P40 1,13 $\pm 0,09$, KO P40 2,35 $\pm 0,3$, WT T P40 1,03 $\pm 0,03$, T P40 1,31 $\pm 0,2$

Abkürzungen: *: $p<0,05,{ }^{* * *}: p<0,001$, Mecp2: Methyl-Cytosin-phosphatidyl-Guanin-Bindungsprotein 2, P7: postnatal 7 Tage alt, P40: postnatal 40 Tage alt, Tph2: Tryptophanhydroxylase 2; $\mathrm{n}=3$ in jeder der acht Gruppen. Quelle: Eigene Entwicklung 
Bei Ddc - Dopadecarboxylase - lagen bezüglich des postnatalen Entwicklungsstadiums $\mathrm{P} 7$ die relativen Expressionen für $\mathrm{WT}_{\mathrm{KO}} \mathrm{P} 7$ bei $0,84 \pm 0,14$ und für KO P7 bei 1,04 $\pm 0,24$, so dass eine nicht signifikante $(p=0,4)$ Erhöhung um $24 \%$ bestimmt wurde. Für $\mathrm{WT}_{\mathrm{T}} \mathrm{P} 7$ wurde 0,86 \pm 0,03 und für T P7 wurde 1,12 \pm 0,12 gemessen, so dass es sich hier um eine nicht signifikante $(p=0,44)$ Steigerung von $31 \%$ handelte. Vgl. Abb. 3.10A.

Die relativen $D d c$-Expressionen im postnatalen Entwicklungsstadium P40 wurden bei $\mathrm{WT}_{\text {KO }} \mathrm{P} 40$ mit 1,25 $\pm 0,09$ und bei KO P40 mit 1,82 $\pm 0,22$ bestimmt, so dass sie innerhalb des Mecp2 $2^{-/ y}$-Modells signifikant $(p=0,02)$ um $46 \%$ von $\mathrm{WT}_{\mathrm{KO}}$ auf KO stiegen. Ergebnisse für $\mathrm{WT}_{\mathrm{T}} \mathrm{P} 40$ zeigten Zahlenwerte von 1,34 \pm 0,26 und für $\mathrm{T} P 40$ von 1,05 $\pm 0,21$, somit waren die Werte von $\mathrm{T}$ gegenüber $\mathrm{WT}_{\mathrm{T}}$ nicht signifikant ( $p=0,41)$ um $22 \%$ niedriger. Vgl. Abb. 3.10B.
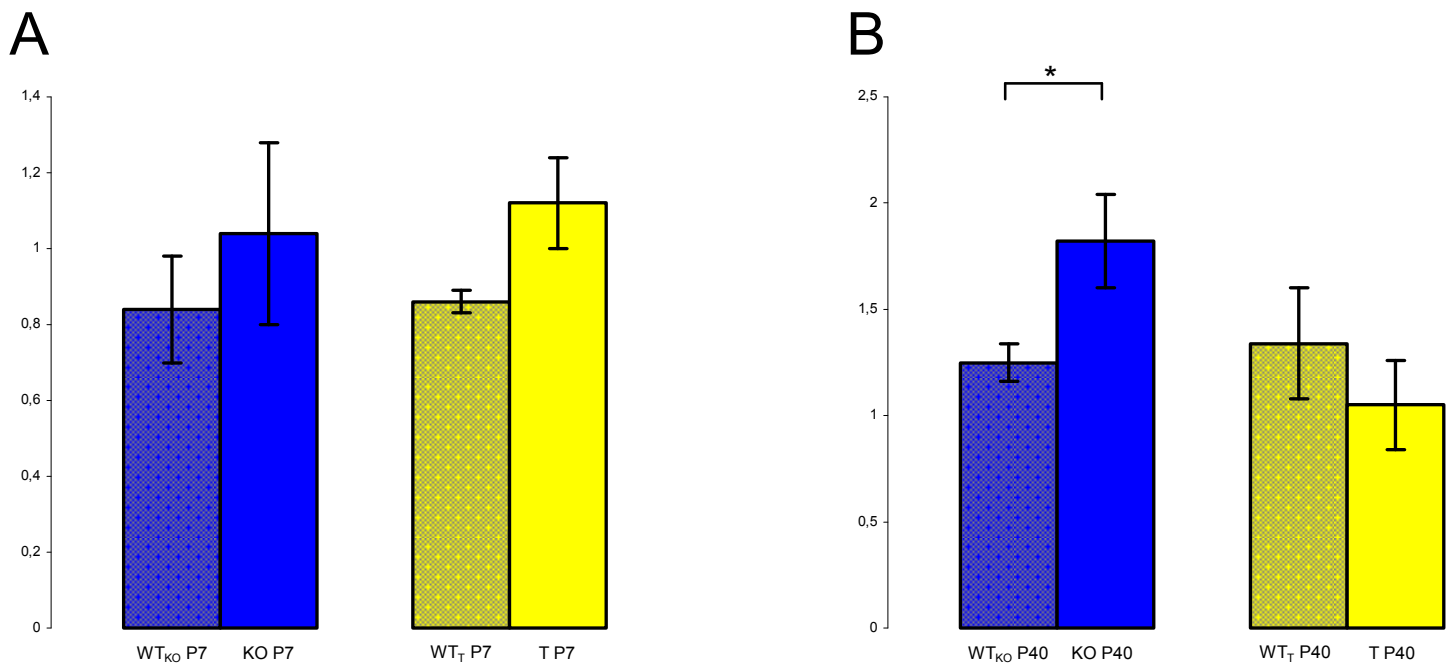

Abb. 3.10 Relative Genexpression von $D d c$ im $\operatorname{Mecp}^{-/ y}$ - (KO) und Mecp2 $2^{T /,+/ y}$-Modell (T) gegenüber Wildtyp (WTKO beziehungsweise $\mathrm{WT}_{\mathrm{T}}$ ) in den postnatalen Entwicklungsstadien P7 und P40. (A) Relative Genexpression von Ddc im postnatalen Entwicklungsstadium P7; Mittelwert \pm Standardabweichung für $\mathrm{WT}_{\text {KO }} \mathrm{P7}$ 0,84 \pm 0,14, KO P7 1,04 $\pm 0,24, \mathrm{WT}_{\mathrm{T}} \mathrm{P7}$ $0,86 \pm 0,03$, T P7 1,12 $\pm 0,12$. (B) Relative Genexpression von Ddc im postnatalen Entwicklungsstadium P40; Mittelwert \pm Standardabweichung für WT Ko P40 1,25 $\pm 0,09$, KO P40 1,82 $\pm 0,22, W_{T} P 401,34 \pm 0,26, T P 401,05 \pm 0,21$.

Abkürzungen: *: p<0,05, Mecp2: Methyl-Cytosin-phosphatidyl-Guanin-Bindungsprotein 2, P7: postnatal 7 Tage alt, P40: postnatal 40 Tage alt, $D d c$ : Dopadecarboxylase; $n=3$ in jeder der acht Gruppen. Quelle: Eigene Entwicklung 
Das S/c6a4-Gen steht für „solute carrier family 6 member 4“, ein Transporter für den Neurotransmitter Serotonin. Hierfür beliefen sich die Genexpressionen auf $0,42 \pm 0,06$ für $\mathrm{WT}_{\text {KO }} \mathrm{P} 7,0,88 \pm 0,14$ für KO P7, 1,65 $\pm 0,33$ für $\mathrm{WT}_{\mathrm{T}} \mathrm{P} 7$ sowie auf $1,38 \pm 0,18$ für T P7. Für das Mecp2 $2^{-/ y}$-Modell ergab sich von $\mathrm{WT}_{\mathrm{KO}}$ auf $\mathrm{KO}$ ein nicht signifikanter $(p=0,09)$ Anstieg um $110 \%$ und für das Mecp2 $2^{T /-,+/ y}$-Modell ein nicht signifikanter $(p=0,26)$ Abfall um $16 \%$. Vgl. Abb. 3.11A.

Dem gegenüber stellten sich für S/c6a4 im postnatalen Entwicklungsstadium P40 bei $\mathrm{WT}_{\text {KO }} \mathrm{P} 40$ Zahlenwerte von 1,33 $\pm 0,14$ und bei KO P40 von 2,77 $\pm 0,42$ dar, sowie eine daraus resultierende signifikante $(p=0,00028)$ Steigerung um $108 \%$. Werte von 0,73 $\pm 0,08$ wurden bei $\mathrm{WT}_{\mathrm{T}} \mathrm{P} 40$ und 1,16 $\pm 0,04$ bei T P40 gemessen. Der Anstieg lag hier bei nicht signifikanten $(p=0,08) 59 \%$. Vgl. Abb. 3.11B.
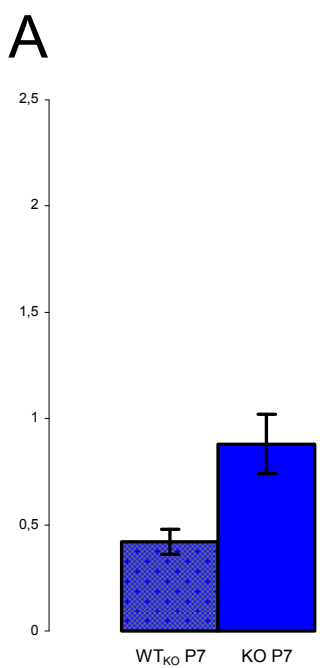
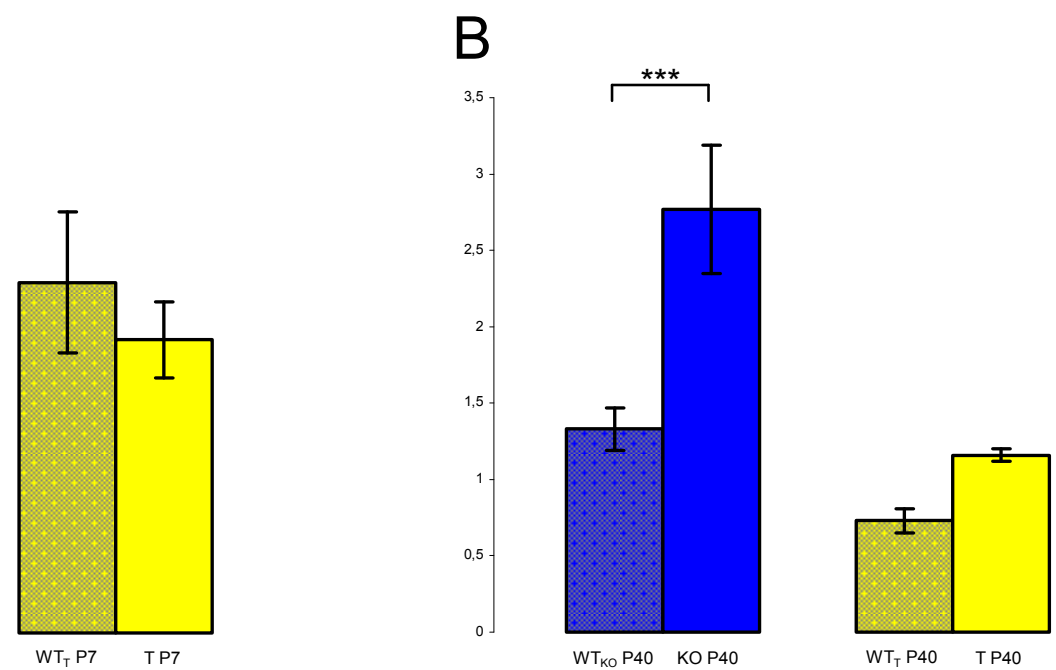

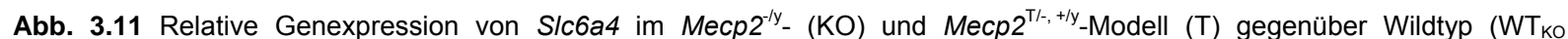
beziehungsweise $\mathrm{WT}_{\mathrm{T}}$ ) in den postnatalen Entwicklungsstadien P7 und P40. (A) Relative Genexpression von S/c6a4 im postnatalen Entwicklungsstadium P7; Mittelwert \pm Standardabweichung für $\mathrm{WT}_{\mathrm{KO}} \mathrm{P} 70,42 \pm 0,06, \mathrm{KO} P 7 \quad 0,88 \pm 0,14, \mathrm{WT}_{\mathrm{T}} \mathrm{P7}$ $1,65 \pm 0,33$, T P7 1,38 \pm 0,18. (B) Relative Genexpression von S/c6a4 im postnatalen Entwicklungsstadium P40; Mittelwert \pm Standardabweichung für $\mathrm{WT}_{\mathrm{KO}} \mathrm{P} 401,33 \pm 0,14, \mathrm{KO} P 402,77 \pm 0,42, \mathrm{WT}_{\mathrm{T}} \mathrm{P} 40$ 0,73 $\pm 0,08, \mathrm{~T} P 401,16 \pm 0,04$.

Abkürzungen: ${ }^{* * *}: p<0,001$, Mecp2: Methyl-Cytosin-phosphatidyl-Guanin-Bindungsprotein 2, P7: postnatal 7 Tage alt, P40: postnatal 40 Tage alt, S/c6a4: solute carrier family 6 member $4 ; n=3$ in jeder der acht Gruppen. Quelle: Eigene Entwicklung 
Die relative Htr4-Expression - 5-Hydroxytryptamin (Serotonin) Rezeptor 4 - für die frühe postnatale Entwicklungsphase $P 7$ lag für $W_{K O} P 7$ bei $0,97 \pm 0,12$ und für KO P7 bei 2,37 $\pm 0,58$. Daraus folgte eine signifikante $(p=0,002)$ Erhöhung um $144 \%$. Für $\mathrm{WT}_{\mathrm{T}} \mathrm{P} 7$ lagen die Werte bei 1,79 $\pm 0,33$ und für $\mathrm{T} P 7$ bei 0,62 $\pm 0,02$. Hier zeigte sich ein signifikantes $(p=0,00025)$ Absinken der Werte um $66 \%$. Vgl. Abb. 3.12A.

Expressionsergebnisse bezüglich des Htr4-Gen beliefen sich in der späten postnatalen Entwicklungsphase $\mathrm{P} 40$ auf $0,86 \pm 0,14$ bei $\mathrm{WT}_{\mathrm{KO}} \mathrm{P} 40,0,85 \pm 0,14$ bei KO P40, 0,76 $\pm 0,07$ bei $\mathrm{WT}_{\mathrm{T}} \mathrm{P} 40$ sowie auf $0,79 \pm 0,11$ bei T P40. Errechnet wurden damit nicht signifikant $(p=1)$ um $4 \%$ geringer liegende Expressionswerte von KO auf $\mathrm{WT}_{\text {KO }}$ sowie nicht signifikant $(p=0,82)$ um $4 \%$ höher liegende von T gegenüber $\mathrm{WT}_{\mathrm{T}}$. Vgl. Abb. 3.12B.

A

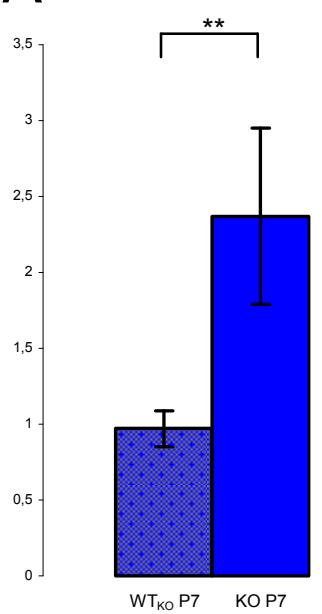

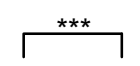

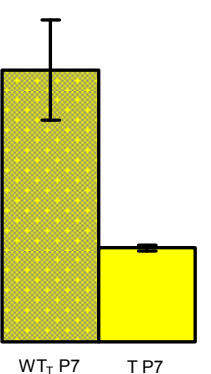

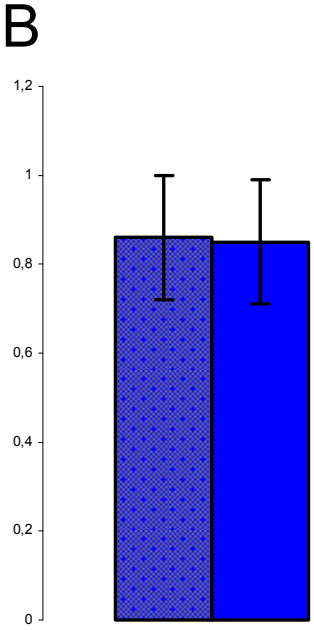

$W T_{\text {KO }} \mathrm{P} 40 \quad$ KO P40

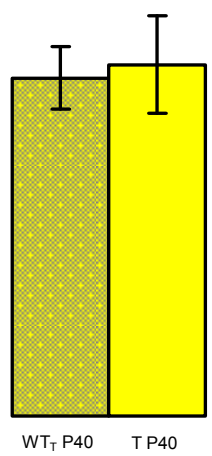

Abb. 3.12 Relative Genexpression von Htr4 im Mecp2 $2^{-/ y}$ (KO) und Mecp2 $2^{T /-,+/ y}$-Modell (T) gegenüber Wildtyp (WTKO beziehungsweise $\mathrm{WT}_{\mathrm{T}}$ ) in den postnatalen Entwicklungsstadien P7 und P40. (A) Relative Genexpression von Htr4 im postnatalen Entwicklungsstadium P7; Mittelwert \pm Standardabweichung für $\mathrm{WT}_{\mathrm{KO}} \mathrm{P} 70,97 \pm 0,12, \mathrm{KO} \mathrm{P7} 2,37 \pm 0,58, \mathrm{WT}$, P7 $1,79 \pm 0,33$, T P7 0,62 \pm 0,02. (B) Relative Genexpression von Htr4 im postnatalen Entwicklungsstadium P40; Mittelwert \pm Standardabweichung für $\mathrm{WT}_{\mathrm{KO}} \mathrm{P} 40$ 0,86 \pm 0,14, KO P40 0,85 $\pm 0,14, \mathrm{WT}_{\mathrm{T}} \mathrm{P} 40$ 0,76 \pm 0,07, T P40 0,79 \pm 0,11.

Abkürzungen: ${ }^{* *}: p<0,01,{ }^{* * *}: p<0,001$, Mecp2: Methyl-Cytosin-phosphatidyl-Guanin-Bindungsprotein 2, P7: postnatal 7 Tage alt, P40: postnatal 40 Tage alt, Htr4: 5 Hydroxytryptamin (Serotonin) Rezeptor 4; $n=3$ in jeder der acht Gruppen. Quelle: Eigene Entwicklung 
Bei Htr5b - 5-Hydroxytryptamin (Serotonin) Rezeptor 5B - lagen die relativen Expressionen in der Altersgruppe $\mathrm{P} 7$ für $\mathrm{WT}_{\mathrm{KO}} \mathrm{P} 7$ bei $0,41 \pm 0,06$ und für $\mathrm{KO} \mathrm{P} 7$ bei $1,06 \pm 0,29$. Daraus ergab sich eine signifikante $(p=0,002)$ Erhöhung um $159 \%$. Für $\mathrm{WT}_{\mathrm{T}} \mathrm{P} 7$ wurden $0,77 \pm 0,07$ und für T P7 wurden 0,64 $\pm 0,07$ gemessen, so dass sich eine nicht signifikante ( $p=0,11)$ Minderung um $16 \%$ ermittelte. Vgl. Abb. 3.13A. Die Daten in der Altersgruppe P40 für Htr5b wurden für $\mathrm{WT}_{\text {KO }} \mathrm{P} 40$ mit 0,32 $\pm 0,08$ und für KO P40 mit 4,12 $\pm 0,05$ bestimmt. Somit belieft sich die signifikante $(p=0)$ Erhöhung auf $1188 \%$ innerhalb des Mecp2 ${ }^{-/ y}$-Modells. Für WTT P40 ließen sich Zahlenwerte von 1,48 $\pm 0,09$ und für T P40 von 1,1 \pm 0,1 messen und daraus eine signifikante $(p=0,002)$ Reduktion von T gegenüber $\mathrm{WT}_{\mathrm{T}}$ um $26 \%$ errechnen. Vgl. Abb. 3.13B.

A

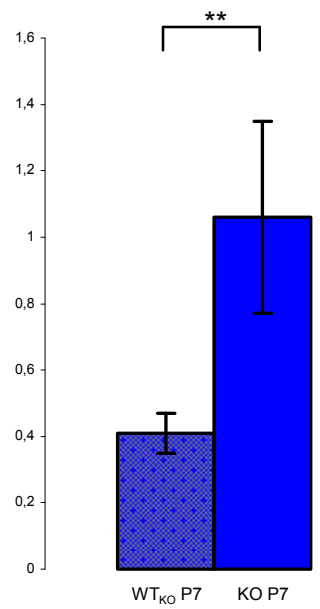

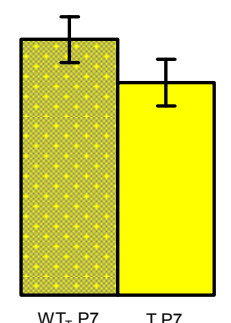

B

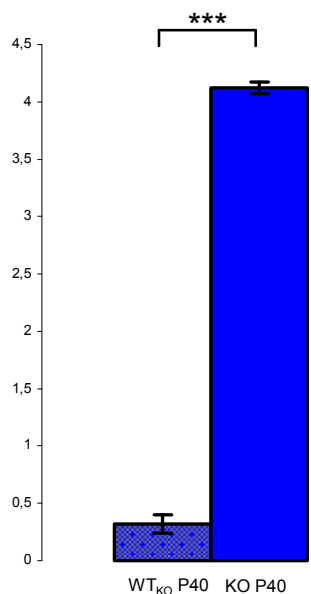

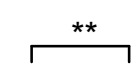

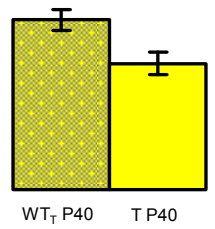

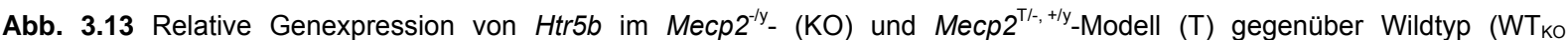
beziehungsweise $\mathrm{WT}_{\mathrm{T}}$ ) in den postnatalen Entwicklungsstadien P7 und P40. (A) Relative Genexpression von Htr5b im postnatalen Entwicklungsstadium $\mathrm{P} 7$; Mittelwert \pm Standardabweichung für $\mathrm{WT}_{\mathrm{KO}} \mathrm{P} 70,41 \pm 0,06, \mathrm{KO} \mathrm{P} 71,06 \pm 0,29, \mathrm{WT} \mathrm{P}_{\mathrm{T}} \mathrm{P}$ $0,77 \pm 0,07$, T P7 0,64 $\pm 0,07$. (B) Relative Genexpression von Htr5b im postnatalen Entwicklungsstadium P40; Mittelwert \pm Standardabweichung für WT $\mathrm{WO}_{\mathrm{K}} \mathrm{P} 40$ 0,32 \pm 0,08, KO P40 4,12 \pm 0,05, $\mathrm{WT}_{\mathrm{T}} \mathrm{P} 401,48 \pm 0,09, \mathrm{~T}$ P40 1,1 \pm 0,1.

Abkürzungen: ${ }^{* *}: p<0,01,{ }^{* * *}: p<0,001$, Mecp2: Methyl-Cytosin-phosphatidyl-Guanin-Bindungsprotein 2, P7: postnatal 7 Tage alt, P40: postnatal 40 Tage alt, Htr5b: 5 Hydroxytryptamin (Serotonin) Rezeptor 5B; $n=3$ in jeder der acht Gruppen. Quelle: Eigene Entwicklung 


\subsubsection{Das dopaminerge und opioiderge Transmittersystem}

Die zwei Gene Drd4 - Dopaminrezeptor D4 - und Oprm1 - $\mu$-Opioidrezeptor 1 stellen Vertreter des dopaminergen und opioidergen Systems dar.

Das Drd4-Gen im postnatalen Entwicklungsstadium P7 zeigte relative Expressionsergebnisse von 2,05 \pm 0,11 für $\mathrm{WT}_{\mathrm{KO}} \mathrm{P} 7,1,51 \pm 0,15$ für KO P7, 0,97 $\pm 0,05$ für $\mathrm{WT}_{\mathrm{T}} \mathrm{P} 7$ sowie 1,15 $\pm 0,1$ für T P7. Für das Mecp2-/y - Modell ergab sich eine signifikante $(p=0,0002)$ Abnahme von $\mathrm{WT}_{\mathrm{KO}}$ auf $\mathrm{KO}$ um $26 \%$ und für das transgene Modell eine nicht signifikante $(p=0,94)$ Zunahme von $19 \%$. Vgl. Abb. $3.14 \mathrm{~A}$.

Messdaten für Drd4 im postnatalen Entwicklungsstadium P40 beliefen sich bei $W_{\text {KO }} P 40$ auf 0,39 , bei KO P40 auf $0,1 \pm 0,01$, bei $W T_{T} P 40$ auf $1,02 \pm 0,18$ und bei T P40 auf 1,03 $\pm 0,19$. Somit lagen die Werte von KO gegenüber $\mathrm{WT}_{\mathrm{KO}}$ signifikant ( $p=0,005)$ um $74 \%$ niedriger und von T gegenüber $\mathrm{WT}_{\mathrm{T}}$ nicht signifikant $(p=1)$ um $1 \%$ höher. Vgl. Abb. 3.14B.

A

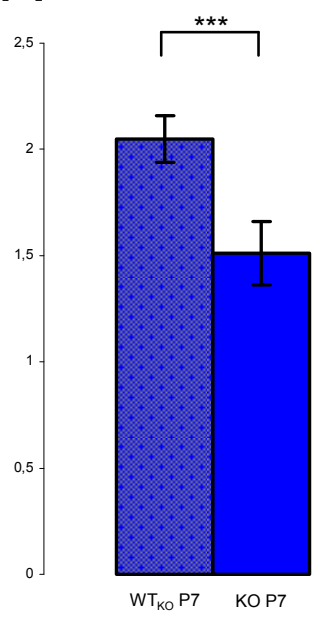

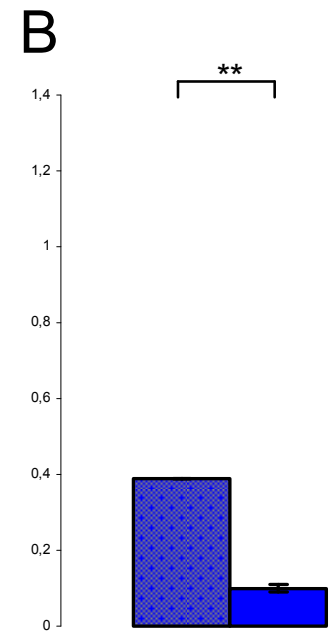

$\mathrm{WT}_{\mathrm{KO}} \mathrm{P} 40 \quad \mathrm{KOP} 40$

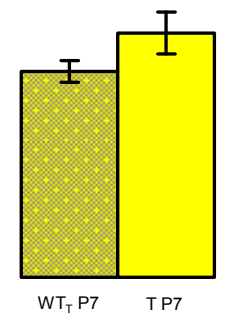

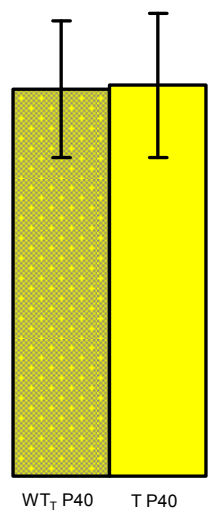

Abb. 3.14 Relative Genexpression von Drd4 im Mecp2 $2^{-/ y}$ (KO) und Mecp2 $2^{T /-,+/ y}$-Modell (T) gegenüber Wildtyp (WTKO beziehungsweise $\mathrm{WT}_{\mathrm{T}}$ ) in den postnatalen Entwicklungsstadien P7 und P40. (A) Relative Genexpression von Drd4 im postnatalen Entwicklungsstadium P7; Mittelwert \pm Standardabweichung für $\mathrm{WT}_{\mathrm{KO}} \mathrm{P} 72,05 \pm 0,11, \mathrm{KO}$ P7 1,51 $\pm 0,15$, WT $\mathrm{P} 7$ $0,97 \pm 0,05$, T P7 1,15 $\pm 0,1$. (B) Relative Genexpression von Drd4 im postnatalen Entwicklungsstadium P40; Mittelwert \pm

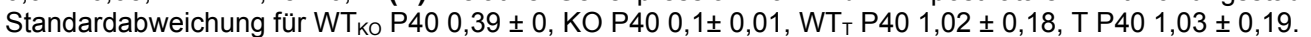

Abkürzungen: **: $p<0,01,{ }^{* * *}: p<0,001$, Mecp2: Methyl-Cytosin-phosphatidyl-Guanin-Bindungsprotein 2, P7: postnatal 7 Tage alt, P40: postnatal 40 Tage alt, Drd4: Dopamin-Rezeptor 4; $\mathrm{n}=3$ in jeder der acht Gruppen. Quelle: Eigene Entwicklung 
Im postnatalen Entwicklungsstadium $\mathrm{P} 7$ lag die Expression für Oprm1 für $\mathrm{WT}_{\mathrm{KO}} \mathrm{P} 7$ bei 0,66 $\pm 0,04$ und für KO P7 bei 0,65 $\pm 0,2$. Daraus folgte eine nicht signifikante $(p=0,9)$ Verringerung um $2 \%$. Für $W_{T} P 7$ lagen die Werte bei 0,85 0,02 und für T P7 bei $0,86 \pm 0,04$. Hier zeigte sich ein nicht signifikanter $(p=0,98)$ Anstieg von $1 \%$. Vgl. Abb. 3.15A.

Die Oprm1-Ergebnisse im späteren Entwicklungsstadium $\mathrm{P} 40$ beliefen sich bei $\mathrm{WT}_{\text {KO }} \mathrm{P} 40$ auf $1,54 \pm 0,17$ und bei KO P40 auf 0,77 $\pm 0,05$. Somit errechnete sich eine signifikante $(p=0,009)$ Abnahme innerhalb des Mecp2-ly -Modells um $50 \%$. Zudem zeigten sich bei $\mathrm{WT}_{\mathrm{T}} \mathrm{P} 40$ Zahlenwerte von 1,1 $\pm 0,23$ sowie bei T P40 von $1,85 \pm 0,15$. Hieraus ermittelte sich eine signifikante $(p=0,0007)$ Zunahme von $\mathrm{WT}_{\mathrm{T}}$ auf T um $68 \%$. Vgl. Abb. 3.15B.

A

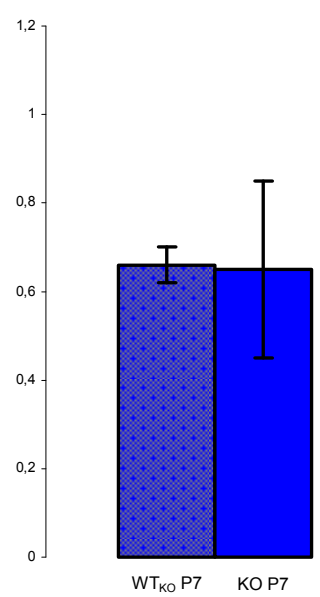

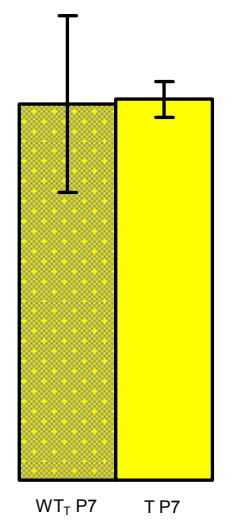

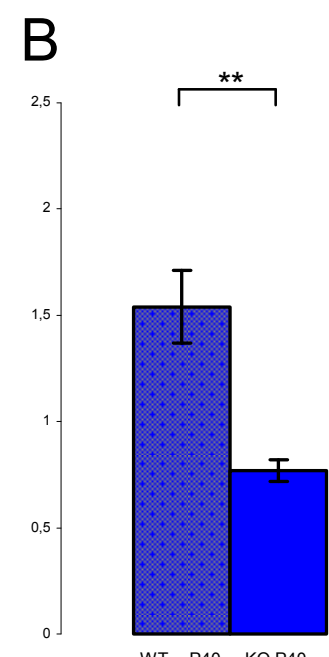

$W T_{K O} P 40 \quad K O P 40$

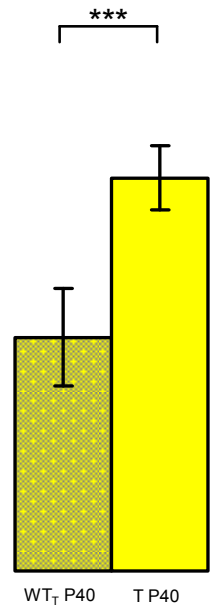

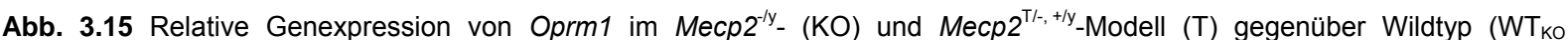
beziehungsweise $\mathrm{WT}_{\mathrm{T}}$ ) in den postnatalen Entwicklungsstadien P7 und P40. (A) Relative Genexpression von Oprm1 im postnatalen Entwicklungsstadium P7; Mittelwert \pm Standardabweichung für $\mathrm{WT}_{\mathrm{KO}} \mathrm{P} 70,66 \pm 0,04, \mathrm{KO} P 7 \quad 0,65 \pm 0,2, \mathrm{WT}_{\mathrm{T}} \mathrm{P7}$ $0,85 \pm 0,02$, T P7 0,86 $\pm 0,04$. (B) Relative Genexpression von Oprm1 im postnatalen Entwicklungsstadium P40; Mittelwert \pm Standardabweichung für WT $\mathrm{WO}_{\mathrm{O}} \mathrm{P} 401,54 \pm 0,17, \mathrm{KO}$ P40 0,77 $\pm 0,05$, WT $\mathrm{P} 40$ 1,1 $\pm 0,23$, T P40 1,85 $\pm 0,15$.

Abkürzungen: ${ }^{* *}: p<0,01,{ }^{* * *}: p<0,001$, Mecp2: Methyl-Cytosin-phosphatidyl-Guanin-Bindungsprotein 2, P7: postnatal 7 Tage alt, P40: postnatal 40 Tage alt, Oprm1: $\mu$-Opioid-Rezeptor 1; $n=3$ in jeder der acht Gruppen. Quelle: Eigene Entwicklung 


\subsubsection{Vokalisation}

Bei Foxp2 - „forkhead box P2“ - lagen die Genexpressionen für WTKO P7 bei $1,1 \pm 0,17$ und für KO P7 bei 1,24 $\pm 0,23$. Dadurch zeigte sich eine nicht signifikante $(p=0,21)$ Zunahme um $13 \%$. Für $\mathrm{WT}_{\mathrm{T}} \mathrm{P} 7$ wurden $1,95 \pm 0,2$ und für $\mathrm{T} P 7$ $1,11 \pm 0,02$ gemessen, so dass sich eine signifikante $\left(p=4 \times 10^{-5}\right)$ Abnahme um $43 \%$ bestimmen ließ. Vgl. Abb. 3.16A.

Relative Expressionsergebnisse in der postnatalen Entwicklungsphase P40 ergaben für Foxp2 folgende Zahlenwerte: $\mathrm{WT}_{\mathrm{KO}} \mathrm{P} 40$ 0,22 \pm 0,01, KO P40 0,56 \pm 0,07, $\mathrm{WT}_{\mathrm{T}} \mathrm{P} 40$ 0,68 $\pm 0,02, \mathrm{~T} P 40 \quad 0,46 \pm 0,07$. Daraus errechnete sich eine signifikante $\left(p=5,2 \times 10^{-5}\right)$ Zunahme im Mecp2 ${ }^{-/ y}$-Modell von $\mathrm{WT}_{\mathrm{KO}}$ auf KO um $155 \%$ und im Mecp $2^{T /-,+/ y}$-Modell eine signifikante $(p=0,04)$ Abnahme um 32 \%. Vgl. Abb. 3.16B.
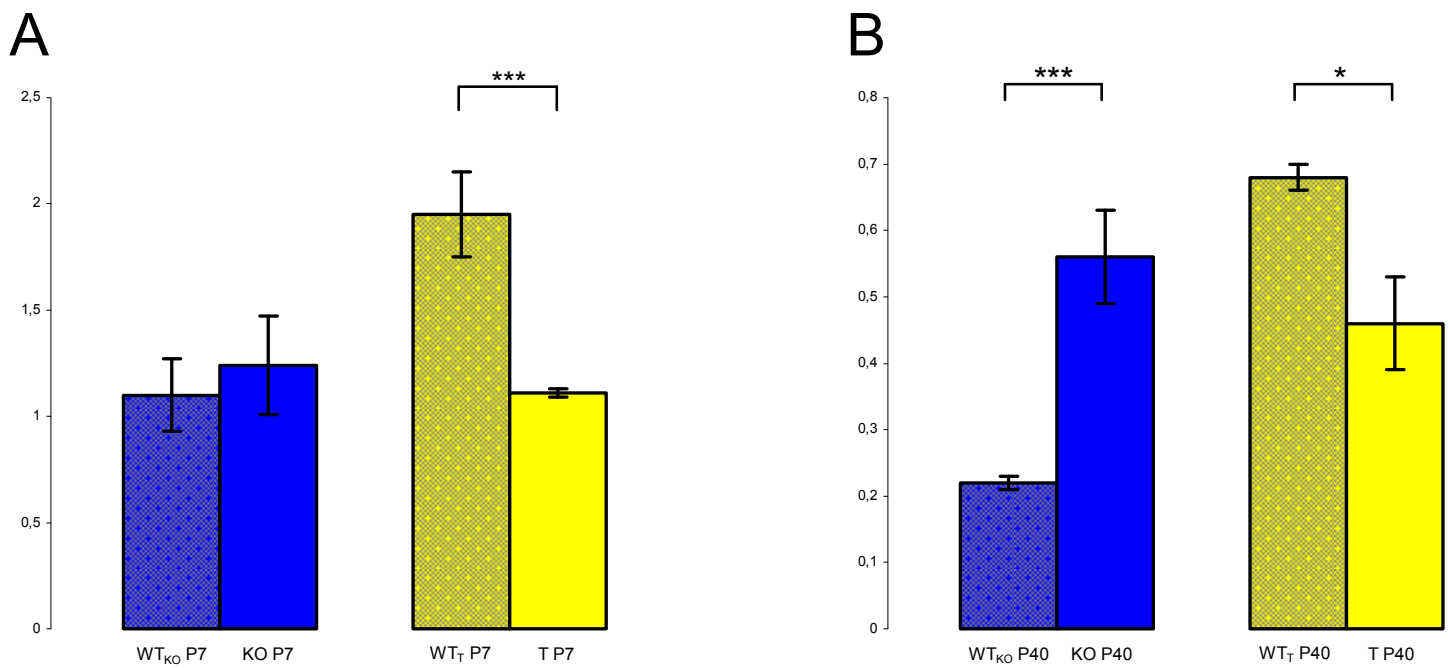

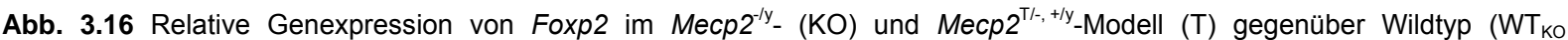
beziehungsweise $\mathrm{WT}_{\mathrm{T}}$ ) in den postnatalen Entwicklungsstadien P7 und P40. (A) Relative Genexpression von Foxp2 im

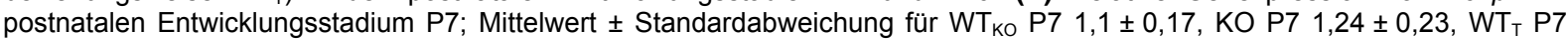
$1,95 \pm 0,2$, T P7 1,11 $\pm 0,02$. (B) Relative Genexpression von Foxp2 im postnatalen Entwicklungsstadium P40; Mittelwert \pm Standardabweichung für $\mathrm{WT}_{\text {KO }} \mathrm{P} 40$ 0,22 \pm 0,01, KO P40 0,56 \pm 0,07, WT T P40 0,68 \pm 0,02, T P40 0,46 \pm 0,07.

Abkürzungen: ${ }^{*}: p<0,05,{ }^{* * *}: p<0,001$, Mecp2: Methyl-Cytosin-phosphatidyl-Guanin-Bindungsprotein 2, P7: postnatal 7 Tage alt, P40: postnatal 40 Tage alt, Foxp2: forkhead box P2; $\mathrm{n}=3$ in jeder der acht Gruppen. Quelle: Eigene Entwicklung 


\subsubsection{Relative Genexpressionen von Gliazellmarkern}

Im frühen postnatalen Entwicklungsstadium P7 beliefen sich für das Gen des Gliazellmarkers GFAP - „glial fibrillary acidic protein“ - die relativen Expressionswerte für $\mathrm{WT}_{\mathrm{KO}} \mathrm{P7}$ auf $1,5 \pm 0,17$ und für KO P7 auf 1,53 $\pm 0,13$. Daraus resultierte eine nicht signifikante $(p=1)$ Steigerung von $2 \%$. Im Mecp $2^{T /-,+/ y}-$ Modell wurde eine Expression von 1,18 $\pm 0,03$ für $\mathrm{WT}_{\mathrm{T}}$ und von 1,17 $\pm 0,12$ für $\mathrm{T}$ und damit ein nicht signifikantes ( $p=0,93)$ Absinken von $1 \%$ gemessen. Vgl. Abb. 3.17A.

Im Mecp2-/y -Modell zeigten sich für $\mathrm{WT}_{\mathrm{KO}}$ im Altersstadium P40 1,44 \pm 0,18 sowie für KO P40 2,31 \pm 0,19. Bei $W T_{T} P 40$ ergab sich 0,69 $\pm 0,04$ sowie für T P40 0,88 $\pm 0,09$ als relative Expression für Gfap. Damit lagen die Werte innerhalb des Mecp $2^{-/ y}$-Modells signifikant $(p=0,0014)$ um $60 \%$ und innerhalb des $M e c p 2^{T /-,+/ y_{-}}$ Modells signifikant $(p=0,03)$ um $28 \%$ höher. Vgl. Abb. 3.17B.

A

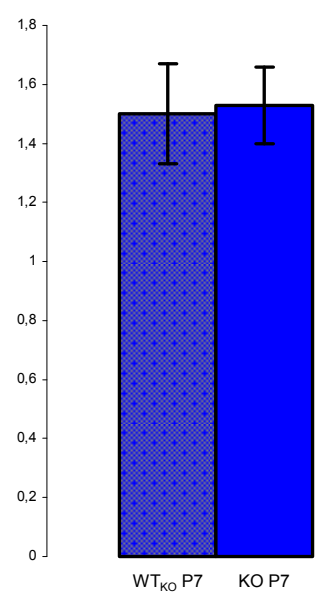

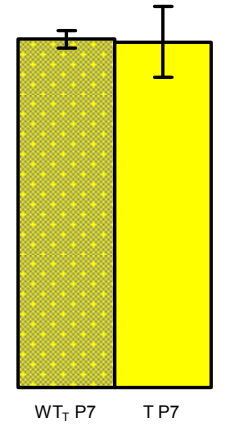

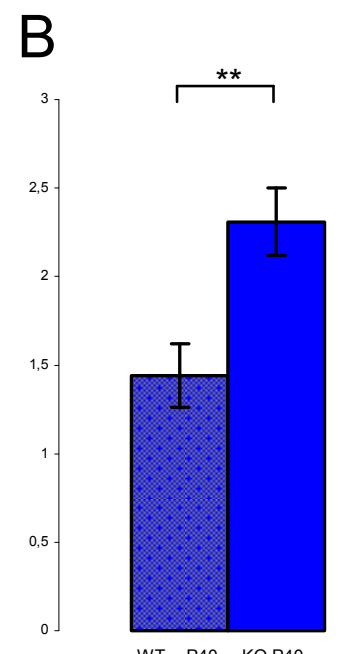

$W T_{K O} P 40 \quad K O P 40$

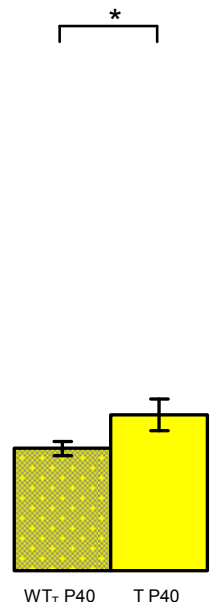

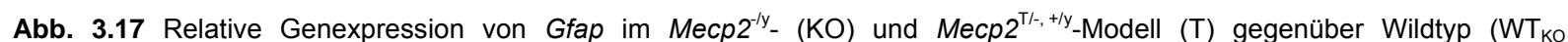
beziehungsweise $\mathrm{WT}_{\mathrm{T}}$ ) in den postnatalen Entwicklungsstadien P7 und P40. (A) Relative Genexpression von Gfap im postnatalen Entwicklungsstadium P7; Mittelwert \pm Standardabweichung für $\mathrm{WT}_{\mathrm{KO}} \mathrm{P} 7 \mathrm{1,5} \pm 0,17, \mathrm{KO} \mathrm{P} 71,53 \pm 0,13, \mathrm{WT} \mathrm{T}_{\mathrm{T}} \mathrm{P} 7$ $1,18 \pm 0,03$, T P7 1,17 $\pm 0,12$. (B) Relative Genexpression von Gfap im postnatalen Entwicklungsstadium P40; Mittelwert \pm Standardabweichung für $\mathrm{WT}_{\text {KO }} \mathrm{P} 401,44 \pm 0,18$, KO P40 2,31 \pm 0,19, WT $\mathrm{T}$ P40 0,69 \pm 0,04, T P40 0,88 $\pm 0,09$.

Abkürzungen: *: $p<0,05,{ }^{* *}: p<0,01$, Mecp2: Methyl-Cytosin-phosphatidyl-Guanin-Bindungsprotein 2, P7: postnatal 7 Tage alt, P40: postnatal 40 Tage alt, Gfap: glial fibrillary acidic protein; $n=3$ in jeder der acht Gruppen. Quelle: Eigene Entwicklung 
Für das Gen S100b - „calcium binding protein beta“ - ergaben sich im frühen

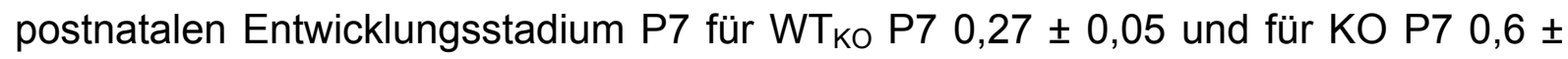

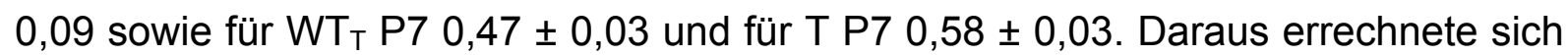
eine signifikante $(p=0,01)$ Erhöhung innerhalb des Mecp2-ly-Modells von $\mathrm{WT}_{\mathrm{KO}}$ auf KO um $122 \%$ und im transgenen Modell eine nicht signifikante $(p=0,15)$ um $23 \%$. Vgl. Abb. 3.18A.

Expressionsergebnisse bezüglich des S100b-Gen in der späteren Entwicklungsphase P40 beliefen sich im Mecp2 ${ }^{-/ y}$-Modell auf 1,79 $\pm 0,17$ bei WTKO P40 und $3,01 \pm 0,14$ bei KO P40 sowie im transgenen Modell auf $1,5 \pm 0,07$ bei WT $P 40$ und auf $1,44 \pm 0,1$ bei $T$ P40. Errechnet wurden somit ein signifikantes $\left(p=10^{-5}\right)$ Ansteigen um $68 \%$ innerhalb des Mecp $^{-1 / y}$-Modells und ein nicht signifikantes $(p=0,25)$ Abfallen um $4 \%$ im transgenen Modell. Vgl. Abb. 3.18B.

A

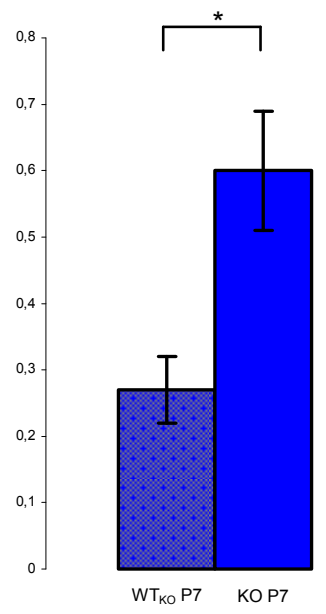

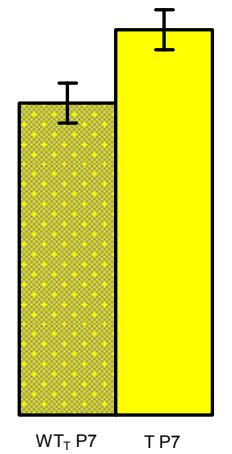

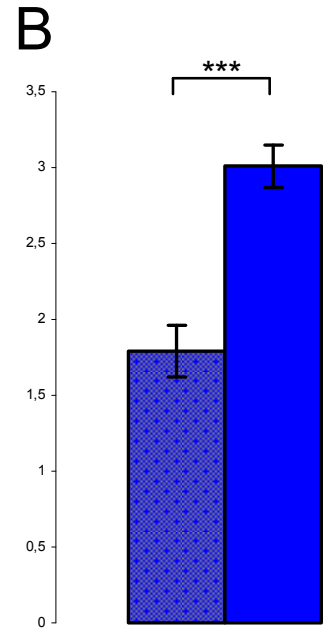

$W T_{K O} P 40 \quad K O P 40$

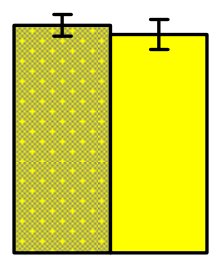

$W_{T}$ P40 TP40

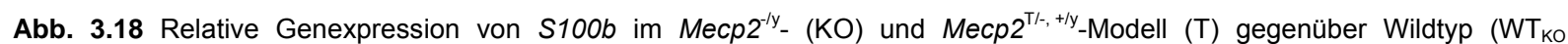
beziehungsweise $\mathrm{WT}_{\mathrm{T}}$ ) in den postnatalen Entwicklungsstadien P7 und P40. (A) Relative Genexpression von S100b im postnatalen Entwicklungsstadium P7; Mittelwert \pm Standardabweichung für $\mathrm{WT}_{\mathrm{KO}} \mathrm{P7}$ 0,27 $\pm 0,05, \mathrm{KO} P 7 \quad 0,6 \pm 0,09, \mathrm{WT}_{\mathrm{T}} \mathrm{P7}$ $0,47 \pm 0,03$, T P7 0,58 $\pm 0,03$. (B) Relative Genexpression von S100b im postnatalen Entwicklungsstadium P40; Mittelwert \pm Standardabweichung für WT $\mathrm{WO}_{\mathrm{O}} \mathrm{P} 401,79 \pm 0,17$, KO P40 3,01 $\pm 0,14, \mathrm{WT}_{\mathrm{T}} \mathrm{P} 40$ 1,5 $\pm 0,07, \mathrm{~T}$ P40 1,44 $\pm 0,1$.

Abkürzungen: *: $p<0,05,{ }^{* * *}$ : $p<0,001$, Mecp2: Methyl-Cytosin-phosphatidyl-Guanin-Bindungsprotein 2, P7: postnatal 7 Tage alt, P40: postnatal 40 Tage alt, S100b: $\mathrm{S} 100$ calcium binding protein beta; $\mathrm{n}=3$ in jeder der acht Gruppen. Quelle: Eigene Entwicklung 


\section{Diskussion}

Die vorliegende Dissertation soll der Aufdeckung von Beeinflussungen der Genregulation bei Fehlen beziehungsweise Überexpression des Transkriptionsfaktors MeCP2 (Methyl-CpG-Bindungsprotein 2) im respiratorischen Netzwerk dienen. Aufgeklärt werden soll, ob Gene, von der hier getroffenen Auswahl, aktivierend oder supprimierend reguliert sind, wenn mehr (transgenes Mausmodell) oder gar kein MeCP2 (Knockout-Modell) auf die Gentranskription Einfluss nimmt.

MeCP2 bindet an symmetrisch methylierte CpG-Inseln eines Gens, wodurch eine Strukturveränderung des Chromatins erfolgt und die Gentranskription supprimiert wird. Zudem wirkt MeCP2 aber auch als Aktivator der Transkription (Chahrour et al. 2008). Bisher gelten Bdnf und D/x5 als Zielgene von MeCP2.

Im Folgenden werden die Ergebnisse der Real-time-PCR kritisch diskutiert und in mögliche kausale Zusammenhänge gebracht. Vorab sollte noch Erwähnung finden, dass es leider nicht möglich war für beide Mausmodelle ein und denselben Wildtypstamm als Korrespondenz zu verwenden. Wäre dies der Fall gewesen, könnten Unterschiede in den Wildtyplinien verglichen und diskutiert werden. In der vorliegenden Arbeit ist es nun aufgrund der verschiedenen Mauslinien nicht möglich die Daten der Wildtypstämme untereinander zu vergleichen. Unterschiede der Genexpression innerhalb der Wildtyp-Mausstämme, die sich durchaus eindrucksvoll zeigen, können daher nicht ohne weiteres erklärt werden und sollten gesondert weitergehend untersucht werden. Die Auswertung der folgenden Ergebnisse beschränkt sich daher nur auf den direkten Vergleich zwischen dem Mecp2-Modell und dem korrespondierenden Wildtyp.

\subsection{Wirkungen von MeCP2 in transgenen und Knockout-Mausmodellen}

Mittels Real-time-PCR (quantitative Polymerasekettenreaktion) konnte im $M e c p 2^{T /-,+/ y}$-Modell gezeigt werden, dass auf RNA-Ebene vermehrt Mecp2 exprimiert wird. Dem gegenüber zeigte die Verifikation des $M e c p 2^{-/ y}$-Modells bezüglich der Transkription (RNA-Ebene) keine Expression. Dies zeigte sich sowohl im frühen Entwicklungsstadium P7 also auch im späteren P40, so dass davon ausgegangen werden kann, dass im Mecp $2^{T /,+/ / y}$-Modell die Überexpression beziehungsweise im 
Mecp2 $^{-/ y}$-Modell des Fehlen von MeCP2 auf beide Entwicklungsstadien Einfluss nimmt.

Aufgrund der unterschiedlichen Wildtypstämme der Mausmodelle können die Wildtypstämme untereinander nicht verglichen werden. Trotzdem fällt auf, dass im korrespondierenden Wildtyp des Mecp2-1/y -Modells eine erhöhte Expression von P7 auf P40 und im korrespondierenden Wildtyp des Mecp $2^{T /,++/ y}$-Modells eine geringere Mecp2-Expression von P7 auf P40 gemessen wurde und dass sich die Expressionen sowohl im Altersstadium P7 als auch P40 zwischen den beiden Wildtypstämmen stark unterscheiden. Dieses überraschende Ergebnis der inkongruenten Mecp2Expressionen in den unterschiedlichen Mausstämmen bedarf weiterer intensiver Analysen zur statistischen Absicherung.

Es ist bekannt, dass sowohl ein Funktionsverlust des Mecp2-Gens (Amir et al. 1999, Wan et al. 1999) - hier imitiert durch das Mecp2 $2^{-/ y}$-Modell - als auch eine Duplikation desselben (Collins et al. 2004, Van Esch et al. 2005) - entsprechend dem Mecp2 $2^{T /-,+/ y}-$ Modell - einen Phänotyp des Rett-Syndroms beziehungsweise einen Phänotyp, der Ähnlichkeiten mit dem Rett-Syndrom aufweißt, bedingen können. Bei gegenläufiger Genexpression zwischen transgenem Modell und Knockout-Modell zeigen sich Evidenzen für eine direkte Regulation des untersuchten Gens durch MeCP2. Ein gleichsinniges Expressionsmuster der beiden Mecp2-Modelle könnte eine indirekte Regulation durch den Transkriptionsfaktor vermuten lassen.

Aus der Literatur ist bekannt, dass bei einer vermehrten Expression des Transkriptionsfaktors MeCP2 in Mäusen unter anderem folgende Veränderungen vorliegen:

- verstärktes motorisches und zusammenhängendes Lernen,

- eine erhöhte Plastizität im Hippocampus,

- vermehrte Krampfanfälle,

- Hypoaktivität,

- $\quad$ eine 30 \%ige Letalität (Collins et al. 2004) und

- eine Verstärkung der synaptischen Antwort in glutamatergen Neuronen des Hippocampus durch Hoch-Regulierung der Synapsenanzahl (Chao et al. 2007). 
In Mecp2 ${ }^{-/ y}$-Modellen konnten folgende Beobachtungen gemacht werden:

- durch supprimierende Regulierung der Synapsenanzahl in hippokampalen glutamatergen Neuronen eine Abschwächung der synaptischen Antwort (Chao et al. 2007) sowie

- einen reduzierten Serotoninspiegel (Viemari et al. 2005, Isoda et al. 2009),

- eine verminderte Anzahl an Tyrosin-Hydroxylase-exprimierenden Neuronen (Viemari et al. 2005, Roux et al. 2009) und

- ein geringerer Noradrenalin-Gehalt in der Medulla oblongata (Viemari et al. 2005, Roux et al. 2009),

- ein normales Atemmuster postnatal mit anschließenden unregelmäßigen Atemrhythmen bis hin zu letalen Atemstillständen mit der Hypothese, dass diese Atemstörungen durch einen Mangel in der noradrenergen und serotonergen Modulation des respiratorischen Netzwerks in der Medulla oblongata hervorgerufen werden könnten (Viemari et al. 2005),

- veränderte postinspiratorische Aktivitäten, die Atemdysfunktionen hervorrufen (Stettner et al. 2007). Insbesondere zeigten sich prolongierte Apnoephasen mit einer erhöhten postinspiratorischen Aktivität nach Glutamat-induzierter Aktivierung des pontinen Nucleus Kölliker-Fuse sowie prolongierte Apnoephasen und ein Verlust der Reflex-Desensitivierung als Antwort auf repetitive vagale Stimulationen. Diese respiratorischen Störungen während der Postinspiration im Mecp2 $2^{-/ y}$-Modell ähneln denen bei Rett-Patienten und könnten die klinischen Probleme wie Apnoen, Sprechverlust und Koordinationsstörungen der Atmung und des Schluckens erklären (Stettner et al. 2007).

Laut Jellinger (2003) finden sich bei Rett-Patienten durch neuropathologische Untersuchungen des Hirngewebes reduzierte Spiegel von:

- Dopamin (Ramaekers et al. 2003), Serotonin (Ramaekers et al. 2003), Noradrenalin (Viemari 2008), Glutamat (Horská et al. 2009),

- Endorphinen (Matsuishi et al. 2001),

- Cholin-Acetyltransferase (Ward et al. 2009) und

- neurotrophen Wachstumsfaktoren (Matsuishi et al. 2001). 
Hingegen finden sich bei sowohl erhöhten als auch bei erniedrigten MeCP2-Spiegeln bei Menschen:

- neonatale Enzephalopathien (Meins et al. 2005, Amir und Zoghbi 2000),

- entwicklungsneurologische Erkrankungen wie Formen von milder Lernschwäche bis hin zu Autismus (Meins et al. 2005, Moretti und Zoghbi 2006) und

- mentale Retardierung (Chahrour et al. 2008, Meins et al. 2005, Moretti und Zoghbi 2006).

Über die Validität der aufgeführten Ergebnisse der zahlreichen Arbeitsgruppen kann keine genaue Aussage getroffen werden, da das Studiendesign nicht immer eindeutig transparent erläutert wird. Aus diesem Grund wurden mehrere Studien unabhängiger Arbeitsgruppen berücksichtigt, die ähnliche Ergebnisse über den gleichen Sachverhalt unabhängig voneinander publizierten.

Aus den Aufzählungen ist zu entnehmen, dass MeCP2 auf viele verschiedene Bereiche Einfluss nimmt. Im Folgenden werden die untersuchten Gene auf einen solchen Einfluss diskutiert.

\subsection{Prä-Bötzinger-Komplex-Marker}

Durch Stettner et al. (2007) ist bekannt, dass der respiratorische Phänotyp (Apnoephasen, prolongierte Postinspiration, irregulärer Atemrhythmus) des Mecp2 ${ }^{-1 /}$ _ Mausmodells dem des Rett-Patienten sehr ähnelt. Dieser Phänotyp ist unter anderem gekennzeichnet durch Störungen des Atemrhythmus, die auch letal enden können (Lindberg und Rett 2000). Bei Überexpression von MeCP2 beim Menschen zeigt sich ebenfalls ein mit dem Rett-Syndrom ähnlicher Phänotyp (Van Esch et al. 2005). Für die Rhythmogenese des respiratorischen Netzwerks ist der Prä-BötzingerKomplex (preBotC) als Rhythmusgenerator von entscheidender Bedeutung (Smith et al. 1991). Als Marker hierfür gilt zum einen der Tachykininrezeptor 1, auch Neurokinin-1-Rezeptor (NK-1-R) genannt. Bei Zerstörung von NK-1-Rezeptortragenden Neuronen konnten Gray et al. (2001) ein pathologisches Atemmuster feststellen. Zudem zeigten Liu YY et al. (2001) und Stornetta et al. (2003), dass NK-1-Rezeptoren auf den meisten der kleinen und mittelgroßen Zellen sowie auf 
glutamatergen Interneuronen des preBotC exprimiert werden, worauf der NK-1-R zu einem preBotC-Marker etabliert wurde.

In der postnatalen Entwicklungsstufe P7 zeigte sich sowohl im Mecp2 $2^{-/ y}$ als auch im Mecp $2^{T /-,+/ y}$-Modell keine statistisch signifikante Veränderung der relativen Expression von Tacr1. Im späteren Entwicklungsstadium P40 zeigte sich eine signifikante Verminderung von $56 \%$ im Mecp2-ly-Modell, so dass hier eine Beeinflussung der Tacr1-Expression aufgrund des Fehlens des Transkriptionsfaktors MeCP2 nicht auszuschließen ist. Ein direkter Zusammenhang zwischen MeCP2 und dem NK-1-Rezeptorgen Tacr1 ist aufgrund des gezeigten Expressionsmusters innerhalb der untersuchten Entwicklungsstadien nicht zu vermuten. Guiard et al. (2007) zeigten, dass Injektionen von Substanz P, der Ligand des NK-1-Rezeptors, in die Raphekerne zu einer geringeren Serotoninausschüttung im Kortex und zu einer erhöhten Ausschüttung von Serotonin im dorsalen Raphekern führen. Ferner zeigten sie, dass die durch Substanz $P$ ausgelöste Überaktivität der 5-HT $1 \mathrm{~A}-$ Autorezeptoren im dorsalen Raphekern die kortikale Serotoninausschüttung limitiert. Hingegen führt die Gabe von SSRI (selektive Serotonin-Wiederaufnahmehemmer) wie auch die Blockade von NK-1-Rezeptoren zu einer Desensibilisierung der 5-HT 1 A-Autorezeptoren im dorsalen respiratorischen Netzwerk (Guiard et al. 2005). David et al. (2004) wiederum beschrieben bei NK-1-Rezeptor-defizienten Mäusen eine erhöhte kortikale Serotoninantwort bei Gabe eines SSRI (wie Paroxetin). Substanz P wie auch sein Rezeptor NK-1 stehen somit im direkten Zusammenhang mit dem Serotoninspiegel des Zentralnervensystems. Vgl. Abb. 4.1.

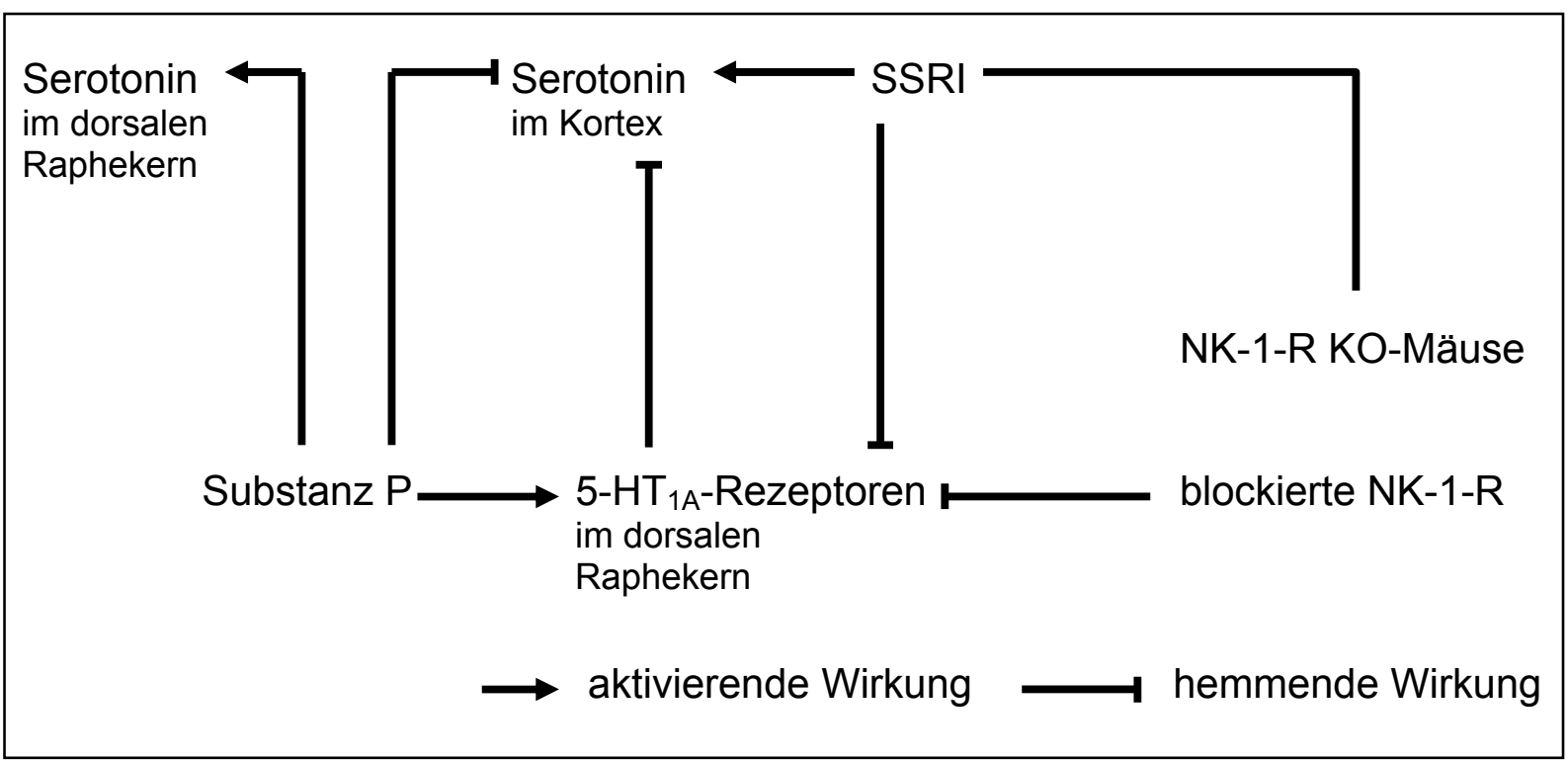

Abb. 4.1 Schematische Darstellung des direkten Zusammenhangs zwischen Substanz P, ihrem Rezeptor NK-1 und dem serotonergen System. Quelle: Eigene Entwicklung 
Wie Jellinger (2003) zeigte, liegen bei Rett-Patienten verminderte Serotoninspiegel vor. Ein Einfluss von MeCP2 auf den Serotoninspiegel durch eine Beeinflussung von Substanz $\mathrm{P}$ beziehungsweise dessen Rezeptor NK-1 wäre zwar somit denkbar, kann aber durch die hier gefunden Ergebnisse nicht eindeutig bestätigt werden.

Zum anderen diente als preBotC-Marker Somatostatin (Stornetta et al. 2003), das in besonders hohem Maße auf glutamatergen Interneuronen des preBotC mit NK-1Rezeptoren exprimiert wird. Als Neurotransmitter hat Somatostatin (Sst) mehrere regulatorische Aufgaben, wie zum Beispiel Hormon- und Neurotransmitterausschüttung und neuronale Feuerungsaktivität (Reisine 1995). Die Ergebnisse

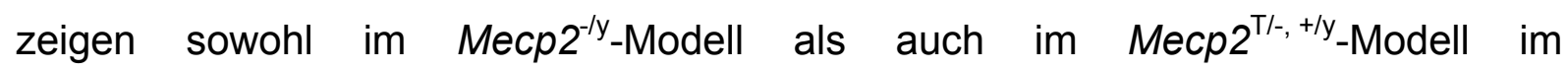
Entwicklungsstadium P7 eine Zunahme der relativen Somatostatinexpression, allerdings statistisch signifikant nur im Mecp2-ly-Modell. Dies schließt eine direkte Kontrolle von MeCP2 auf Sst nahezu aus. Ein eventuell indirekter Zusammenhang kann hingegen vermutet werden. Im späteren Entwicklungsstadium P40 finden sich gegensinnige Expressionswerte, aber auch hier nur statistisch signifikant im $M_{\text {ecp }} 2^{-/ y}$-Modell. Zusammenfassend liefern die vorliegenden Ergebnisse keine statistisch signifikanten Anhaltspunkte für eine direkte Kontrolle von MeCP2 auf die Genexpression von Sst. Direkte Zusammenhänge zwischen MeCP2 und Somatostatin mit aktivierender Wirkung werden vermutet, sind aber bisher noch nicht eindeutig belegt worden. Die Arbeitsgruppe Chahrour et al. (2008) fand vergleichbare und signifikante Ergebnisse für Sst im Hypothalamus für 42 Tage alte Mecp2-Mäuse. Die Hypothese eines direkten Zusammenhangs wird dort untermauert durch die Tatsache, dass Sst die Konsensussequenz für MeCP2 enthält. Das heißt, der Transkriptionsfaktor MeCP2 könnte an Sst binden.

Zusammenfassend kann beurteilt werden, dass beide Gene für die preBotC-Marker zwar überwiegend differentiell exprimiert werden und auch Hypothesen über einen Zusammenhang zwischen ihnen und MeCP2 bestehen aber die vorliegenden Ergebnisse keine ausreichenden Hinweise auf einen direkten Zusammenhang zeigen. 


\subsection{Das exzitatorische System}

Ein Grundprinzip der Neuronen im respiratorischen Netzwerk basiert auf der reziprok hemmenden Verschaltung durch die Neurotransmitter Glycin und GABA. Glutamat hingegen wirkt als relevanter Transmitter exzitatorisch innerhalb dieses Netzwerkes (Richter et al. 1996). Die drei untersuchten Gene Grin1, Grin2a und Grin2d, die für ionotrophe NMDA-Glutamatrezeptoren 1, 2A und 2D kodieren, beinhalten alle die Konsensussequenz für MeCP2, welche eine Bindung des Transkriptionsfaktors ermöglichen würde. Grin1, Grin2a und Grin2d zeigen alle im postnatalen Entwicklungsstadium P7 eine gegensinnige RNA-Expression im Mecp2-ly Mecp2 $2^{T /-,+/ y}$-Modell. Grin1 und Grin2a sind im Mecp2-/y $2^{-M o d e l l}$ höher und im Mecp $2^{T /-,+/ y}$-Modell vermindert exprimiert, so dass trotz statistisch nicht signifikanter Werte ein direkter Zusammenhang mit supprimierender Wirkung von MeCP2 auf die Gene Grin1 und Grin2a im postnatalen Altersstadium P7 nicht ausgeschlossen werden kann. Dem gegenüber scheint Grin2d, aufgrund statistisch signifikant niedriger Expressionswerte im Mecp2 $2^{-/ y}$-Modell und erhöhter Werte im Mecp2 $2^{T /-,+/ y_{-}}$ Modell, von MeCP2 aktivierend reguliert zu sein. Darüber hinaus zeigen die Ergebnisse, wenn auch statistisch nicht signifikant, im späten postnatalen Entwicklungsstadium P40 bei Grin2a eine deutlich gleichsinnige RNA-Expression in den Mausmodellen. Ein indirekter Zusammenhang kann bei sowohl überexprimiertem als auch fehlendem MeCP2 und jeweils sinkenden Grin2a-Werten im Entwicklungsstadium P40 nicht ausgeschlossen werden. Messungen bei Grin1 und Grin2d im Altersstadium P40 ergaben statistisch signifikante Expressionsabnahmen im Mecp2 $2^{-/ y}$-Modell, hingegen im $M e c p 2^{T /-,+/ y}-$ Modell zeigten sich keine wesentlichen Änderungen. Somit ist ein Zusammenhang zwischen dem Transkriptionsfaktor MeCP2 und den Genen Grin1 und Grin2d nicht zu vermuten.

Bisher sind aus der Literatur keine direkten Zusammenhänge zwischen MeCP2 und Glutamatrezeptoren bekannt. Bestimmte Verbindungen sind jedoch gefunden worden. Glutamat spielt für das respiratorische Netzwerk eine entscheidende Rolle. Eine gestörte respiratorische Aktivität, zum Beispiel durch eine Blockade des Krebszyklus, kann durch die Gabe von Glutamin neutralisiert werden, wie Hülsmann et al. (2000) zeigten. Glutamin steht mit Glutamat über Transaminierungsreaktionen im Gleichgewicht. Darüber hinaus beschrieb Jellinger (2003), dass bei Rett-Patienten verminderte Glutamatspiegel bestehen. Unter der Annahme, dass niedrigere 
Glutamatspiegel zur optimalen Ausschöpfung des Liganden eine Zunahme von Glutamatrezeptoren bedingen, korreliert die erhöhte RNA-Expression im hier verwendeten Mecp2 $^{-/ y}$-Modell im postnatalen Entwicklungsstadium P7 für die für Glutamatrezeptoren kodierenden Gene Grin1 und Grin2a. Des Weiteren wird vermutet, dass die Gene Grin1 (Georgi et al. 2007, Carter 2007a, b sowie Lang et al. 2007), Grin2a (Carter 2007a, b und Lang et al. 2007) und Grin2d (Makino et al. 2005) Bedeutung für die Äthiologie und Pathogenese von Schizophrenie haben. Da das Rett-Syndrom unter anderem mit veränderten Serotonin- und Dopaminspiegeln einhergeht (Jellinger 2003) und diese wiederum mit Schizophrenie (Lang et al. 2007) in Zusammenhang stehen, könnte eine Verbindung von MeCP2 und der Genexpression von Glutamatrezeptoren vermutet werden. Vgl. Abb. 4.2.

Zusammenfassend ergeben sich Hinweise auf eine mögliche direkte Regulation von MeCP2 auf Grin1 (supprimierend) und Grin2d (aktivierend) im postnatalen Entwicklungsstadium P7.

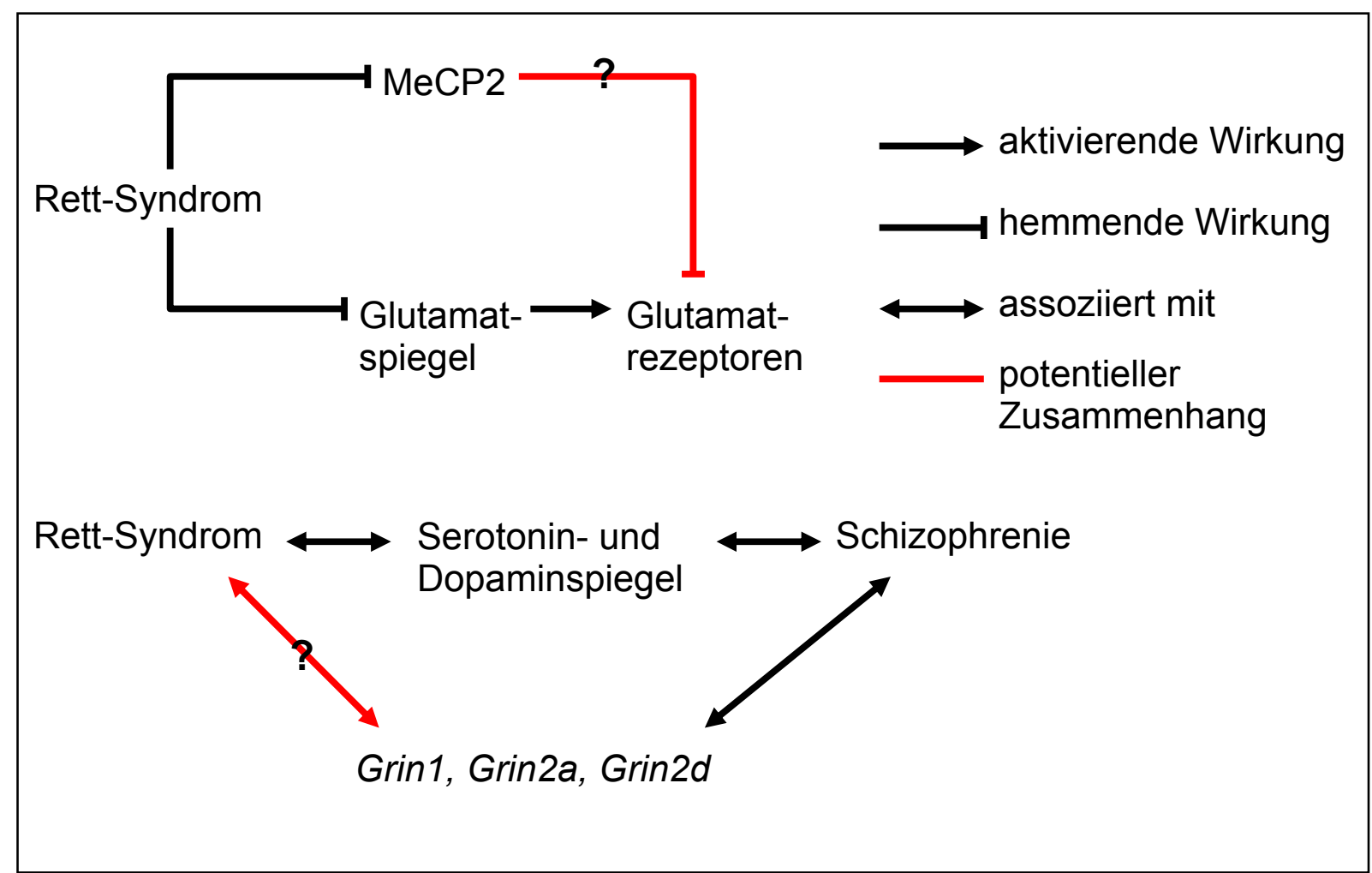

Abb. 4.2 Schematische Darstellung des potentiellen Zusammenhangs zwischen Rett-Syndrom und Glutamatrezeptoren. Quelle: Eigene Entwicklung 


\subsection{Das inhibitorische System}

Das Prinzip der reziprok hemmenden Verschaltung im respiratorischen Netzwerk erfolgt unter anderem durch den Transmitter $y$-Aminobuttersäure (GABA). Die Ergebnisse der untersuchten Gene Gabra6 und Gabrb1 für GABA $A_{A}-$ Rezeptoren zeigen für Gabra6 statistisch signifikant gleichsinnig veränderte relative RNAExpressionen. Im Entwicklungsstadium P7 erhöhen sich die Werte sowohl im Mecp2 $2^{-/ y}$ - als auch im Mecp2 $2^{T /-,+/ y}-$ Modell im Vergleich zum korrespondierenden Wildtyp. Im späteren Entwicklungsstadium P40 hingegen liegen die Expressionswerte in beiden Modellen gegenüber ihren Wildtypen niedriger. Daher liegt die Vermutung eines indirekten Effekts von MeCP2 auf Gabra6 nahe, wohingegen im frühen postnatalen Entwicklungsstadium P7 überexprimiertes MeCP2 aktivierend und im späten Entwicklungsstadium P40 supprimierend zu wirken scheint. Die Expressionswerte des Gabrb1-Gens bezogen auf das Altersstadium P7 zeigen hingegen im $M e c p 2^{-/ y}$-Modell einen statistisch nicht signifikanten Anstieg und im Mecp2 $2^{T /,+1 / y}$-Modell einen ebenso statistisch nicht signifikanten Abfall. Dieses gegensinnige Expressionsmuster könnte dennoch eine direkt supprimierende Regulation von MeCP2 auf Gabrb1 als Schlussfolgerung zulassen. Über das Altersstadium P40 lassen sich aufgrund der Veränderungen, die weder statistisch signifikant noch tendenziell zu erkennen sind, keine genauen Aussagen treffen.

In experimentellen Analysen (Liu $Y Y$ et al. 2001) wurde im preBotC eine Kolokalisation von NK-1-R und $\mathrm{GABA}_{A}-$ Rezeptoren entdeckt. Aus früheren Studien

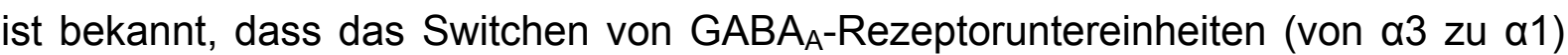
zu einer Veränderung der GABAergen Transmission im preBotC führen kann (Liu $Q$ und Wong-Riley 2006). Ein Ungleichgewicht zwischen exzitatorischer und inhibitorischer Neurotransmission soll laut Muñoz-Yunta et al. (2008) im Zusammenhang mit Epilepsie stehen. Epileptische Anfälle gehören zu den typischen Symptomen des Rett-Syndroms. Ebenso soll diese Unausgeglichenheit der Transmission von exzitatorischen und inhibitorischen Botenstoffen die RettSymptomatik - unter anderem Atemdysregulationen - mitbestimmen (Medrihan et al. 2008). Diese Arbeitsgruppe zeigte bei Mecp2 ${ }^{-1 / y}-$ Mäusen im postnatalen Entwicklungsstadium P7 eine Transmissionsdysbalance in der ventrolateralen Medulla oblongata. Im Speziellen wurde eine supprimierte GABAerge Transmission gefunden, was darauf hindeuten könnte, dass in $M e c p 2^{-/ y}-M a ̈ u s e n ~ s p e z i f i s c h e$ 
Signalwege im Hirnstamm während der frühen postnatalen Entwicklung beeinträchtigt sind (Medrihan et al. 2008). Die in dieser Arbeit dargestellten relativen Expressionsergebnisse zeigen zwar im gleichen Entwicklungsstadium Veränderungen, wodurch sowohl eine indirekte als auch eine direkte Wirkung von MeCP2 auf die Rezeptorgene vermutet werden kann. Allerdings ist noch nicht geklärt, ob die verminderte GABAerge Transmission auf einer Veränderung des GABA $_{A}-$ Rezeptorspiegels beruht. Des Weiteren besteht laut Lang et al. (2007) und Petryshen et al. (2005) für Gabra6 ebenfalls ein Zusammenhang mit der Erkrankung Schizophrenie, die mit dem Rett-Syndrom über die Veränderung der Transmitterspiegel in Verbindung gebracht werden kann. Ebenso ist eine assoziierende Rolle bei Autismus für Gabra6 und Gabrb1 beschrieben (Ma et al. 2005). Auch Collins et al. (2006) konnte diesen Zusammenhang zumindest für Gabrb1 finden. Ferner finden sich Mutationen im MECP2-Gen laut Samaco et al. (2005) und Carney et al. (2003) auch bei der Erkrankung Autismus. Vgl. Abb. 4.3.

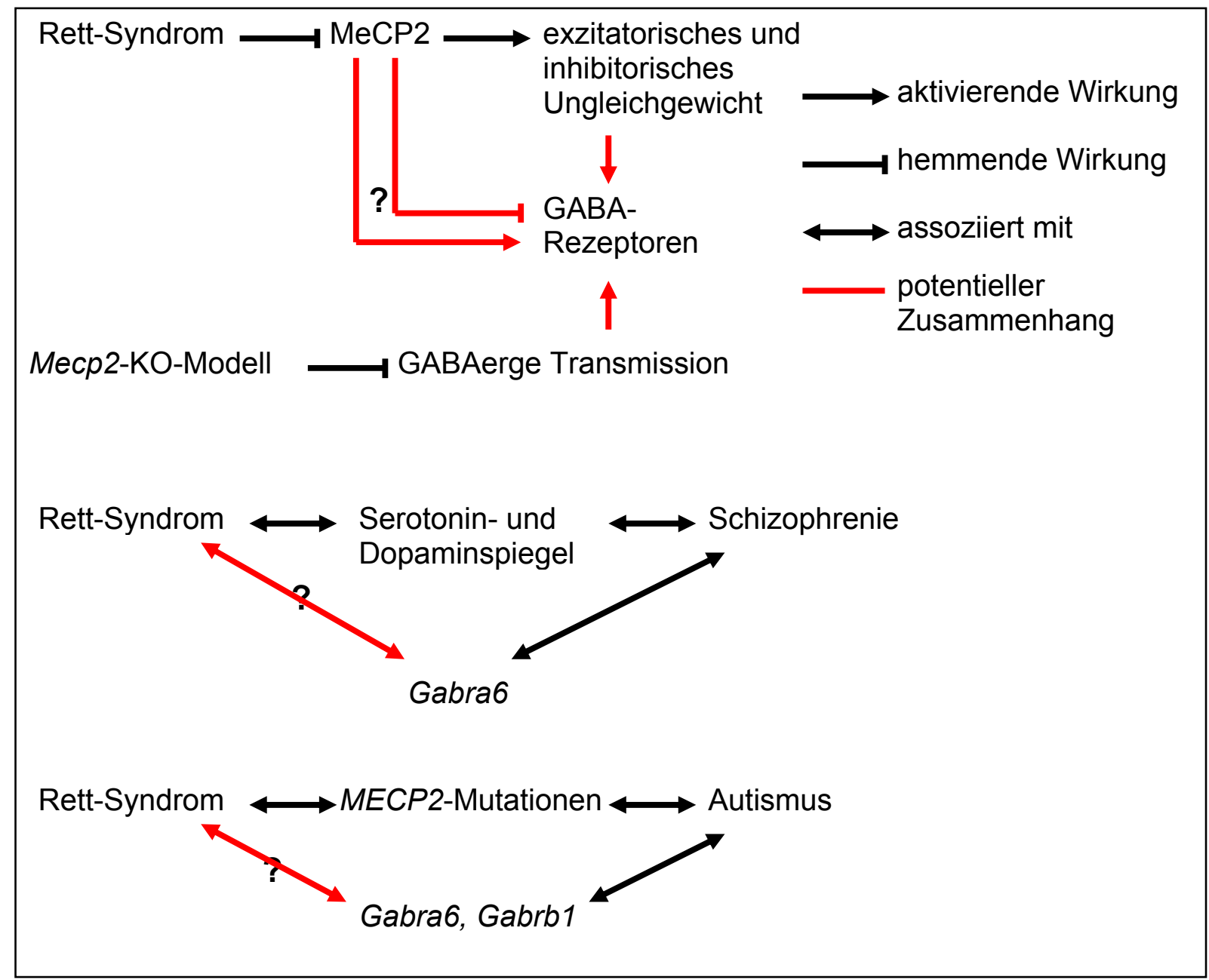

Abb. 4.3 Schematische Darstellung des potentiellen Zusammenhangs zwischen Rett-Syndrom und GABA-Rezeptoren. Quelle: Eigene Entwicklung 
Ein Zusammenhang zwischen der Expression von $G A B A_{A}-$ Rezeptorgenen und dem Transkriptionsfaktor MeCP2 ist plausibel und kann aufgrund eigener Ergebnisse für Gabra6 auf eine indirekte Regulation hinweisen. Zudem besitzen die Gene Gabra6 und Gabrb1 die für die Bindung von MeCP2 nötige Konsensussequenz.

\subsection{Das serotonerge System}

Es ist aus neuropathologischen Untersuchungen des Gehirns bekannt, dass RettPatienten genauso viele serotonerge Zellen (Paterson et al. 2005) aber geringere Serotoninspiegel als Gesunde besitzen (Ramaekers et al. 2003, Jellinger 2003). Ferner ist der Einfluss von MeCP2 als Transkriptionsfaktor auf BDNF - kodierendes humanes Gen für BDNF - bekannt (Wang et al. 2006). BDNF (brain-derived neurotrophic factor) wiederum ist ein neurotropher Wachstumsfaktor für serotonerge Neurone (Paterson et al. 2005), wodurch die Untersuchung des serotonergen Systems an Bedeutung gewinnt. Ramaekers et al. (2003) zeigten, dass bei RettPatienten ein reduzierter Spiegel an Serotonin und Dopamin vorliegt, der durch eine Ausschöpfung von Folsäure im zentralen Nervensystem hervorgerufen werden könnte. Auf welcher Stufe genau MeCP2 auf das serotonerge System wirkt oder ob die Wirkung nur über BDNF zur Geltung kommt, ist noch nicht geklärt.

Die RNA-Expressionen der beiden Serotoninsynthesegene Tph2 - kodierendes Gen für das Protein Tryptophan-Hydroxylase 2, Geschwindigkeitsbestimmender Syntheseschritt - und Ddc - kodierendes Gen für das Enzym DODA-Decarboxylase lassen einen direkten Zusammenhang mit MeCP2 vermuten. Im frühen postnatalen Entwicklungsstadium P7 ergab sich ein gegensinniges Expressionsmuster für Tph2, welches auf eine supprimierende Wirkung von MeCP2 hindeutet. Ein vergleichbares Expressionsmuster wurde für das Ddc-Gen im späten Altersstadium P40 gemessen. MeCP2 scheint somit eine direkte Wirkung auf Tph2 in der frühen und auf $D d c$ in der späteren postnatalen Entwicklungsphase zu haben. Bei einer Reduktion des Serotoninspiegels, wie sie bei Rett-Patienten typisch ist, wäre eine Hochregulierung von Syntheseproteinen wie Tryptophan-Hydroxylase 2 und DODA-Decarboxylase sowie des Serotonintransporters und auch der Serotoninrezeptoren sinnvoll, um eine optimale Substratausschöpfung zu erreichen. Dieses biologische Prinzip, die vorliegenden Expressionsergebnisse und das Vorhandensein der Konsensus- 
sequenz von MeCP2 in den Genen Tph2 und Ddc, geben berechtigten Anhalt für eine direkte Einflussnahme des Transkriptionsfaktors auf die Synthesegene von Serotonin. Vgl. Abb. 4.4.

Das Gen für den Serotonintransporter Slc6a4 wird im postnatalen Entwicklungsstadium P7 im Mecp2 $2^{-/ y}$-Modell vermehrt und im Mecp2 $2^{T /-,+/ y}{ }_{-M o d e l l}$ vermindert exprimiert, woraus eine direkt supprimierende Wirkung als Schlussfolgerung gezogen werden könnte. Eine gleichsinnige RNA-Expression mit stets erhöhten Werten stellte sich im späten Entwicklungsstadium P40 dar. Dies könnte auf einen indirekten Effekt von MeCP2 auf Slc6a4 hinweisen. Laut Paterson et al. (2005) findet keine Desensitivierung des Bindungsverhaltens an den Serotonintransporter, wie es bei gesunden Menschen der Fall ist, bei Rett-Patienten statt. Daraus kann noch nicht eindeutig geschlossen werden, ob bei fehlendem beziehungsweise überexprimiertem MeCP2 mehr oder weniger Serotonintransporter vorliegen. Theoretisch müsste die Expressivität des Transporters bei verminderten Serotoninspiegeln steigen. Vgl. Abb. 4.4. Die vorliegenden Ergebnisse können dies für das Mecp2 $2^{-/ y}$-Modell bestätigen. Slc6a4 enthält zudem auch die MeCP2Konsensussequenz, wodurch sich mehrere Hinweise auf einen Zusammenhang zwischen MeCP2 und Slc6a4 ergeben.

Es wird vermutet, dass bestimmte Serotoninrezeptoren essentiell für die Modulation des respiratorischen Rhythmus sind (Manzke 2004). Verdeutlicht wurde von Manzke et al. (2003), dass 5- $\mathrm{TH}_{4(\mathrm{a})}$-Rezeptoren stark im preBotC auf inspiratorischen Neuronen exprimiert werden. Normalerweise bewirken Opioide über die $\mu$-Opioidrezeptoren ( $\mu$-OR) neben einer Analgesie auch eine Atemdepression, die aber nach Gabe von pharmakologischen 5- $\mathrm{HT}_{4(\mathrm{a})}$-Rezeptoragonisten ohne Verlust der Analgesie kompensiert werden kann. Dies beruht auf einen sich antagonisierenden Signalweg der beiden Rezeptoren. Beide Rezeptoren sind GProtein gekoppelt und wirken aktivierend $\left(5-\mathrm{HT}_{4(\mathrm{a})}-\mathrm{R}\right)$ beziehungsweise hemmend ( $\mu$-OR) auf die membrangebundene Adenylatzyklase, wodurch intrazellulär zyklisches Adenosinmonophosphat (cAMP) ansteigt $\left.\left(5-\mathrm{HT}_{4(\mathrm{a})}\right)^{-\mathrm{R}}\right)$ oder vermindert $(\mu-\mathrm{OR})$ gebildet wird (Manzke et al. 2003). Eine ähnliche Wirkung konnte auch für den $5-\mathrm{HT}_{1 \mathrm{~A}}-\mathrm{R}$ gefunden werden (Guenther et al. 2009). Zusätzlich zur kompensierenden Wirkung auf die Atemdepression konnten Manzke et al. (2008) in der Ontogenese von Ratten zeigen, dass innerhalb des preBotC der $5-\mathrm{HT}_{4(\mathrm{a})}-\mathrm{R}$ einer differenziellen 
Exprimierung unterliegt. Am achtzehnten Embryonaltag zeigte sich eine ausgedehnte Anfärbung von $5-\mathrm{HT}_{4(\mathrm{a})}-\mathrm{R}$ im Bereich des preBotC. Zu diesem Zeitpunkt ähnelt der pränatale Atemrhythmus in Frequenz und Amplitude dem des neonatalen Rhythmus (Greer et al. 1992). Bis zur Geburt und auch neonatal sank die Anzahl an 5-HT4(a)-Rexprimierenden Zellen im preBotC ab. Serotoninrezeptoren vermitteln somit neurotrophe Aktionen, die wichtig für die Formation des respiratorischen Netzwerks sind. Die beim Rett-Syndrom typisch auftretenden respiratorischen Dysfunktionen können vielleicht durch einen Zusammenhang zwischen MePC2 und den 5-HT-R erklärt werden. Die Ergebnisse der relativen Genexpressionen für die $5-\mathrm{HT}_{4}$ - und $5-\mathrm{HT}_{5 \mathrm{~B}}$-Rezeptoren zeigen im postnatalen Entwicklungsstadium $\mathrm{P} 7$ gegensinnige Werte, die auf einen direkten Zusammenhang mit supprimierender Wirkung des überexprimierten MeCP2 hindeuten. Sogar im späteren Entwicklungsstadium P40 lassen sich bezogen auf den $5-\mathrm{HT}_{5 B}-\mathrm{R}$, über den bisher noch wenig bekannt ist, aber der die MeCP2-Konsensussequenz besitzt, ähnliche Schlussfolgerungen ziehen. MeCP2 scheint demnach direkten Einfluss als Suppressor auf die Htr5b- und in der frühen Entwicklungsphase P7 auf die Htr4-Expression zu haben.

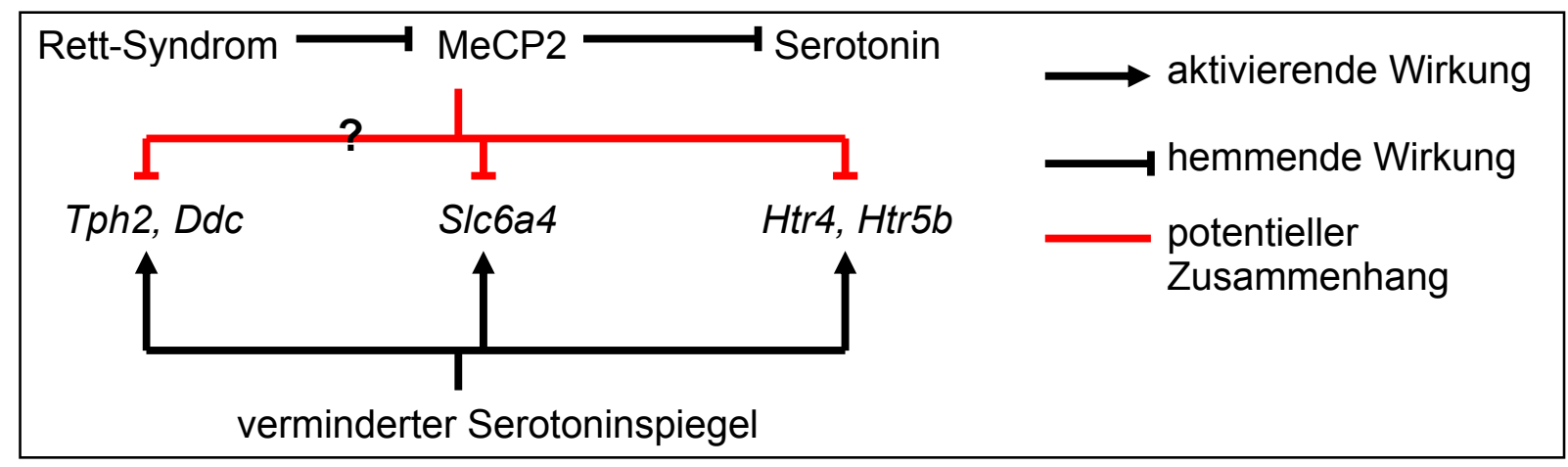

Abb. 4.4 Schematische Darstellung des potentiellen Zusammenhangs zwischen Rett-Syndrom und serotonergem Systems. Quelle: Eigene Entwicklung

Zusammenfassend ergeben sich Hinweise auf eine supprimierende Wirkung von MeCP2 auf Ddc im Entwicklungsstadium P40, auf Tph2, Slc6a4 und Htr4 im Entwicklungsstadium P7 sowie auf Htr5b in beiden Entwicklungsstadien. Insbesondere sind die Gene Htr4 und Htr5b mit ihren statistisch signifikanten Änderungen der relativen Expression zu nennen, wodurch die Vermutung nahe liegt, dass MeCP2 auf Htr4 im Entwicklungsstadium P7 und auf Htr5b im Entwicklungsstadium $P 7$ als auch im Entwicklungsstadium P40 direkten Einfluss nimmt. 


\subsection{Das dopaminerge und opioiderge Transmittersystem}

Es ist bekannt, dass bei Individuen mit geistiger Behinderung, hyperaktivem, stereotypem, aggressivem und selbst verletzendem Verhalten (Loupe et al. 2002) sowie bei Schizophrenie (Lang et al. 2007) Abnormalitäten in ihrem dopaminergen System zu finden sind. Auch Jellinger (2003) und Ramaekers et al. (2003) verdeutlichten, dass bei Rett-Patienten nicht nur der Serotoninspiegel sondern auch der Dopaminspiegel vermindert ist. Vgl. Abb. 4.5. Die Expressionsergebnisse für das Gen des Dopaminrezeptors D4 weisen tatsächlich auf einen direkten Zusammenhang zwischen Drd4 und MeCP2 hin. Im postnatalen Entwicklungsstadium P7 des Meсp2-/y -Modells liegen die Werte gegenüber dem korrespondierenden Wildtyp niedriger und $\mathrm{im}$ Mecp $2^{T /,+, / y}$-Modell lässt sich ein höherer Wert messen. Die Vermutung liegt nahe, dass MeCP2 aktivierend auf Drd4 in der frühen postnatalen Entwicklungsphase wirken könnte, zudem auch Drd4 die für die Bindung von MeCP2 notwendige Konsensussequenz enthält.

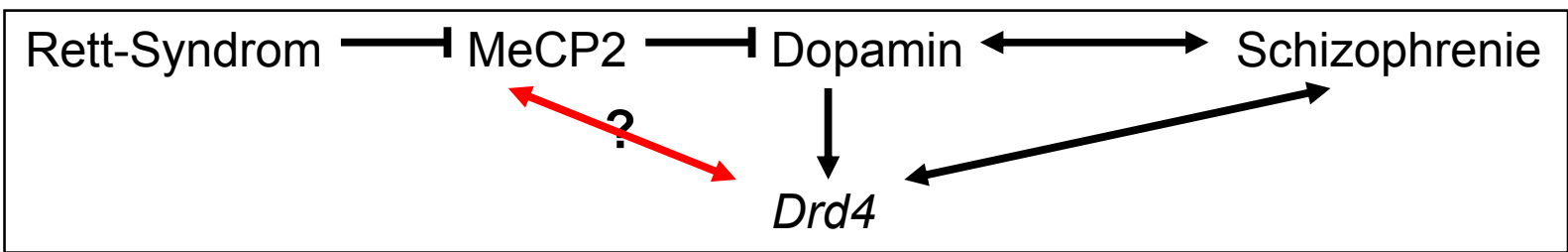

Abb. 4.5 Schematische Darstellung des potentiellen Zusammenhangs zwischen Rett-Syndrom und Dopaminrezeptor D4. Quelle: Eigene Entwicklung

Die Überlegung eines Zusammenhangs zwischen MeCP2 und Opioidrezeptoren begründet sich zum einen darauf, dass die perinatale Atemfrequenz von $\mu$-Opioidrezeptoren moduliert wird (Takita et al. 1997). Zum anderen stellten Manzke et al. (2003) fest, dass im preBotC respiratorische Neurone direkt von Opioiden gehemmt werden. Darüber hinaus kann die unerwünschte Nebenwirkung Atemdepression aufgrund opioiderger Schmerzmedikation durch 5- $\mathrm{HT}_{4(\mathrm{a})^{-}}$ Rezeptoragonisten kompensiert werden. Manzke et al. zeigten 2008, dass zu jedem Zeitpunkt der Embryogenese der Ratte $\mu$-Opioidrezeptoren mit 5- $\mathrm{HT}_{4(\mathrm{a})}$-Rezeptoren stark koexprimiert werden. Mit geringerer Koexpressivität zum 5-HT4(a)-Rezeptor befindet sich der $\mu$-Opioidrezeptor auch im Hinterhorn des Rückenmarks, wo die Verschaltung des Schmerzreizes auf das zweite Neuron stattfindet. Die analgetische Wirkung bleibt somit bei der Gabe eines 5-HT $4(a)$-Rezeptoragonisten unverändert. Direkte Zusammenhänge zwischen MeCP2 und Opioidrezeptoren sind von Chahrour et al. (2008) beschrieben worden. Diese Arbeitsgruppe konnte zeigen, dass MeCP2 
an Oprk1 - kodierendes Gen für den k-Opioidrezeptor 1 - bindet und dass in Mecp2defizienten Mäusen die relative Oprk1-Expression erhöht ist. Die Vermutung liegt nahe, dass Oprk1 einer direkt supprimierenden Wirkung von MeCP2 unterliegt. Opioide und deren Rezeptoren könnten mit den respiratorischen Dysfunktionen des Rett-Syndroms in Verbindung stehen. Das für den $\mu$-Opioidrezeptor 1 kodierende Gen Oprm1 weist im älteren postnatalen Entwicklungsstadium P40 ein gegensinniges Expressionsmuster auf, was eine aktivierende Regulation von MeCP2 bedeuten könnte. Im postnatalen Entwicklungsstadium P7 zeigten sich keine signifikant differentiellen Expressionsveränderungen, so dass der direkte Einfluss von MeCP2 auf spätere Entwicklungsphasen begrenzt zu sein scheint.

Sowohl für Drd4 als auch für Oprm1 zeigen sich Hinweise auf einen direkt aktivierenden Zusammenhang zu MeCP2. Drd4 könnte im Entwicklungsstadium P7 reguliert sein. Stärkere Hinweise durch statistisch signifikante Ergebnisse zeigen sich jedoch im Entwicklungsstadium P40 für Oprm1.

\subsection{Vokalisation}

Laut Enard et al. (2002) und Spiteri et al. (2007) sind Mutationen im FOXP2-Gen (forkhead box P2) für Sprach- und Sprechstörungen verantwortlich. Da RettPatienten unter anderem auch einen Sprech- und Sprachverlust erleiden (Lindberg und Rett 2000), liegt die Vermutung nahe, dass MeCP2 einen Einfluss auf FOXP2 hat. Im Mecp2-/y-Modell von Stettner et al. (2007) zeigte sich ein dem Rett-Syndrom ähnlicher respiratorischer Phänotyp, insbesondere mit einer Störung der Postinspiration. Die Vokalisation und Atmung stehen in enger Beziehung zueinander, denn Phonieren ist nur in der Postinspiration und Exspiration möglich (Schmidt RF et al. 2000). Darüber hinaus fungiert das Protein FoxP2 wie MeCP2 als Transkriptionsfaktor. Es bestehen Hypothesen, die FoxP2 die Rolle eines möglichen Gegenspielers von MeCP2 zuschreiben, was aufgrund der Konsensussequenz von MeCP2 innerhalb von Foxp2 durch eine Bindung möglich wäre. Des Weiteren soll FoxP2 im Zusammenhang mit Epilepsie stehen (Muñoz-Yunta et al. 2008) und epileptische Anfälle treten nicht selten beim Rett-Syndrom auf. Diese Theorien werden durch die relativen Expressionsdaten von Foxp2 im frühen (P7) wie auch im späten postnatalen Entwicklungsstadium (P40) untermauert. Im Mecp2 $2^{-/ y}$-Modell ließen sich 
im Vergleich zum korrespondierenden Wildtyp erhöhte und im Mecp2 ${ }^{T /,+, / y}$-Modell verminderte Werte messen, was einen direkten Zusammenhang zwischen MeCP2 auf Foxp2 vermuten lässt. Das Expressionsmuster deutet auf einen supprimierenden Effekt des überexprimierten MeCP2 hin. Darüber hinaus werden von Wassink et al. (2002) und von O'Brien et al. (2003) ebenso Assoziationen von FOXP2 zu dem Krankheitsbild Autismus beschrieben, so dass auch hier über MECP2-Mutationen eine Verbindung zum Rett-Syndrom besteht. Vgl. Abb. 4.6.

Foxp2 könnte aufgrund der statistisch signifikanten Ergebnisse und des Expressionsmusters als ein weiteres Zielgen von MeCP2 angesehen werden.

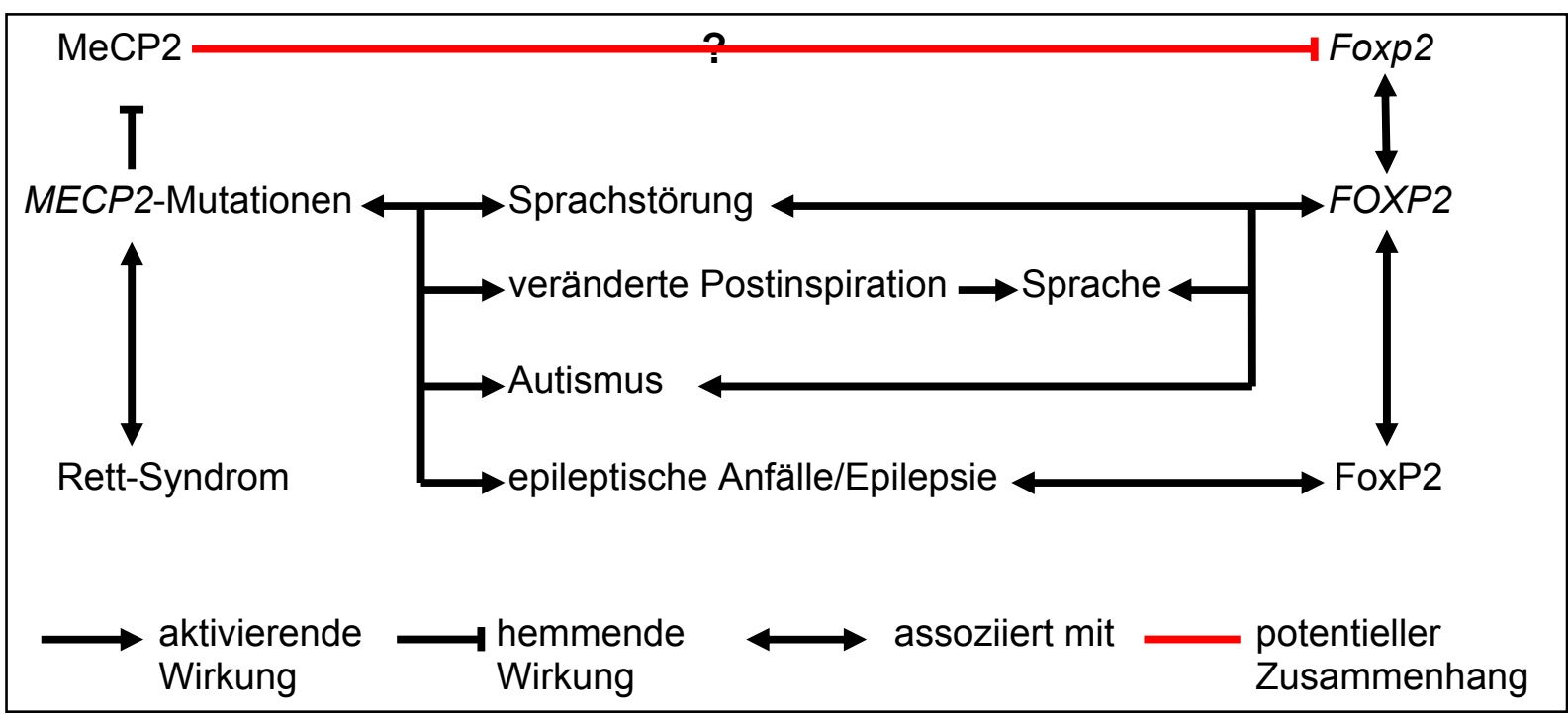

Abb. 4.6 Schematische Darstellung des potentiellen Zusammenhangs zwischen MeCP2 und Foxp2. Quelle: Eigene Entwicklung

\subsection{Gliazell-Marker}

Bei GFAP, „glial fibrillary acidic protein“ einem Marker für Astrozyten und Gliazellen (Privat et al. 1995, Shao und McCarthy 1994, Gomes et al. 1999), stellten sich die Ergebnisse der RNA-Expression des Gens Gfap im postnatalen Entwicklungsstadium P40 sowohl im Mecp2 $2^{-/ y}$-Modell als auch im Mecp2 ${ }^{\text {T/-, }+/ y}{ }_{-M o d e l l}$ mit erhöhten Werten im Vergleich zu den korrespondierenden Wildtypen dar. Dies könnte auf einen indirekten Zusammenhang hindeuten. Im frühen Entwicklungsstadium P7 ließen sich keine signifikanten Veränderungen messen, so dass eine eventuelle Regulierung aufgrund der Daten nur in späteren Entwicklungsphasen plausibel erscheint. Einen direkten Zusammenhang zwischen MeCP2 und Gfap konnten Setoguchi et al. (2006) beschreiben. MeCP2 bindet in 
Neuronen an das methylierte Exon 1 des Gfap-Gens, welches die Konsensussequenz von MeCP2 beinhaltet. Normalerweise wird der Gfap-Promotor demethyliert, wodurch die Astrozytendifferenzierung in Gang gesetzt wird. MeCP2 hemmt demnach die Astrozytendifferenzierung in neuroepithelialen Zellen durch Modulierung der DNA-Methylierung und verschiebt das Gleichgewicht in Richtung Neurogenese. Vgl. Abb. 4.7. Im Mecp2-ly-Modell, in dem kein MeCP2 exprimiert wird, müssten also erhöhte Spiegel von Gfap zu finden sein. Die hier vorliegende Datenlage kann dies für das Entwicklungsstadium $\mathrm{P} 40$ bestätigen. Da im Mecp $2^{T /-,+/ y}$-Modell allerdings auch eine vermehrte Expression zu finden ist, könnte es sich auch um indirekte Zusammenhänge handeln. Die Arbeitsgruppe Lipani et al. (2000) beschrieb hingegen in Gehirnen von Rett-Patienten einen GFAP-Spiegel bei oder unterhalb des Minimalspiegels der Kontrollpersonen. Eine Reduktion der GFAPExpression bei vorliegender MeCP2-Defizienz widerspricht dem oben genannten. Tatsache ist, dass MeCP2 an Gfap bindet und dadurch Einfluss auf die Astrozytendifferenzierung nimmt. Die genauen Regulationsmechanismen zwischen Gfap und MeCP2 bedürfen jedoch noch weiterer Erforschung.
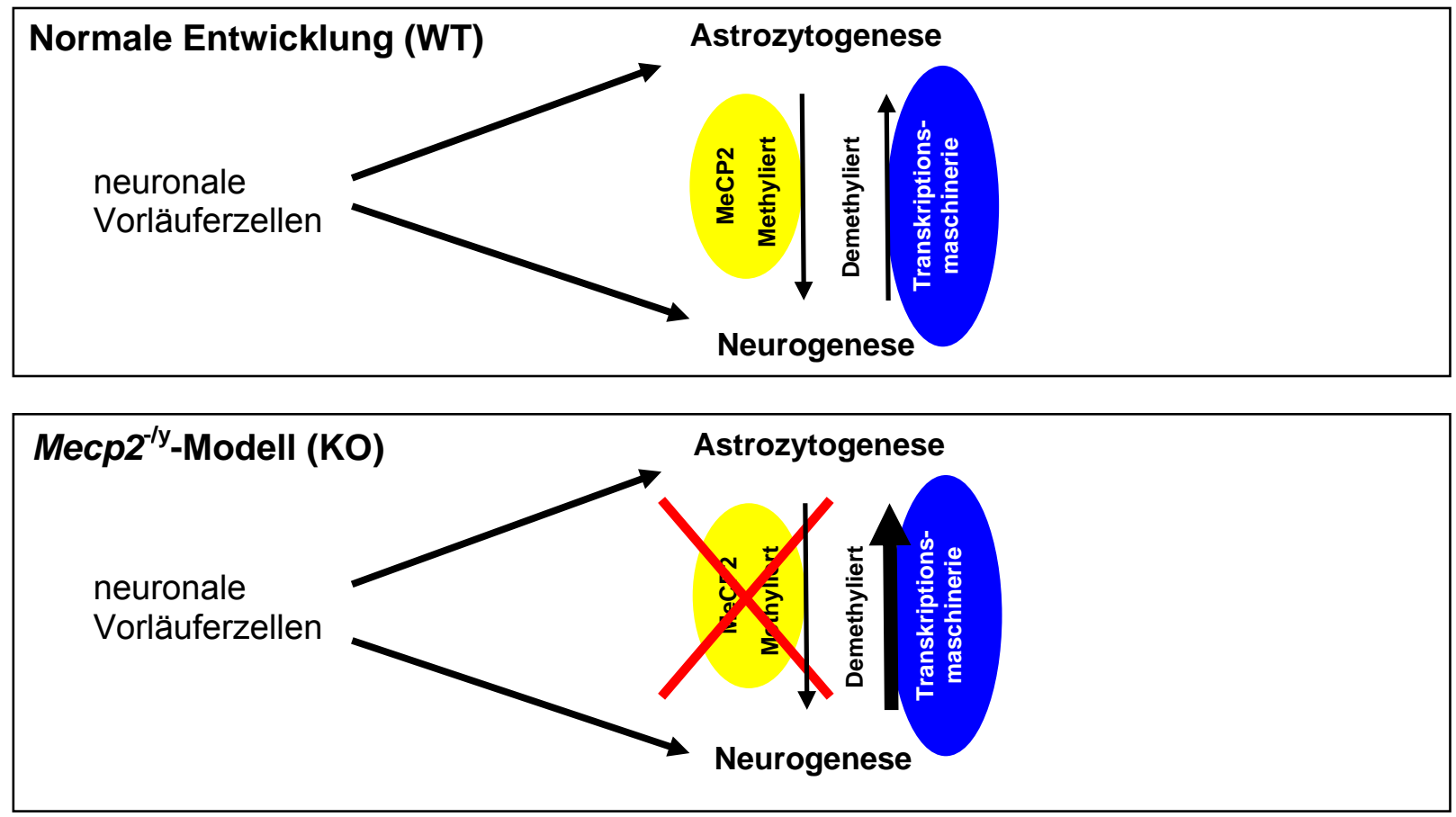

Abb. 4.7 Schematische Darstellung der Astrozytendifferenzierung während der normalen Entwicklung und im Mecp2 ${ }^{-1 y}$-Modell. Modifiziert nach Setoguchi et al. (2006)

S100B („S100 calcium binding protein Beta“ und ebenfalls ein Marker für Gliazellen) wirkt nicht nur neurotroph auf serotonerge Zellen (Eriksen et al. 2002), sondern spielt auch eine große Rolle in der Differenzierung von Neuroglia und Neuronen. Eine 
Überexpression von S100B fördert die Reifung von Gliazellen (Raponi et al. 2007) und laut den Arbeitsgruppen Park et al. (2004) und Donato (2007) bestehen Zusammenhänge mit der Neuronenreifung in mehreren Regionen des Zentralnervensystems. Eine Überexpression von S100B kann bei abnormalen Hirnfunktionen und damit auch beim Down-Syndrom und bei der Krankheit Schizophrenie auftreten (Park et al. 2004). Überexpressionen von S100B während der Hirnentwicklung könnten somit eine Rolle für Hirndysfunktionen spielen. Schon 2000 zeigten Park et al., dass eine passive Immunisierung mit S100B zu Abnormalitäten in der Hirnstruktur von Gliazellen führt und damit Zeichen einer verspäteten Gehirnentwicklung erkennbar werden. Raponi et al. (2007) beschrieben, dass die Expression des Gliazell-Markers dazu führt, dass undifferenzierte GFAPexprimierende Stammzellen ihr neuronales Stammzellpotential verlieren und damit die neuronale Entwicklung moduliert wird. Unter der Gabe von Fluoxetin, ein selektiver Serotonin-Wiederaufnahmehemmer, konnten Tramontina et al. (2008) ein S100B-Anstieg beobachten, so dass auch hier eine Assoziation zum serotonergen System besteht. Vgl. Abb. 4.8.

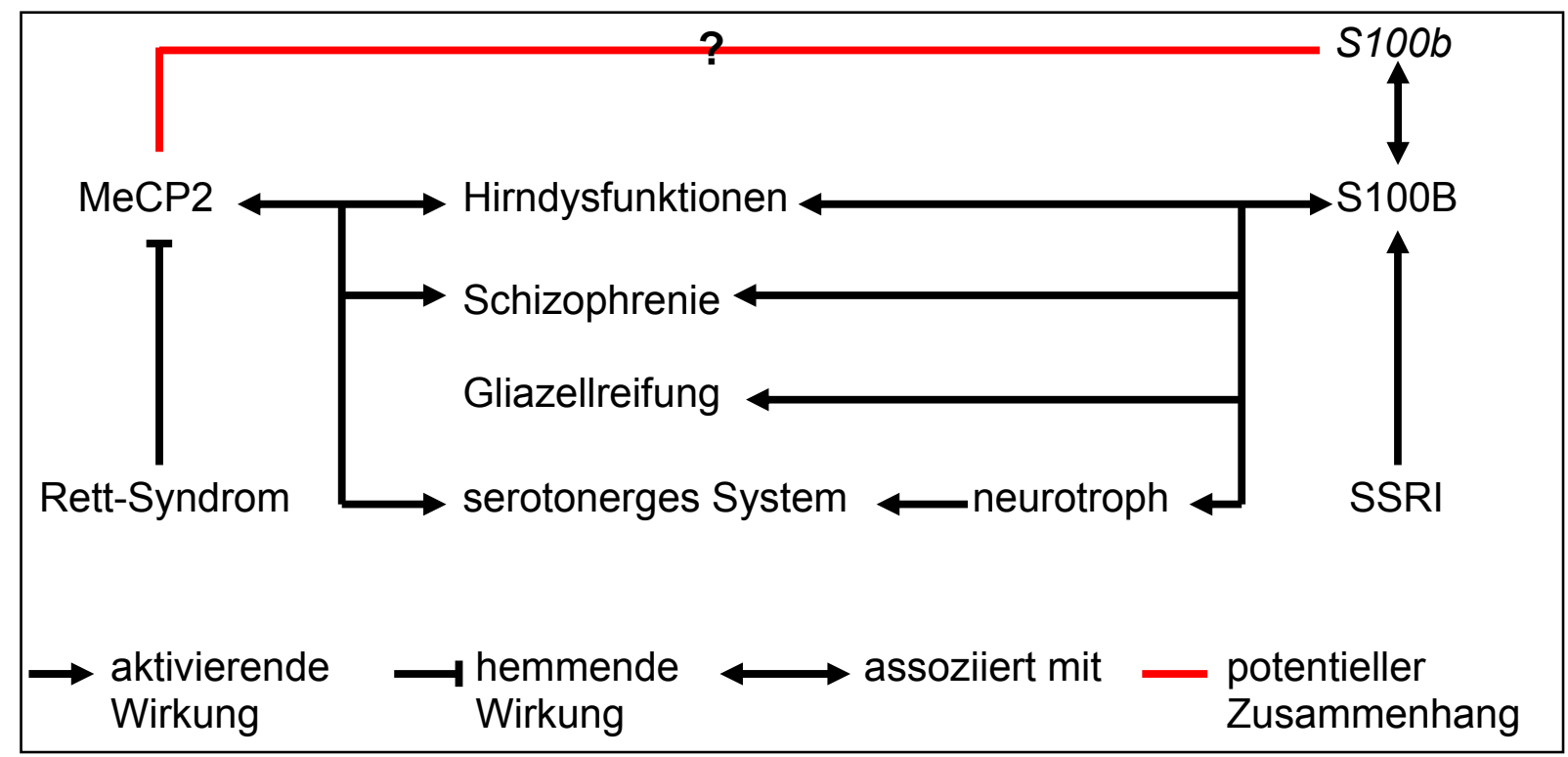

Abb. 4.8 Schematische Darstellung des potentiellen Zusammenhangs zwischen MeCP2 und S100b. Quelle: Eigene Entwicklung

Die relativen Expressionswerte lagen im postnatalen Entwicklungsstadium P7 sowohl im Mecp2 $2^{-/ y_{-}}$als auch im Mecp2 $2^{T /-,+/ y}-$ Modell gegenüber korrespondierenden Wildtypen höher. Eine derartig gleichsinnige Veränderung kann einen indirekten Zusammenhang zwischen MeCP2 und S100b zumindest für das frühe postnatale Entwicklungsstadium P7 vermuten lassen. Ob der Modulationsweg über das serotonerge System abläuft, muss noch weiter erforscht werden. 
Zwar bestehen Verbindungen zwischen S100B und MeCP2, jedoch zeigen die vorliegenden Expressionsergebnisse keinen Hinweis auf eine direkte Regulation von MeCP2 auf S100b. Es ist bekannt, dass MeCP2 an Gfap bindet. Trotzdem ergeben die Ergebnisse der relativen Genexpression von Gfap lediglich Hinweise auf einen indirekten Zusammenhang im Entwicklungsstadium P40.

\subsection{Synopsis}

Aus diesen Daten können folgende Befunde abgeleitet werden:

1. Im Mecp2 ${ }^{-/ y}$-Mausmodell wird keine Mecp2-RNA exprimiert.

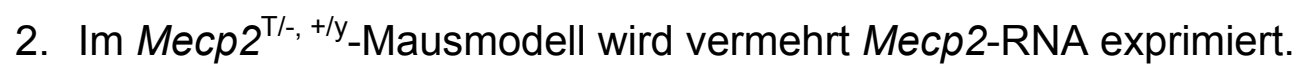

3. Es wurden signifikante Unterschiede in der RNA-Expression von untersuchten Genen sowohl im Mecp2 $2^{-/ y}$ - als auch im Mecp2 $2^{T /-,+/ y}-$ Mausmodell gefunden.

4. Ein potentiell direkter Zusammenhang zwischen MeCP2 und den folgenden Genen kann vermutet werden:

\begin{tabular}{|c|c|c|c|}
\hline Genname & $\begin{array}{l}\text { statistisch signifikante } \\
\text { Veränderungen }\end{array}$ & $\begin{array}{l}\text { vermutete direkte Regulation } \\
\text { durch MeCP2 aufgrund der } \\
\text { vorliegenden Ergebnisse }\end{array}$ & $\begin{array}{l}\text { Konsensussequenz } \\
\text { vorhanden }\end{array}$ \\
\hline Tacr1 & KO P40 & nein & nein \\
\hline Sst & KO P7 $\uparrow$, KO P40 $\downarrow$ & nein & ja \\
\hline Grin1 & KO P40 $\downarrow$ & ja P7 $\rightarrow$ Suppressor & ja \\
\hline Grin2a & nein & nein & ja \\
\hline$\underline{G i n} 2 d$ & KO P7 $\downarrow$, KO P40 $\downarrow$ & ja $\mathrm{P} 7 \rightarrow$ Aktivator & ja \\
\hline Gabra6 & 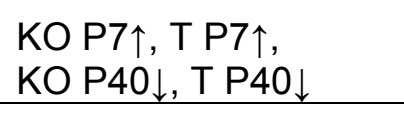 & nein & ja \\
\hline Gabrb1 & nein & nein & ja \\
\hline Tph2 & 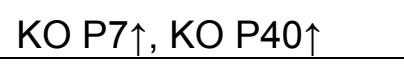 & ja P7 $\rightarrow$ Suppressor & ja \\
\hline$\underline{D d c}$ & 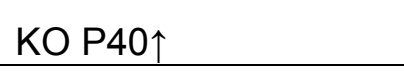 & ja P40 $\rightarrow$ Suppressor & ja \\
\hline Slc6a4 & KO P40个 & ja P7 $\rightarrow$ Suppressor & ja \\
\hline Htr4 & KO P7 $\uparrow, ~ T ~ P 7 \downarrow$ & ja P7 $\rightarrow$ Suppressor & nein \\
\hline Htr5b & 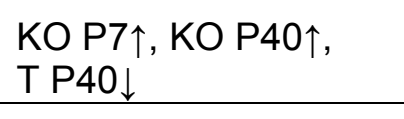 & ja $\rightarrow$ Suppressor & ja \\
\hline Drd4 & KO P7 $\downarrow$, KO P40 $\downarrow$ & ja P7 $\rightarrow$ Aktivator & ja \\
\hline Oprm1 & 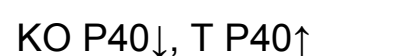 & ja P40 $\rightarrow$ Aktivator & nein \\
\hline
\end{tabular}




\begin{tabular}{|c|c|c|c|}
\hline Foxp2 & 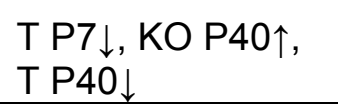 & ja $\rightarrow$ Suppressor & ja \\
\hline Gfap & $\mathrm{KO} \mathrm{P} 40 \uparrow, \mathrm{T} \mathrm{P} 40 \uparrow$ & nein & ja \\
\hline$S 100 b$ & 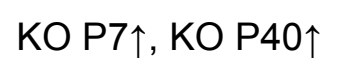 & nein & $?$ \\
\hline
\end{tabular}

\subsection{Klinische Relevanz der Ergebnisse und Forschungsperspektive}

Die vorliegende Dissertation dient der Grundlagenforschung über den Transkriptionsfaktor MeCP2. Seine Wirkmechanismen, besonders wie er als Aktivator auf die Gentranskription seine Wirkung entfaltet, sind weitgehend noch unbekannt. Als Zielgene sind bisher Bdnf und DIx5 entdeckt worden. Die vorliegende Arbeit gibt Hinweise darauf, dass Htr4, Htr5b, Oprm1 und Foxp2 eventuell weitere Zielgene sind.

Zu berücksichtigen ist jedoch, dass die verwendeten Tiermodelle, das Mecp2 $2^{-/ y}$ und Mecp $2^{T /-,+/ y}$-Mausmodell, nicht unmittelbar auf den Menschen übertragbar sind. Obwohl für das Mecp2-/y -Modell der respiratorische Phänotyp charakterisiert wurde und auch dem des Menschen mit Rett-Syndrom ähnelt, fehlen entsprechende Studien für das Mecp $2^{T /-,+/ y}-$ Modell. Ebenso ist noch unklar, ob die bei männlichen Mäusen gemessenen Unterschiede auch bei weiblichen Tieren und insbesondere auch bei Rett-Patienten zu finden sind.

Die hier gefundenen RNA-Expressionen müssten ebenso auf Proteinebene verifiziert werden, da zwischen Transkription und Translation Regulationsmechanismen stattfinden. Bei einer vermehrten RNA-Expression kann nicht zwangsläufig von einer vermehrten Protein-Expression ausgegangen werden.

Neben der Erforschung der näheren Zusammenhänge auf Proteinebene müssten physiologische Experimente erfolgen, in denen die Wirksamkeit von applizierten Targets (zum Beispiel Rezeptoragonisten oder -antagonisten) gegenüber unerwünschten Symptomen, wie zum Beispiel Hyperventilation, untersucht wird. Es müsste verifiziert werden, durch welches Target welcher Rezeptor stimuliert oder blockiert wird, um die Symptomatik behandeln zu können.

Anschließend müssten klinische Pharmaka entwickelt werden, die zunächst am Tiermodell und dann am Menschen getestet werden.

Im Tiermodell ist es bereits gelungen, durch Gabe von spezifischen $5-\mathrm{HT}_{(4 \mathrm{a})^{-}}$ Rezeptoragonisten auf das respiratorische Netzwerk Einfluss zu nehmen, wodurch 
sich Ansatzpunkte für die Entwicklung von klinisch zugelassenen Pharmaka ergeben könnten.

Bezogen auf das Rett-Syndrom laufen derzeit experimentelle Studien mit dem Therapieansatz der Gabe von Buspiron, einem selektiven 5-HT $1 \mathrm{~A}-$ Rezeptoragonisten (Andaku et al. 2005).

Bis zu einer erfolgreichen kausalen Therapie des Rett-Syndroms bedarf es noch experimenteller Studien sowohl auf Proteinebene als auch auf physiologischer und pharmakologischer Ebene. 


\section{$5 \quad$ Zusammenfassung}

Das Rett-Syndrom, das vorzugsweise das weibliche Geschlecht betrifft, ist eine tiefgreifende Entwicklungsstörung. Zu den klinischen Charakteristika der RettErkrankung zählen unter anderem autistische Verhaltensweisen, epileptische Anfälle, Bewegungsstereotypien in Form typischer waschender und knetender Handbewegungen, mentale Retardierung, der Verlust bereits erlernter Fähigkeiten und respiratorische Dysfunktionen. Das Rett-Syndrom wird durch Mutationen im MECP2-Gen hervorgerufen. Sowohl der Verlust als auch die Duplikation des MECP2-Gens bewirken eine Rett-Symptomatik beziehungsweise eine, die ähnlich der Rett-Symptomatik ist. Das sich auf dem X-Chromosom befindende MECP2-Gen kodiert für den Transkriptionsfaktor MeCP2 (Methyl-CpG-Bindungsprotein 2), der an symmetrisch methylierte CpG-Inseln bindet. MeCP2 fungiert sowohl als Transkriptionssuppressor als auch -aktivator. Bisher bekannte Zielgene von MeCP2 sind Bdnf und D/x5. Die vorliegende Arbeit diente der Suche nach weiteren Zielgenen und deren Regulation durch MeCP2. Den oben genannten Atemunregelmäßigkeiten ähnelt der respiratorische Phänotyp (Apnoephasen, prolongierte Postinspiration, irregulärer Atemrhythmus) von Mecp2-KnockoutMäusen im Entwicklungsstadium P40 (postnatal 40 Tage alt). Im früheren Entwicklungsstadium P7 (postnatal 7 Tage alt) zeigt sich bei Mecp2-KnockoutMäusen eine Dysbalance der exzitatorischen und inhibitorischen Transmission, welche unter anderem für die Rett-Symptomatik (wie zum Beispiel Atemdysfunktionen) bei Menschen mit verantwortlich sein soll. Als Ort der Rhythmogenese der Atmung wird der Prä-Bötzinger-Komplex (preBotC) angesehen. Aufgrund dessen wurden die durchgeführten Untersuchungen an RNA-Extraktionen aus dem preBotC von Mecp2-Knockout- und transgenen Mäusen in den Entwicklungsstadien P7 und P40 vorgenommen. Das transgene Mausmodell wurde mit einer zusätzlichen Kopie des Mecp2-Gens generiert, in Anlehnung an das Wissen, dass auch eine Duplikation des MECP2-Gens eine dem Rett-Syndrom ähnliche Symptomatik hervorruft. Mittels quantitativer Polymerasekettenreaktion wurden die relativen RNA-Expressionen von potentiellen Zielgenen des Transkriptionsfaktors MeCP2 bei fehlendem (Knockout-Mausmodell) beziehungsweise überexprimiertem MeCP2 (transgenes Mausmodell) bestimmt. Hierbei ergaben sich Hinweise, dass MeCP2 als Suppressor auf Grin1 (P7), Grin2a (P7), Gabrb1 (P7), Tph2 (P7), Ddc (P40), Slc6a4 (P7), Htr4 (P7) und als Aktivator auf 
Grin2d (P7), Drd4 (P7), Oprm1 (P40) wirken könnte. Sehr starke Evidenzen weisen daraufhin, dass Htr5b und Foxp2 ebenfalls Zielgene von MeCP2 sind und dass MeCP2 supprimierend auf deren Expression wirkt. Um die Zusammenhänge zwischen MeCP2 und seinen Zielgenen und damit auch die Pathogenese des RettSyndroms genauer verstehen zu können, sind jedoch noch weitere Forschungen nötig. 


\section{Literaturverzeichnis}

Adler D, Quaderi N, Brown S, Chapman V, Moore J, Tate P, Disteche C (1995): The $X$-linked methylated DNA binding protein, Mecp2, is subject to $X$ inactivation in the mouse. Mamm Genome $\underline{6}, 491-2$

Alheid GF, Gray PA, Jiang MC, Feldman JL, McCrimmon DR (2002): Parvalbumin in respiratory neurons of the ventrolateral medulla of the adult rat. J Neurocytol $\underline{31}$, 693-717

Amir RE, Zoghbi HY (2000): Rett syndrome: methyl-CpG-binding protein 2 mutations

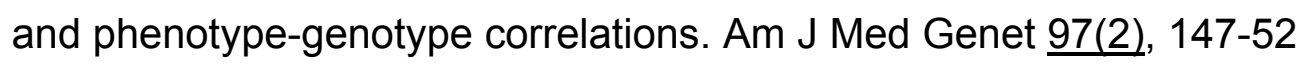

Amir RE, Van den Veyver IB, Wan M, Tran CQ, Francke U, Zoghbi HY (1999): Rett syndrome is caused by mutations in X-linked MECP2, encoding methyl-CpGbinding protein 2. Nat Genet 23(2), 185-8

Andaku DK, Mercadante MT, Schwartzman JS (2005): Buspirone in Rett syndrome respiratory dysfunction. Brain Dev $\underline{27(6)}, 437-8$.

Arunachalam JP: Creation and establishment of transgenic mouse models for Mecp2 gene, causing Rett syndrome. Rer. nat. Diss. (MathematischNaturwissenschaftliche Fakultät der Georg-August-Universität), Göttingen 2007

Beyer KS, Blasi F, Bacchelli E, Klauck SM, Maestrini E, Poustka A (2002):Mutation analysis of the coding sequence of the MECP2 gene in infantile autism. Hum Genet 111(4-5), 305-9

Bienvenu T, Chelly J (2006): Molecular genetics of Rett syndrome: when DNA methylation goes unrecognized. Nat Rev Genet $\underline{7}$, 415-26

Bonaventure P, Hall H, Gommeren W, Cras P, Langlois X, Jurzak M, Leysen JE (2000): Mapping of serotonin 5-HT(4) receptor mRNA and ligand binding sites in the post-mortem human brain. Synapse $\underline{36(1)}$, 35-46 
Carney RM, Wolpert CM, Ravan SA, Shahbazian M, Ashley-Koch A, Cuccaro ML, Vance JM, Pericak-Vance MA (2003): Identification of MeCP2 mutations in a series of females with autistic disorder. Pediatr Neurol 28(3), 205-11

Carter CJ (2007a): elF2B and oligodendrocyte survival: where nature and nurture meet in bipolar disorder and schizophrenia? Schizophr Bull 33(6), 1343-53

Carter CJ (2007b): Multiple genes and factors associated with bipolar disorder converge on growth factor and stress activated kinase pathways controlling translation initiation: implications for oligodendrocyte viability. Neurochem Int $\underline{50(3)}, 461-90$

Cassel S, Carouge D, Gensburger C, Anglard P, Burgun C, Dietrich JB, Aunis D, Zwiller J (2006): Fluoxetine and cocaine induce the epigenetic factors MeCP2 and MBD1 in adult rat brain. Mol Pharmacol 70(2), 487-92

Chahrour M, Jung SY, Shaw C, Zhou X, Wong ST, Qin J, Zoghbi HY (2008): MeCP2, a key contributor to neurological disease, activates and represses transcription. Science $\underline{320(5880)}$, 1224-9

Chao HT, Zoghbi HY, Rosenmund C (2007): MeCP2 controls excitatory synaptic strength by regulating glutamatergic synapse number. Neuron $\underline{56(1)}$, 58-65

Collins AL, Levenson JM, Vilaythong AP, Richman R, Armstrong DL, Noebels JL, David Sweatt J, Zoghbi HY (2004): Mild overexpression of MeCP2 causes a progressive neurological disorder in mice. Hum Mol Genet 13(21), 2679-89

Collins AL, Ma D, Whitehead PL, Martin ER, Wright HH, Abramson RK, Hussman JP, Haines JL, Cuccaro ML, Gilbert JR et al. (2006): Investigation of autism and GABA receptor subunit genes in multiple ethnic groups. Neurogenetics $\underline{7(3)}$, 167-74

David DJ, Froger N, Guiard B, Przybylski C, Jego G, Boni C, Hunt SP, De Felipe C, Hamon M, Jacquot C, Gardier AM, Lanfumey L (2004): Serotonin transporter in substance $P$ (neurokinin 1) receptor knock-out mice. Eur J Pharmacol 492(1), 41-8 
D’Esposito M, Quaderi N, Ciccodicola A, Bruni P, Esposito T, D'Urso M, Brown S (1996): Isolation, physical mapping, and Northern analysis of the X-linked human gene encoding methyl CpG-binding protein, MECP2. Mamm Genome 그, 533-5

Donato R (2007): RAGE: a single receptor for several ligands and different cellular responses: the case of certain S100 proteins. Curr Mol Med $\underline{7(8)}$, 711-24

Dragich J, Houwink-Manville I, Schanen C (2000): Rett syndrome: a surprising result of mutation in MECP2. Hum Mol Genet $\underline{9(16)}$, 2365-75

Enard W, Przeworski M, Fisher SE, Lai CS, Wiebe V, Kitano T, Monaco AP, Pääbo $S$ (2002): Molecular evolution of FOXP2, a gene involved in speech and language. Nature 418(6900), 869-72

Eriksen JL, Gillespie R, Druse MJ (2002): Effects of ethanol and 5-HT1A agonists on astroglial S100B. Brain Res Dev Brain Res 139(2), 97-105

Feldman JL, Mitchell GS, Nattie EE (2003): Breathing: rhythmicity, plasticity, chemosensitivity. Annu Rev Neurosci 26, 239-66

Free A, Wakefield RI, Smith BO, Dryden DT, Barlow PN, Bird AP (2001): DNA recognition by the methyl-CpG binding domain of MeCP2. J Biol Chem 276(5), $3353-60$

Georgi A, Jamra RA, Klein K, Villela AW, Schumacher J, Becker T, Paul T, Schmael C, Höfels S, Klopp N, Illig T, Propping P, Cichon S, Nöthen MM, Schulze TG, Rietschel M (2007): Possible association between genetic variants at the GRIN1 gene and schizophrenia with lifetime history of depressive symptoms in a German sample. Psychiatr Genet 17(5), 308-10

Gomes FC, Paulin D, Moura Neto V (1999): Glial fibrillary acidic protein (GFAP): modulation by growth factors and its implication in astrocyte differentiation. Braz

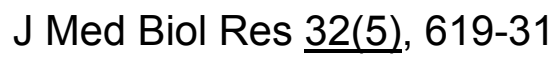

Grailhe R, Grabtree GW, Hen R (2001): Human 5-HT(5) receptors: the 5-HT(5A) receptor is functional but the $5-\mathrm{HT}(5 \mathrm{~B})$ receptor was lost during mammalian evolution. Eur J Pharmacol 418(3), 157-67 
Gray PA, Janczewski WA, Mellen N, McCrimmon DR, Feldman JL (2001): Normal breathing requires preBötzinger complex neurokinin-1 receptor-expressing neurons. Nat Neurosci $\underline{4}, 927-30$

Greer JJ, Smith JC, Feldman JL (1992): Respiratory and locomotor patterns generated in the fetal rat brain stem-spinal cord in vitro. J Neurophysiol $\underline{67}, 996-9$

Guenther U, Manzke T, Wrigge H, Dutschmann M, Zinserling J, Putensen C, Hoeft A (2009): The counteraction of opioid-induced ventilatory depression by the serotonin 1A-agonist 8-OH-DPAT does not antagonize antinociception in rats in situ and in vivo. Anesth Analg 108(4), 1169-76

Guiard BP, Froger N, Hamon M, Gardier AM, Lanfumey L (2005): Sustained pharmacological blockade of NK1 substance $\mathrm{P}$ receptors causes functional desensitization of dorsal raphe 5-HT $1 \mathrm{~A}$ autoreceptors in mice. J Neurochem 95(6), 1713-23

Guiard BP, Guilloux JP, Reperant C, Hunt SP, Toth M, Gardier AM (2007): Substance $P$ neurokinin 1 receptor activation within the dorsal raphe nucleus controls serotonin release in the mouse frontal cortex. Mol Pharmacol $\underline{72(6)}$, 1411-8

Guy J, Hendrich B, Holmes M, Martin JE, Bird A (2001): A mouse Mecp2-null mutation causes neurological symptoms that mimic Rett syndrome. Nat Genet $\underline{27(3)}, 322-6$

Guyenet PG, Sevigny CP, Weston MC, Stornetta RL (2002): Neurokinin-1 receptorexpressing cells of the ventral respiratory group are functionally heterogeneous and predominantly glutamatergic. J Neurosci $\underline{22}$, 3806-16

Hagberg B, Goutieres F, Hanefeld F, Rett A, Wilson J (1985): Rett syndrome: criteria for inclusion and exclusion. Brain Dev $\underline{7}, 372-3$

Hagberg B, Goutieres F, Hanefeld F, Rett A, Wilson J (1985): Rett syndrome: criteria for inclusion and exclusion. Brain Dev $\underline{7}, 372-3$ 
Higuchi R, Fockler C, Dollinger G, Watson R (1993): Kinetic PCR analysis: real-time monitoring of DNA amplification reactions. Biotechnology (N Y) 11(9), 1026-30

Horike S, Cai S, Miyano M, Cheng J-F, Kohwi-Shigematsu T (2005) : Loss of silentchromatin looping and impaired imprinting of DLX5 in Rett syndrome. Nature Genet $\underline{37}, 31-40$

Horská A, Farage L, Bibat G, Nagae LM, Kaufmann WE, Barker PB, Naidu S (2009): Brain metabolism in Rett syndrome: age, clinical, and genotype correlations. Ann Neurol $\underline{65(1)}, 90-7$

Hoyer D, Hannon JP, Martin GR (2002): Molecular, pharmacological and functional diversity of 5-HT receptors. Pharmacol Biochem Behav $\underline{71(4)}$, 533-54

Hülsmann S, Oku Y, Zhang W, Richter DW (2000): Metabolic coupling between glia and neurons is necessary for maintaining respiratory activity in transverse medullary slices of neonatal mouse. Eur J Neurosci 12(3), 856-62

Imessaoudene B, Bonnefont J-P, Royer G, Cormier-Daire V, Lyonnet S, Lyon G, Munnich A, Amiel J (2001): MECP2 mutation in non-fatal, non-progressive encephalopathy in a male. J Med Genet $\underline{38}, 171-4$

Isoda K, Morimoto M, Matsui F, Hasegawa T, Tozawa T, Morioka S, Chiyonobu T, Nishimura A, Yoshimoto K, Hosoi H (2009): Postnatal changes in serotonergic innervation to the hippocampus of methyl-CpG-binding protein 2-null mice. Neuroscience Accepted 13 November 2009. Available online 22 November 2009 [Epub ahead of print]

Jacobs BL, Azmitia EC (1992): Structure and function of the brain serotonin system. Physiol Rev $\underline{72}, 165-229$

Jellinger K (2003): Rett Syndrome - an update. J Neural Transm 110(6), 681-701

Johnson SM, Koshiya N, Smith JC (2001): Isolation of the kernel for respiratory rhythm generation in a novel preparation: the pre-Bötzinger complex "island". J Neurophysiol 85(4), 1772-6 
Kandel ER, Schwartz JH, Jessell TM: Principles of Neural Science. 4. Auflage; Mcgraw-Hill Professional, New York 2000

Kinsey AM, Wainwright A, Heavens R, Sirinathsinghji DJ, Oliver KR (2001): Distribution of 5-ht(5A), 5-ht(5B), 5-ht(6) and 5-HT(7) receptor mRNAs in the rat brain. Brain Res Mol Brain Res $\underline{88(1-2)}$, 194-8

Klose RJ, Sarraf SA, Schmiedeberg L, McDermott SM, Stancheva I, Bird AP (2005): DNA binding selectivity of MeCP2 due to a requirement fpr $A / T$ sequences adjacent to methyl-CpG. Mol Cell $\underline{19}, 667-678$

Koppal T, Lam AG, Guo L, Van Eldik LJ (2001): S100B proteins that lack one or both cysteine residues can induce inflammatory responses in astrocytes and microglia. Neurochem Int 39(5-6), 401-7

Laccone F (2006): Das Rett-Syndrom. Medgen 18, 175-81

Lang UE, Puls I, Muller DJ, Strutz-Seebohm N, Gallinat J (2007): Molecular mechanisms of schizophrenia. Cell Physiol Biochem 20(6), 687-702

Lauder JM (1993): Neurotransmitters as growth regulatory signals: role of receptors and second messengers. Trens Neurosci $\underline{16}, 233-40$

Lewis JD, Meehan RR, Henzel WJ, Maurer-Fogy I, Jeppesen P, Klein F, Bird A (1992): Purification, sequence, and cellular localization of a novel chromosomal protein that binds to methylated DNA. Cell 69(6), 905-14

Lindberg B, Rett A: Rett-Syndrom - Eine Übersicht über psychologische und pädagogische Erfahrungen. 3. Auflage; Facultas.wuv Universitätsverlag, Wien 2000

Lipani JD, Bhattacharjee MB, Corey DM, Lee DA (2000): Reduced nerve growth factor in Rett syndrome postmortem brain tissue. J Neuropathol Exp Neurol $\underline{59(10)}, 889-95$ 
Liu Q, Wong-Riley MT (2006): Developmental changes in the expression of GABAA receptor subunits alpha1, alpha2, and alpha3 in brain stem nuclei of rats. Brain Res 1098(1), 129-38

Liu YY, Ju G, Wong-Riley MT (2001): Distribution and colocalization of neurotransmitters and receptors in the pre-Bötzinger complex of rats. $J$ Appl Physiol 91(3), 1387-95

Loupe PS, Bredemeier JD, Schroeder SR, Tessel RE (2002): Dopamine re-uptake inhibitor GBR-12909 induction of aberrant behaviours in animal models of dopamine dysfunction. Int J Dev Neurosci 20(3-5), 323-33

Ma DQ, Whitehead PL, Menold MM, Martin ER, Ashley-Koch AE, Mei H, Ritchie MD, Delong GR, Abramson RK, Wright HH et al. (2005): Identification of significant association and gene-gene interaction of GABA receptor subunit genes in autism. Am J Hum Genet 77(3), 377-88

MacDermot KD, Bonora E, Sykes N, Coupe AM, Lai CS, Vernes SC, VarghaKhadem F, McKenzie F, Smith RL, Monaco AP, Fisher SE (2005): Identification of FOXP2 truncation as a novel cause of developmental speech and language deficits. Am J Hum Genet $\underline{76(6)}$, 1074-80

Makino C, Shibata H, Ninomiya H, Tashiro N, Fukumaki Y (2005): Identification of single-nucleotide polymorphisms in the human N-methyl-D-aspartate receptor subunit NR2D gene, GRIN2D, and association study with schizophrenia. Psychiatr Genet 15(3), 215-21

Manzke T: Expression and function of serotonin receptor isoforms in the respiratory system. Rer. nat. Diss. (Biologische Fakultät der Georg-August-Universität), Göttingen 2004

Manzke T, Guenther U, Ponimaskin EG, Haller M, Dutschmann M, Schwarzacher S, Richter DW (2003): 5-HT4(a) receptors avert opioid-induced breathing depression without loss of analgesia. Science $\underline{301(5630)}$, 226-9 
Manzke T, Preusse S, Hülsmann S, Richter DW (2008): Developmental changes of serotonin 4(a) receptor expression in the rat pre-Bötzinger complex. J Comp Neurol $\underline{506(5)}, 775-90$

Matsuishi T, Yamashita Y, Kusaga A (2001): Neurobiology and neurochemistry of Rett syndrome. Brain Dev $\underline{23}, 58-61$

McCrimmon DR, Monnier A, Ptak K, Zummo G, Zhang Z, Alheid GF (2001): Respiratory rhythm generation: preBötzinger neuron discharge patterns and persistent sodium current. Adv Exp Med Biol 499, 147-52

Medrihan L, Tantalaki E, Aramuni G, Sargsyan V, Dudanova I, Missler M, Zhang W (2008): Early defects of GABAergic synapses in the brain stem of a MeCP2 mouse model of Rett syndrome. J Neurophysiol 99(1), 112-21

Meins M, Lehmann J, Gerresheim F, Herchenbach J, Hagedorn M, Hameister K, Epplen JT (2005): Submicroscopic duplication in Xq28 causes increased expression of the MECP2 gene in a boy with severe mental retardation and features of Rett syndrome. J Med Genet $\underline{42(2)}$, e12

Miller JH, Azmitia EC (1999): Growth inhibitory effects of a mu opioid on cultured cholinergic neurons from fetal rat ventral forebrain, brainstem, and spinal cord. Brain Res Dev Brain Res 114, 69-77

Mnatzakanian GN, Lohi H, Munteanu I, Alfred SE, Yamada T, MacLeod PJ, Jones JR, Scherer SW, Schanen NC, Friez MJ et al. (2004): A previously unidentified MECP2 open reading frame defines a new protein isoform relevant to Rett syndrome. Nat Genet $\underline{36}, 339-41$

Möller HJ, Laux G, Kapfhammer HP: Psychiatrie und Psychotherapie. 3. Auflage; Springer Medizin Verlag, Heidelberg 2008

Moretti P, Zoghbi HY (2006): MeCP2 dysfunction in Rett syndrome and related disorders. Curr Opin Genet Dev 16(3), 276-81 
Mrzljak L, Bergson C, Pappy M, Huff R, Levenson R, Goldman-Rakic PS (1996): Localization of dopamine D4 receptors in GABAergic neurons of the primate brain. Nature 381(6579), 245-8

Muñoz-Yunta JA, Palau-Baduell M, Salvadó-Salvadó B, Valls-Santasusana A, Rosendo-Moreno N, Clofent-Torrentó M, Manchado F (2008): Autism, epilepsy and genetics. Rev Neurol 46 Suppl 1, S71-7

Nan X, Campoy F, Bird A (1997): MeCP2 is a transcriptional repressor with abundant binding sites in genomic chromatin. Cell $\underline{88}, 471-81$

Nelson DL (2004): 5-HT5 receptors. Curr Drug Targets CNS Neurol Disord 3(1), $53-8$

O'Brien EK, Zhang X, Nishimura C, Tomblin JB, Murray JC (2003): Association of specific language impairment (SLI) to the region of 7q31. Am J Hum Genet 72(6), $1536-43$

Onimaru H, Homma I (2003): A novel functional neuron group for respiratory rhythm generation in the ventral medulla. J Neurosci $\underline{23}, 1478-86$

Pagliardini S, Ren J, Greer JJ (2003): Ontogeny of the pre-Botzinger complex in perinatal rats. J Neurosci $\underline{23}, 9575-84$

Park ES, Park CI, Baek SY, Kim SW, Baek SK, Kim HO (2000): Serum immunoreactivity to $\mathrm{S}-100$ in children with cerebral palsy and delayed development and in their healthy parents. Yonsei Med J $\underline{41(3)}$, 328-32

Park ES, Park Cl, Choi KS, Choi IH, Shin JS (2004): Over-expression of S100B protein in children with cerebral palsy or delayed development. Brain Dev 26(3), $190-6$

Paterson D, Thompson EG, Belliveau RA, Antalffy BA, Trachtenberg FL, Armstrong DD, Kinney HC (2005): Serotonin transporter abnormality in the dorsal motor nucleus of the vagus in Rett syndrome: potential implications for clinical autonomic dysfunction. J Neuropathol Exp Neurol 64(11), 1018-27 
Petryshen TL, Middleton FA, Tahl AR, Rockwell GN, Purcell S, Aldinger KA, Kirby A, Morley CP, McGann L, Gentile KL et al. (2005): Genetic investigation of chromosome 5q GABAA receptor subunit genes in schizophrenia. Mol Psychiatry 10(12), 1074-88

Pfaffl MW (2001): A new mathematical model for relative quantification in real-time RT-PCR. Nucleic Acids Res 29(9), e45

Preuss P (2004): Solving the Mechanism of Rett Syndrome - How the First Identified Epigenetic Disease Turns on the Genes That Produce its Symptoms. Research News Berkeley Lab 20(12), 1

Preuße S: Untersuchung der entwicklungsabhängigen Expression des Serotonin 4(a) Rezeptors im PräBötzinger Komplex der Ratte. Med. Diss., Göttingen 2005

Privat A, Gimenez-Ribota M, Ridet JL: Morphology of astrocytes. Oxford University Press, New York 1995, 3-22

Ramaekers VT, Hansen SI, Holm J, Opladen T, Senderek J, Häusler M, Heimann G, Fowler B, Maiwald R, Blau N (2003): Reduced folate transport to the CNS in female Rett patients. Neurology $\underline{61(4)}, 506-15$

Raponi E, Agenes F, Delphin C, Assard N, Baudier J, Legraverend C, Deloulme JC (2007): S100B expression defines a state in which GFAP-expressing cells lose their neural stem cell potential and acquire a more mature developmental stage. Glia $\underline{55(2)}, 165-77$

Rasch B, Friese M, Hofmann W, Naumann E: Quantitative Methoden 1. 2. Auflage; Springer-Verlag Gmbh, Berlin 2006

Reisine T (1995): Somatostatin. Cell Mol Neurobiol 15(6), 597-614

Renieri A, Meloni I, Longo I, Ariani F, Mari F, Pescucci C, Cambi F (2003): Rett syndrome: the complex nature of a monogenic disease. J Mol Med 81(6), 346-54

Richter DW, Spyer KM (2001): Studying rhythmogenesis of breathing: comparison of in vivo and in vitro models. Trends Neurosci $\underline{24}, 464-72$ 
Richter DW, Pierrefiche O, Lalley PM, Polder HR (1996): Voltage-clamp analysis of neurons within deep layers of the brain. J Neurosci Methods $\underline{67}, 121-3$

Roux JC, Panayotis N, Dura E, Villard L (2009): Progressive noradrenergic deficits in the locus coeruleus of Mecp2 deficient mice. J Neurosci Res 8 [Epub ahead of print]

Samaco R, Hogart A, LaSalle J (2005): Epigenetic overlap in autism-spectrum neurodevelopmental disorders: MECP2 deficiency causes reduced expression of UBE3A and GABRB3. Hum Mol Genet $\underline{14}$, 483-92

Schmidt S (1998): S100B: pathogenetic and pathophysiologic significance in neurology. Nervenarzt $\underline{69(8)}, 639-46$

Schmidt RF, Thews G, Lang F: Physiologie des Menschen. 28. Auflage; SpringerVerlag, Berlin 2000

Schwarzacher SW, Smith JC, Richter DW (1995): Pre-Bötzinger complex in the cat. J Neurophysiol $\underline{73}, 1452-61$

Serrats J, Raurich A, Vilaró MT, Mengod G, Cortés R (2004): 5-ht5B receptor mRNA in the raphe nuclei: coexpression with serotonin transporter. Synapse $\underline{51(2)}, 102-$ 11

Setoguchi H, Namihira M, Kohyama J, Asano H, Sanosaka T, Nakashima K (2006): Methyl-CpG binding proteins are involved in restricting differentiation plasticity in neurons. J Neurosci Res $\underline{84(5)}$, 969-79

Shao Y, McCarthy KD (1994): Plasticity of astrocytes. Glia 11(2), 147-55

Shapiro LA, Marks A, Whitaker-Azmitia PM (2004): Increased clusterin expression in old but not young adult S100B transgenic mice: evidence of neuropathological aging in a model of Down Syndrome. Brain Res 1010(1-2), 17-21

Siegel GJ, Albers RW: Basic Neurochemistry. Molecular, Cellular and Medical Aspects. 7th edition; Academic Press, London 2006 
Smith JC, Ellenberger HH, Ballanyi K, Richter DW, Feldman JL (1991): PreBötzinger complex: a brainstem region that may generate respiratory rhythm in mammals. Science $\underline{254}, 726-9$

Spiteri E, Konopka G, Coppola G, Bomar J, Oldham M, Ou J, Vernes SC, Fisher SE, Ren B, Geschwind DH (2007): Identification of the transcriptional targets of FOXP2, a gene linked to speech and language, in developing human brain. Am J Hum Genet $\underline{81(6)}, 1144-57$

Squire LR, Bloom FE, Spitzer NC, du Lac S, Ghosh A, Berg D: Fundamental Neuroscience. 3rd Revised edition; Academic Press, London 2008

Stettner GM, Huppke P, Brendel C, Richter DW, Gärtner J, Dutschmann M (2007): Breathing dysfunctions associated with impaired control of postinspiratory activity in Mecp2-/y knockout mice. J Physiol 579(Pt 3), 863-76

Stornetta RL, Rosin DL, Wang H, Sevigny CP, Weston MC, Guyenet PG (2003): A group of glutamatergic interneurons expressing high levels of both neurokinin-1 receptors and somatostatin identifies the region of the pre-Bötzinger complex. $\mathrm{J}$ Comp Neurol $\underline{455(4)}$, 499-512

Takita K, Herlenius EA, Lindahl SG, Yamamoto Y (1997): Actions of opioids on respiratory activity via activation of brainstem mu-, delta- and kappa-receptors; an in vitro study. Brain Res $\underline{778(1)}, 233-4$

Tanaka Y, Marumo T, Omura T, Yoshida S (2008): Relationship between cerebrospinal and peripheral S100B levels after focal cerebral ischemia in rats. Neurosci Lett $\underline{436(1)}, 40-3$

Tramontina AC, Tramontina F, Bobermin LD, Zanotto C, Souza DF, Leite MC, Nardin P, Gottfried C, Gonçalves CA (2008): Secretion of S100B, an astrocytederived neurotrophic protein, is stimulated by fluoxetine via a mechanism independent of serotonin. Prog Neuropsychopharmacol Biol Psychiatry 32(6), $1580-3$ 
Van Esch H, Bauters M, Ignatius J, Jansen M, Raynaud M (2005): Duplication of the MECP2 Region Is a Frequent Cause of Severe Mental Retardation and Progressive Neurological Symptoms in Males. Am J Hum Genet $\underline{77}$, 442-53

Vargha-Khadem F, Watkins K, Alcock K, Fletcher P, Passingham R (1995): Praxic and nonverbal cognitive deficits in a large family with a genetically transmitted speech and language disorder. Proc Natl Acad Sci USA 92(3), 930-3

Viemari JC (2008): Noradrenergic modulation of the respiratory neural network. Respir Physiol Neurobiol 164(1-2), 123-30

Viemari JC, Roux JC, Tryba AK, Saywell V, Burnet H, Peña F, Zanella S, Bévengut M, Barthelemy-Requin M, Herzing LB et al. (2005): Mecp2 deficiency disrupts norepinephrine and respiratory systems in mice. J Neurosci 25(50), 11521-30

Walther DJ, Bader M (2003): A unique central tryptophan hydroxylase isoform. Biochem Pharmacol 66(9), 1673-80

Wan M, Lee SS, Zhang X, Houwink-Manville I, Song HR, Amir RE, Budden S, Naidu S, Pereira JL, Lo IF et al. (1999): Rett syndrome and beyond: recurrent spontaneous and familial MECP2 mutations at CpG hotspots. Am J Hum Genet $\underline{65(6)}, 1520-9$

Wang H, Chan SA, Ogier M, Hellard D, Wang Q, Smith C, Katz DM (2006): Dysregulation of brain-derived neurotrophic factor (BDNF) expression and neurosecretory function in Mecp2 null mice. J Neurosci 26(42), 10911-5

Wang H, Stornetta RL, Rosin DL, Guyenet PG (2001): Neurokinin-1 receptorimmunoreactive neurons of the ventral respiratory group in the rat. $\mathrm{J}$ Comp Neurol $\underline{434}, 128-46$

Ward BC, Kolodny NH, Nag N, Berger-Sweeney JE (2009): Neurochemical changes in a mouse model of Rett syndrome: changes over time and in response to perinatal choline nutritional supplementation. J Neurochem 108(2), 361-71 
Wassink TH, Piven J, Vieland VJ, Pietila J, Goedken RJ, Folstein SE, Sheffield VC (2002): Evaluation of FOXP2 as an autism susceptibility gene. Am J Med Genet $\underline{114(5)}, 566-9$

Watson C, Pelka G, Radziewic T, Shahbazian M, Christodoulou J, Williamson S, Tam P (2005): Reduced proportion of Purkinje cells expressing paternally derived mutant Mecp2308 allele in female mouse cerebellum is not due to a skewed primary pattern of X-chromosome inactivation. Hum Mol Genet 14(13), $1851-61$

Watson P, Black G, Ramsden S, Barrow M, Super M, Kerr B, Clayton-Smith J (2001): Angelman syndrome phenotype associated with mutations in MECP2, a gene encoding a methyl CpG binding protein. J Med Genet $\underline{38}, 224-8$

Weaving L, Williamson S, Bennetts B, Davis M, Ellaway C, Leonard H, Thong $M-K$, Delatycki M, Thompson E, Laing N et al. (2003): Effects of MECP2 mutation type, location and $\mathrm{X}$-inactivation in modulating Rett syndrome phenotype. Am J Med Genet 118A, 103-14 


\section{Danksagung}

Zuallererst möchte ich mich bei meinem Doktorvater Prof. Dr. med. Rothenberger für die Übernahme dieser Dissertation, für seine Anregungen und wertvollen Ratschläge bedanken.

Besonderer Dank gebührt dem gesamten Team des Labors des „European Neuroscience Institute" - in dem die Versuche für diese Dissertation ihren Anfang nahmen - Olivier Bidon für seine unendliche Geduld, Dr. Jayamuruga Pandian Arunachalam für die Generierung und Bereitstellung der Mecp2-Mäuse (unter Anleitung von Prof. Dr. Engel), Dr. Matthias Dutschmann für die Anregung, die Dissertation in der Neurophysiologie zu beginnen, und Dr. Nathalie Bock für ihre vielen Korrekturvorschläge.

Insbesondere möchte ich meinem liebenswerten und sehr professionellen Betreuer Herrn Dr. rer. nat. Dr. med. Till Manzke danke sagen, ohne dessen Hilfe und tatkräftige Unterstützung diese Arbeit weder begonnen noch beendet hätte werden können. Seine unzähligen Ratschläge waren mir in meiner Arbeit stets ein Wegweiser.

Für die gewissenhaften Korrekturen möchte ich allen Beteiligten sehr danken, hierbei sind besonders meine Mutter und Janne Kleinhans hervorzuheben.

Bedanken möchte ich mich auch bei all meinen Freunden, Bekannten, Verwandten und Kommilitonen, die mich stets durch Aufmunterungen, Ratschläge oder Kaffee weiter motiviert haben, so dass diese Arbeit zügiger beendet werden konnte.

Mein besonderer Dank gilt jedoch meinen Eltern, die es überhaupt erst möglich gemacht haben, dass ich Medizin studieren und eine solche Dissertation beginnen konnte. Sie haben mir stets mit uneingeschränkter Kraft, Rat und Trost zur Seite gestanden. 